\title{
What can the sound of earthquakes tell us about a
} planet's interior structure?

Quentin Brissaud, NORSAR, Kjeller, Norway

Siddharth Krishnamoorthy, NASA JPL

Jennifer M. Jackson, Caltech

Daniel C. Bowman, Sandia Laboratory

Attila Komjathy, NASA JPL

James A. Cutts, NASA JPL

Zhongwen Zhan, NASA JPL

Michael T. Pauken, NASA JPL

Jacob S. Izraelevitz, NASA JPL

Gerald J. Walsh, NASA JPL

\section{AGU AOU MERTING}

New Orleans, LA \& Online Everywhere

13-17 December 2021

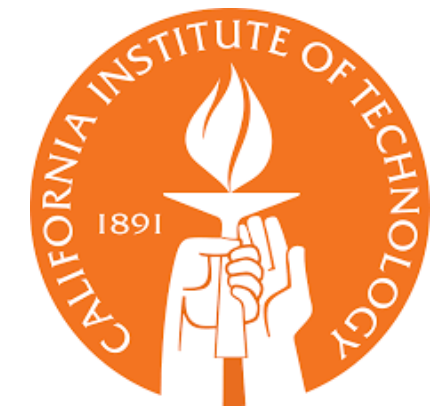

Jet Propuls
California I
?1

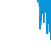

Sandia

National Laboratories

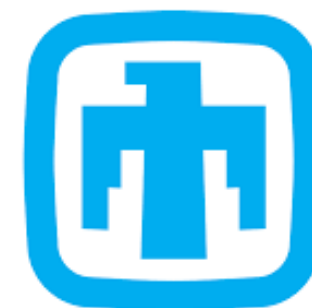

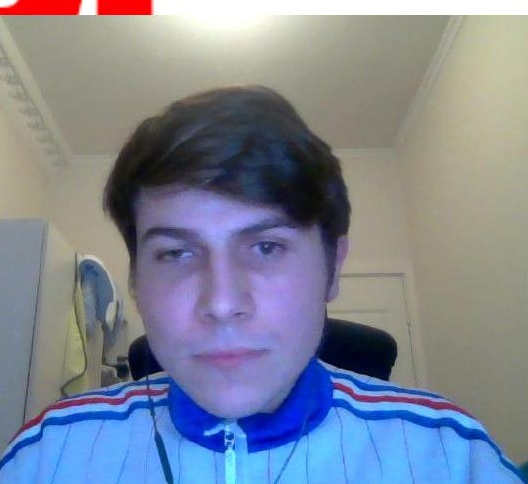




\section{The challenge of ground station coverage}

The determination of seismic source dynamics and subsurface velocities generally relies on the analysis of seismic phases recorded networks deployed at the ground

On Venus, harsh surface conditions (> 460 C, 90 bar) prevent the deployment of seismic stations

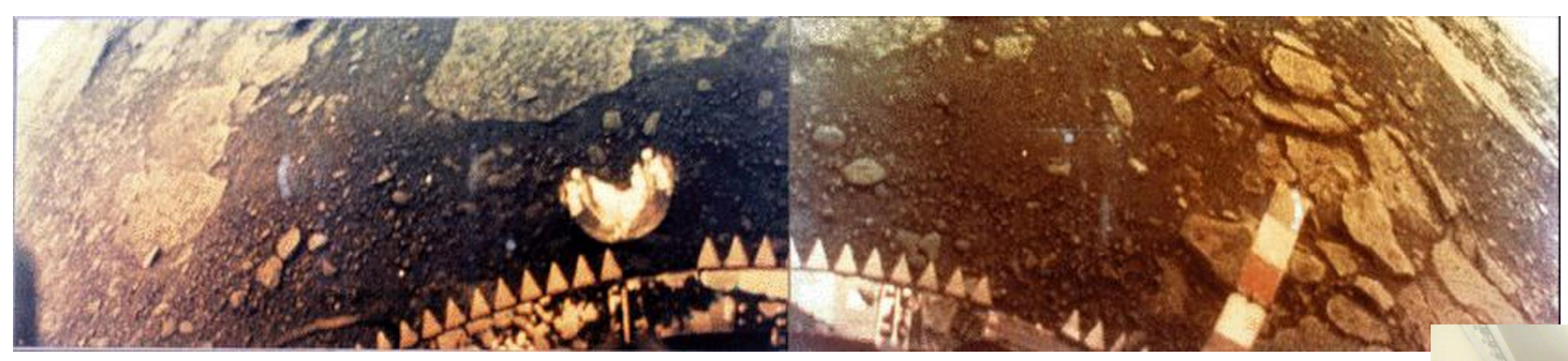

Figure: Photo of the Venusian surface by Venera 13 (1983). credit: NASA-JPL

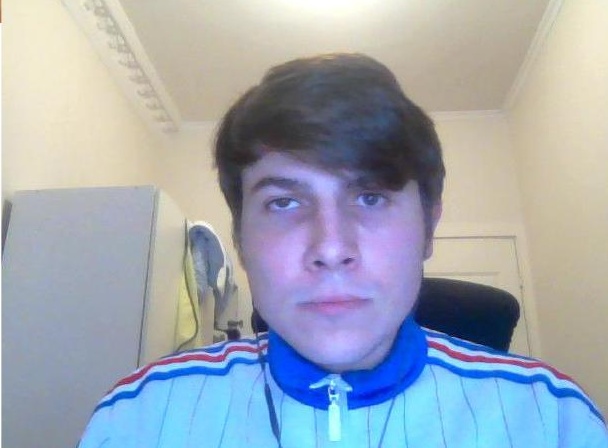




\section{The challenge of ground station coverage}

The determination of seismic source dynamics and subsurface velocities generally relies on the analysis of seismic phases recorded networks deployed at the ground

On Venus, harsh surface conditions (> 460 C, 90 bar) prevent the deployment of seismic stations

On Earth, investigations of shallow events lack resolution to constrain accurately seismic source parameters (location, depth, moment tensor) in regions of poor station coverage such as polar regions, oceans, or volcanos
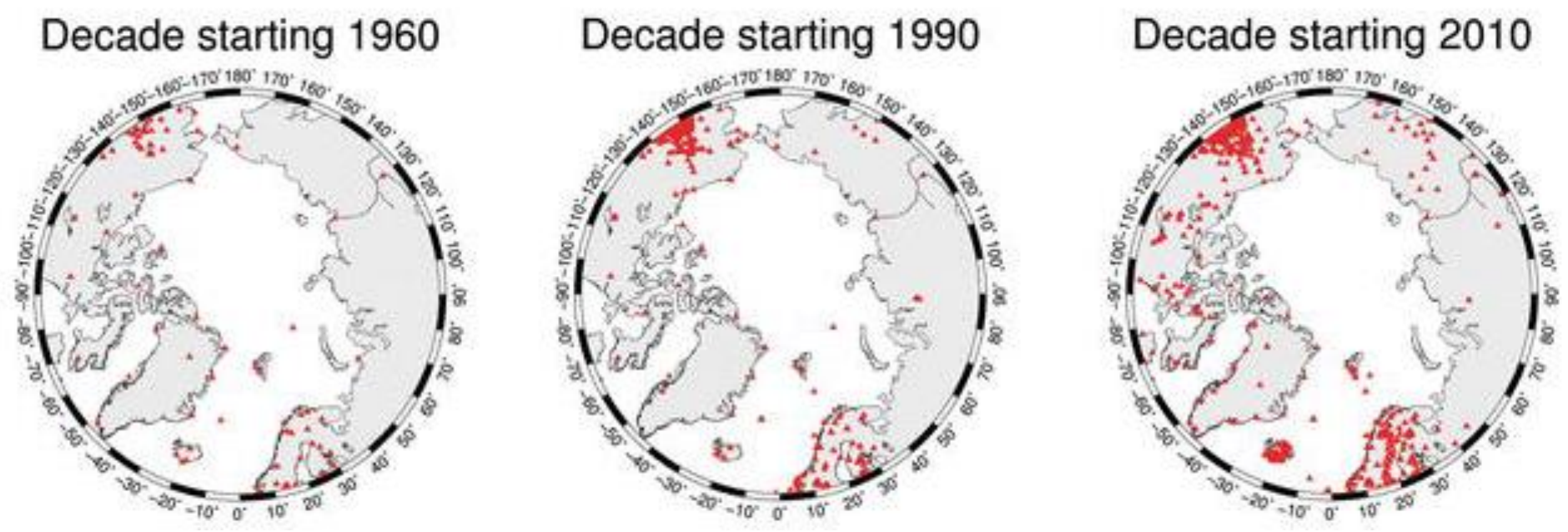

Figure: Distribution of seismic station (red triangle) in polar regions. (Kanao, 2018)

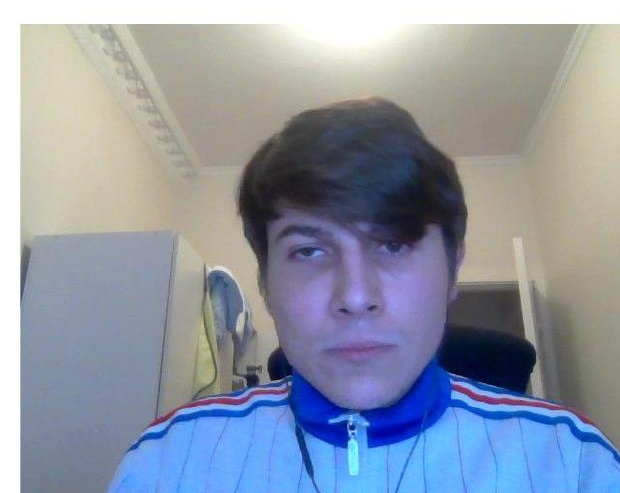




\section{An answer might lie in the atmosphere}

Seismic waves couple to the atmosphere and propagate over large distances as low frequency $(<20 \mathrm{~Hz})$ acoustic waves, called infrasound, which carry information about the seismic velocities and subsurface processes
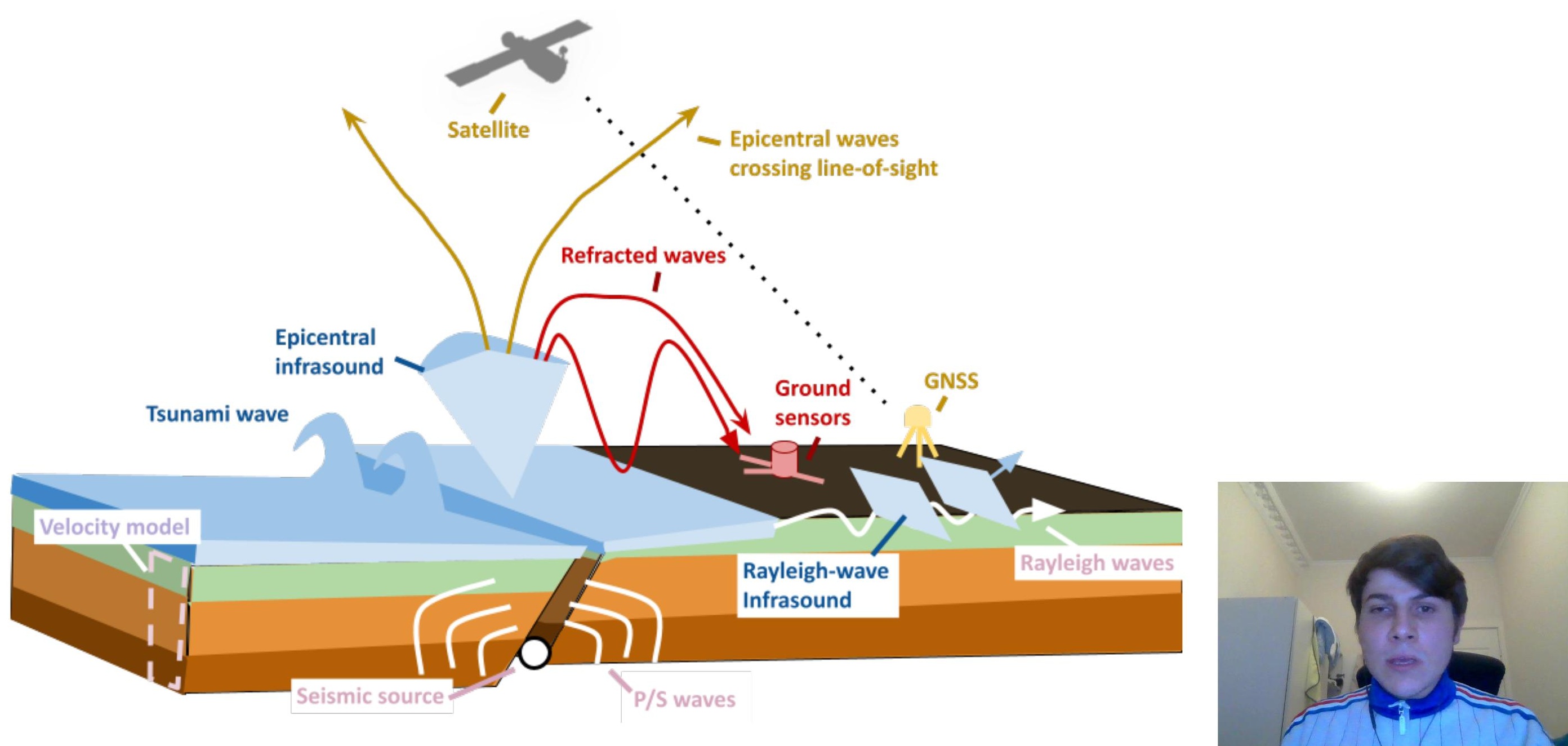


\section{Ground observations}

\section{Source characteristics}

- Amplitude + time: Sound pressure level from seismic waves (e.g., Hernandez, 2018)

- Relative amplitude phases + time: Focal depth (Averbuch, 2020)

- Amplitude + polarity + time: Focal mechanism (Shani-Kadmiel, 2021)

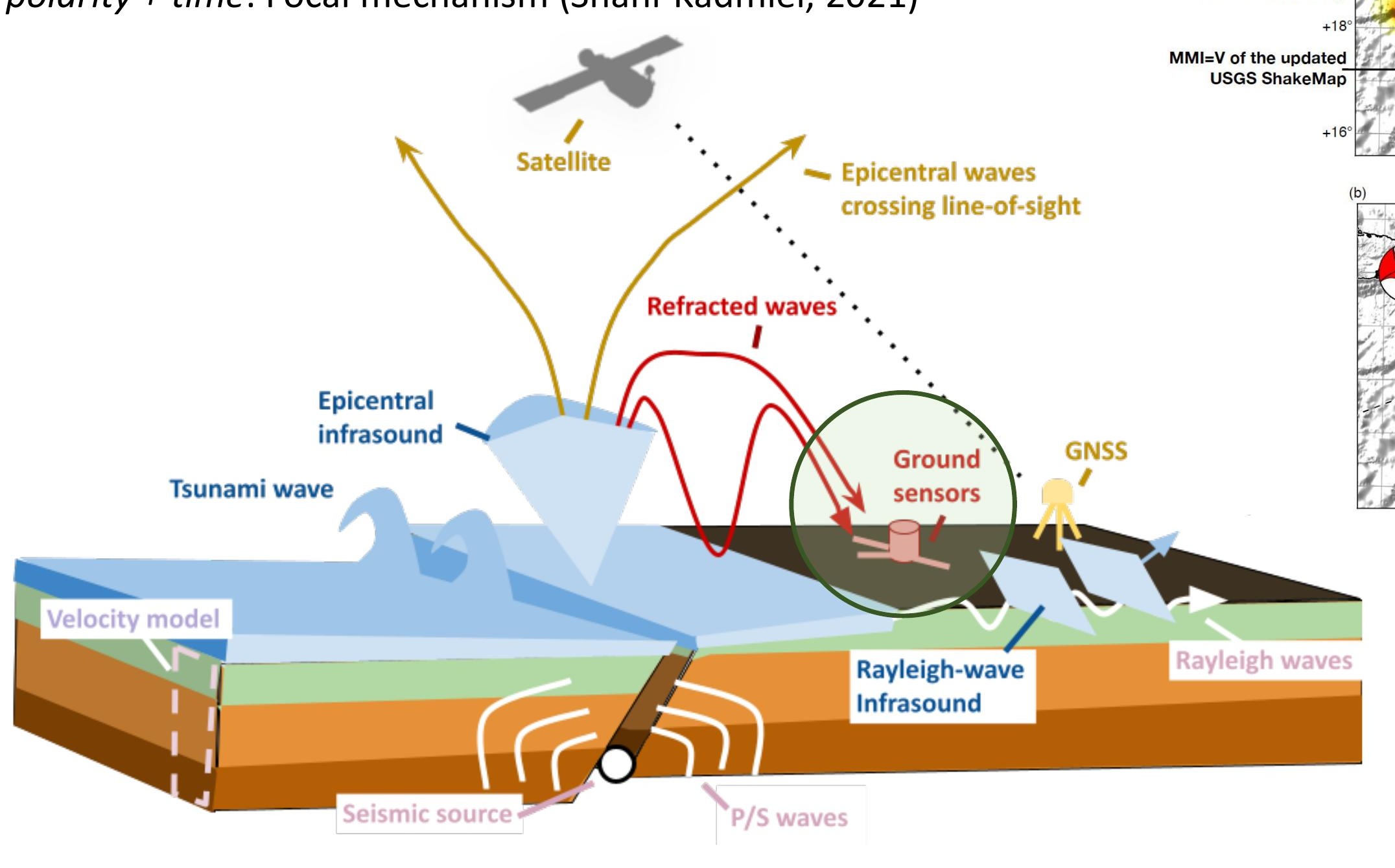

Figure: Reconstruction of seismic hazard maps and projected focal mechanisms after Haiti earthquake (Shani-Kadmiel, 2021)
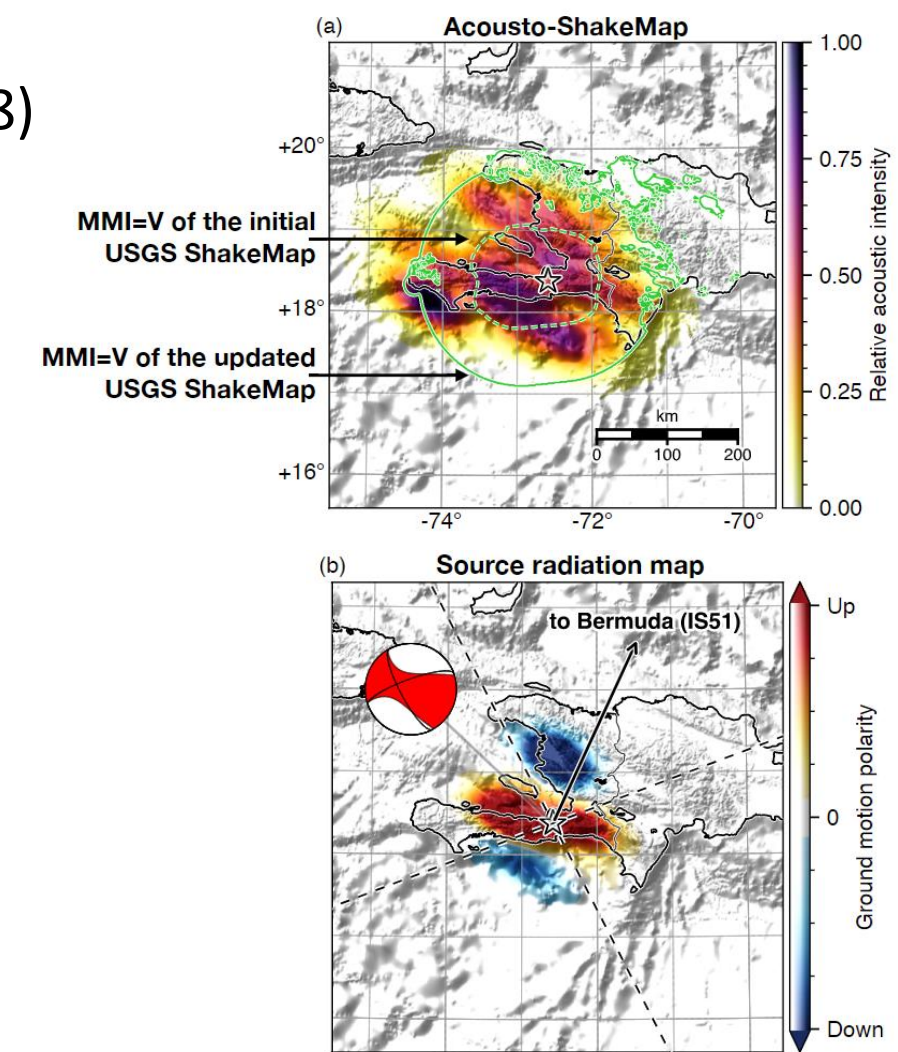

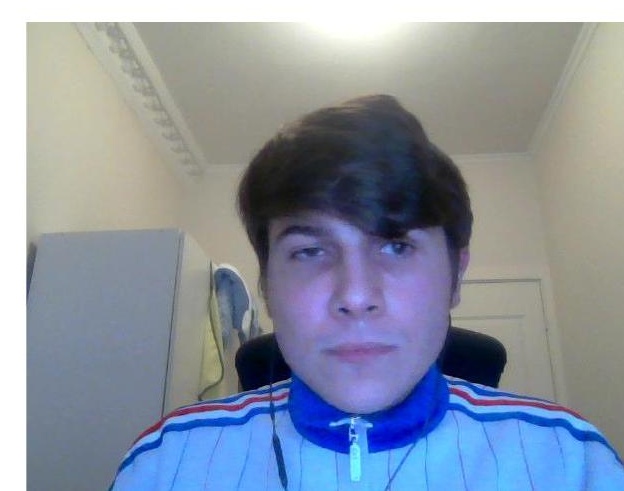




\section{Ionospheric observations}

\section{Source characteristics}

- Amplitude: Magnitude (Astafyeva, 2013)

- Time: Maximum slip location (Zedek, 2021)

- Waveform: Fault dynamics (Inchin, 2021)

\section{Subsurface characteristics}

- Relative amplitude:

Basin amplification (Liu, 2021)

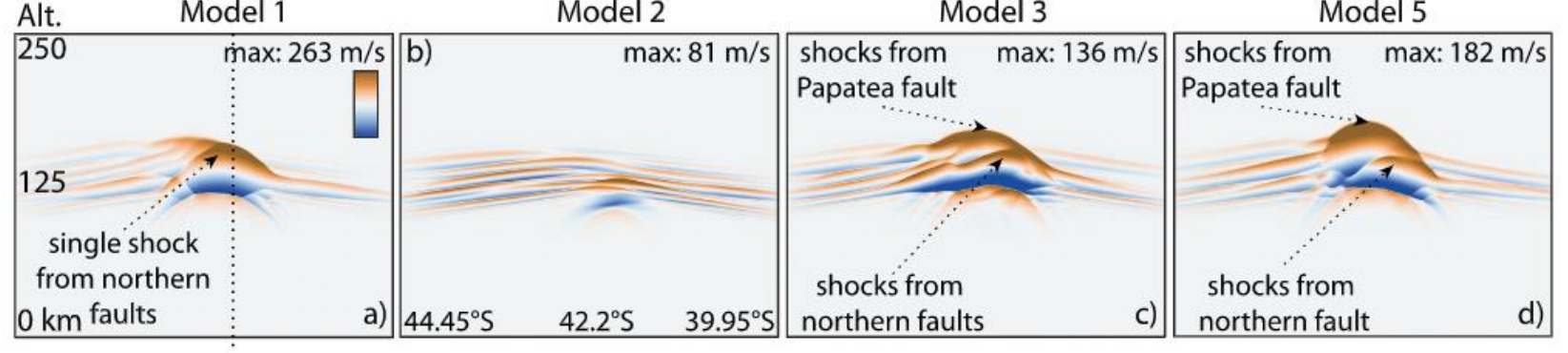

Figure: Latitude-altitude diagrams of vertical fluid velocity for the meridional slice along $173.98^{\circ} \mathrm{E}$ from simulations with different rupture models at $\mathrm{T}=500 \mathrm{~s}$. From (Inchin, 2021).
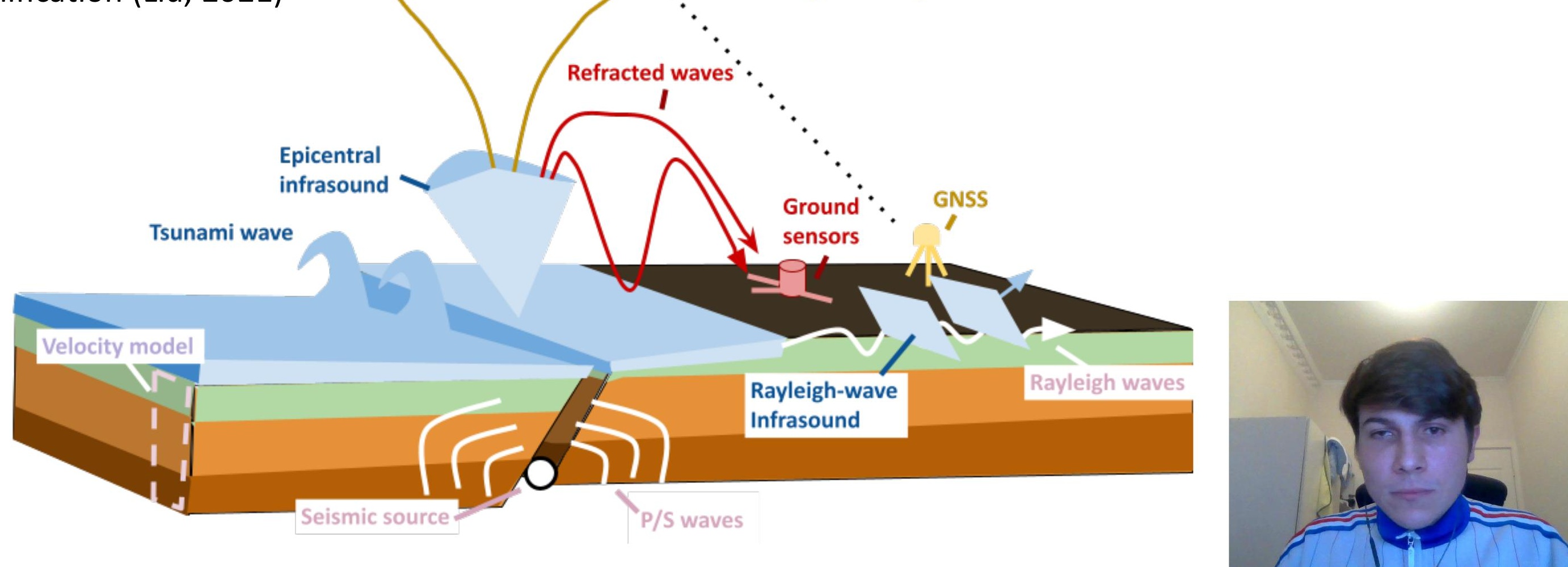


\section{Balloons as flying seismometers?}

At low altitudes, the atmosphere is non-dispersive and infrasound waves can be considered "copies" of their seismic counterparts

Balloons provide an inexpensive alternative to ground stations and satellite-based techniques for seismic monitoring and surface source investigations
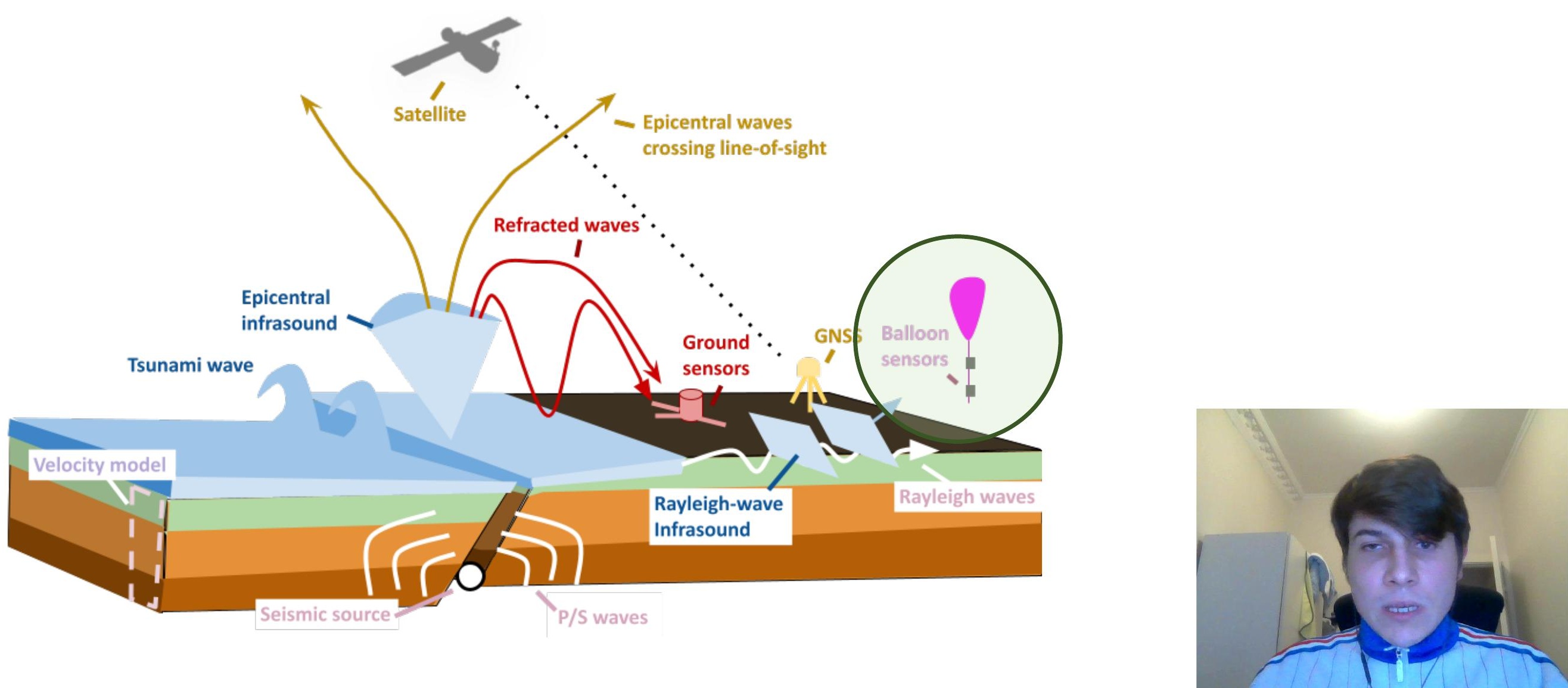


\section{July $22^{\text {nd }} 2019,16: 26: 56$ (Brissaud et al, 2021)}

In July 2019, JPL, Caltech, and Sandia deployed a free-floating balloon equipped with pressure sensors near the Ridgecrest earthquake epicenter to detect potential aftershocks

On July $22^{\text {nd }}$, pressure waveforms recorded at the balloon showed high correlation with seismic arrivals and good match with numerical simulations

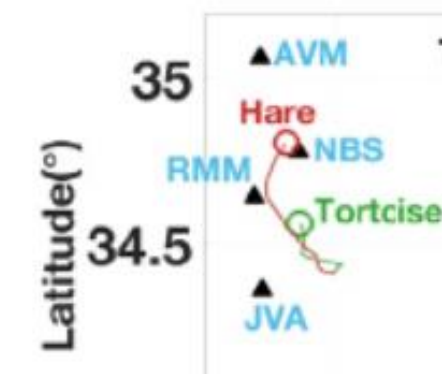

34

Epicenter

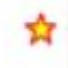

$-116.5$ Longitude $\left({ }^{\circ}\right)$

$-116$

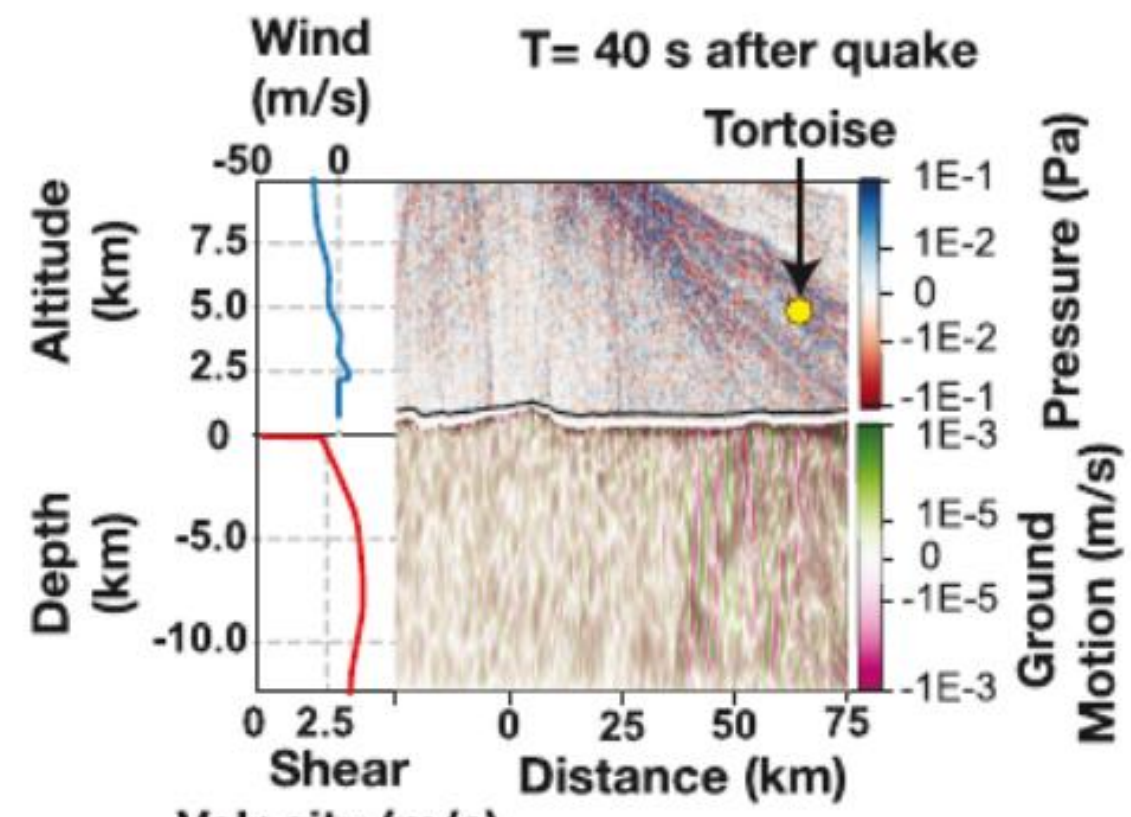

Velocity $(\mathrm{m} / \mathrm{s})$
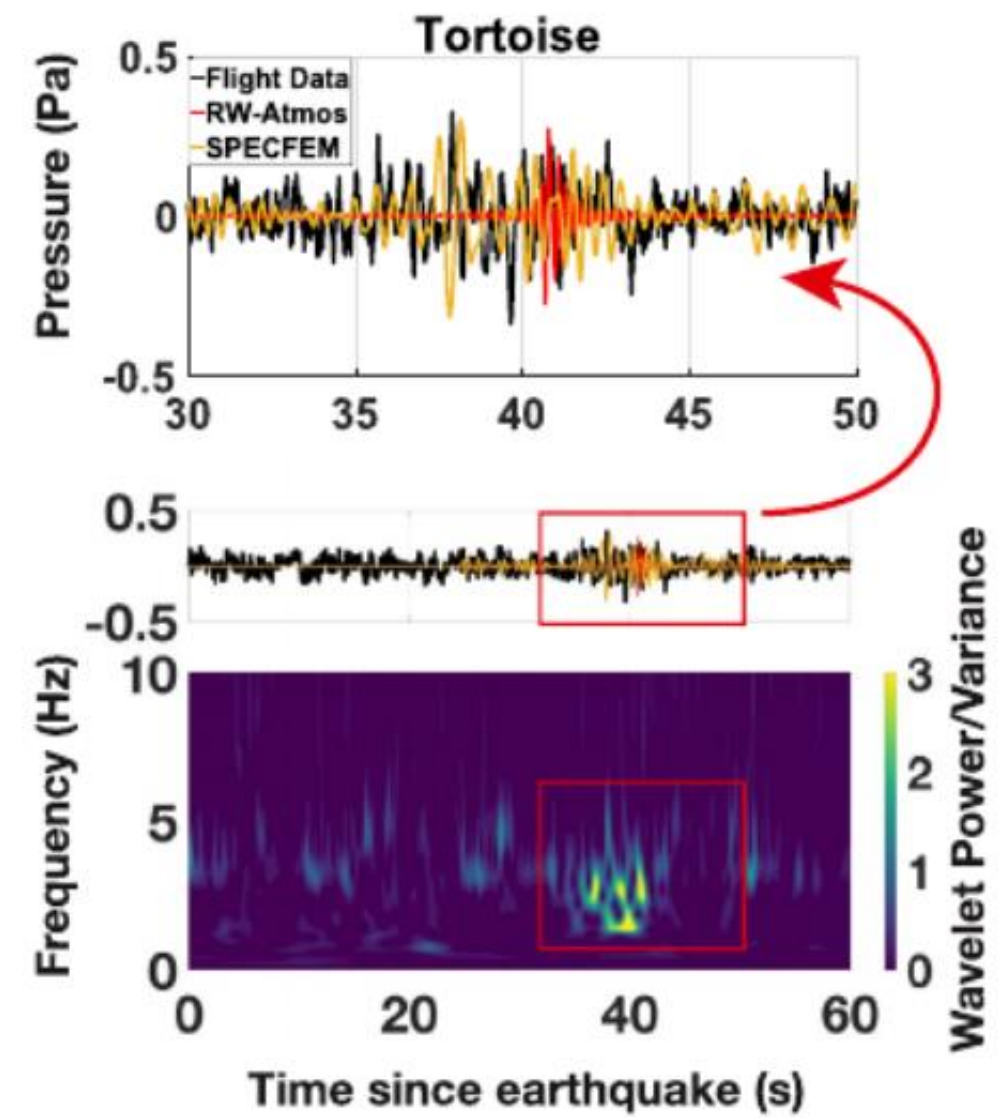


\section{Infrasound as a shifted-in-time copy of seismic motion}

The Frequency-Time ANalysis (FTAN) enables us to investigate the dispersion properties of both infrasound and seismic signals

Similarities in terms of higher-order Rayleigh-wave (RW) group velocity values in the frequency range of interest $1-2.5 \mathrm{~Hz}$
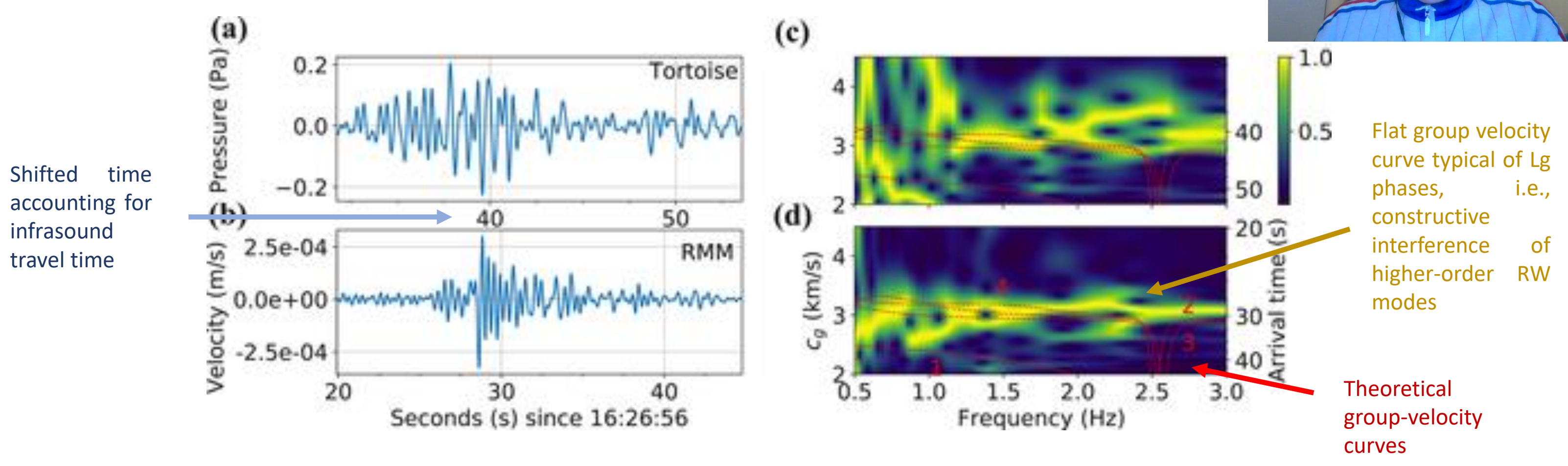

Considering the peak sensitivity of RWs $d(m, \lambda)=\frac{1}{2} m \lambda$, the range of extracted group velocity values give a depth $\approx 2.4 \pm 0.6 \mathrm{~km}$. 


\section{Inversions are challenging at high-frequency...}

Waveforms of high-frequency phases such as Lg phases are extremely sensitive to the thickness of shallow velocity layers as well as lateral variations of crustal velocities

Extracted group velocities from Lg phases correspond to average crustal velocities and lack vertical resolution

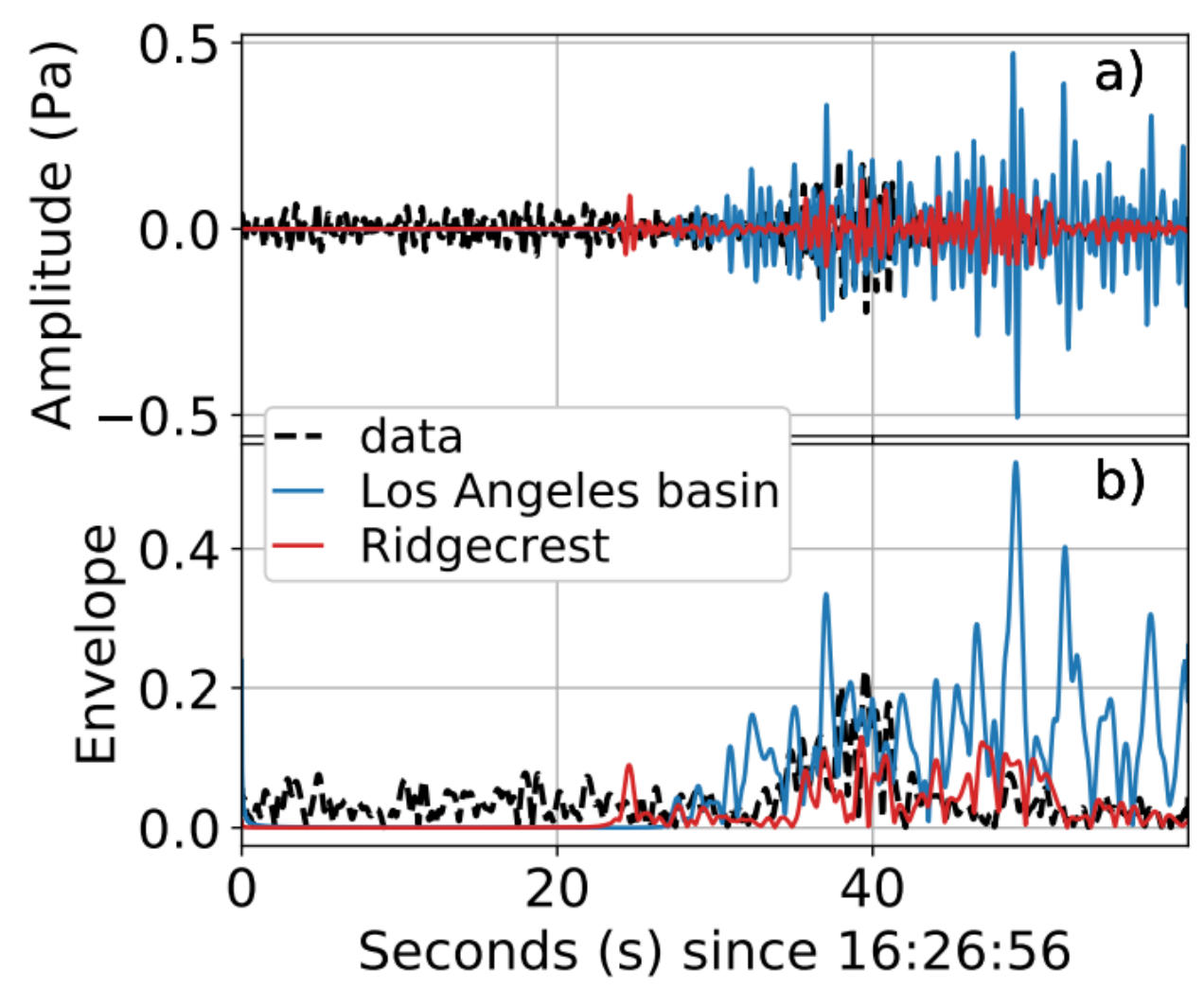

Ridgecrest $\underline{\text { Tomographic models }}$ Los Angeles

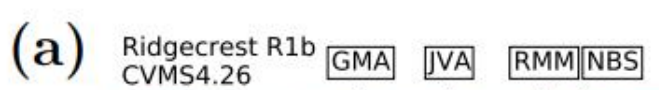

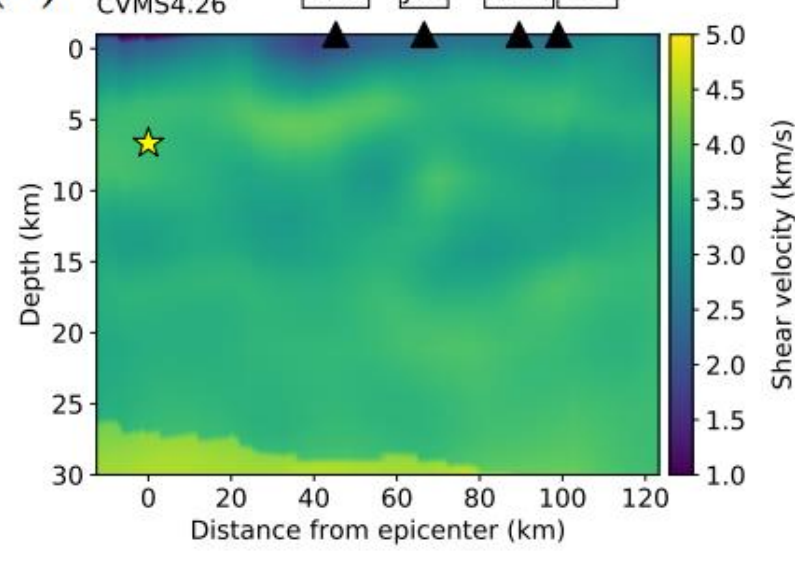

(c) Los Angeles basin GMA [VA RMM [NBS

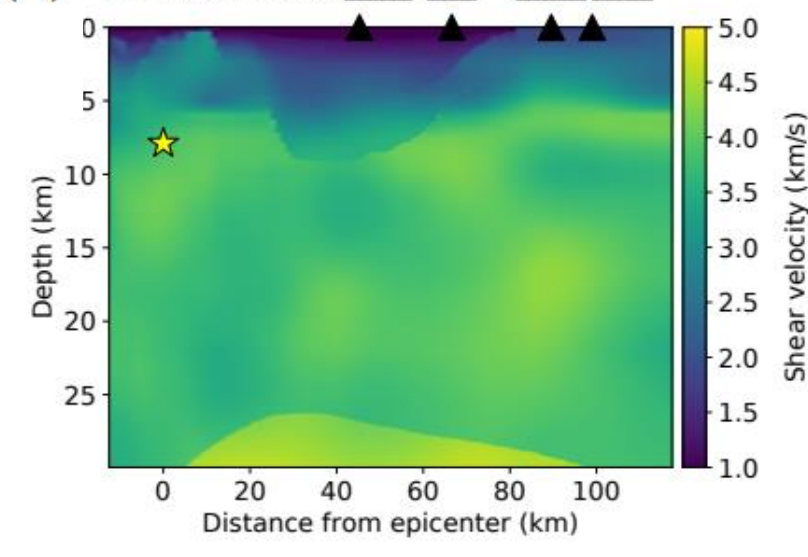

Larger-magnitude events will excite more energetic Rayleigh-wave modes and more energy at low frequency which give access to better vertical resolution and larger depths

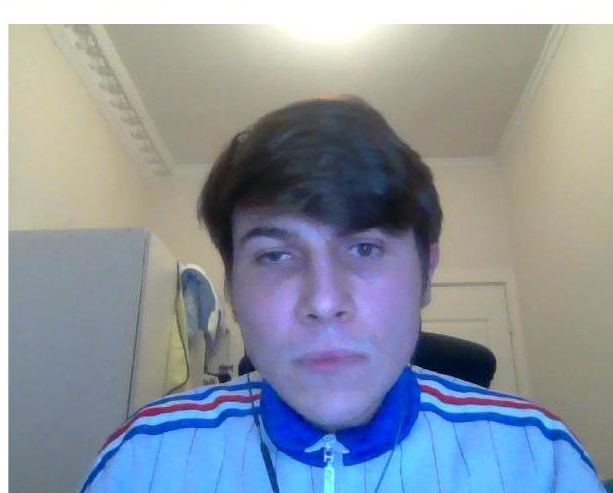




\section{Designing an inversion framework}

Epicentral + RW arrival

times (+ satellite

airglow detections

(Komjathy, 2018))<smiles>CC1CC1</smiles>

\section{Arrival-time}

2 epicenter localization

Grid-based solver

(Blom, 2015)

genetic algorithm
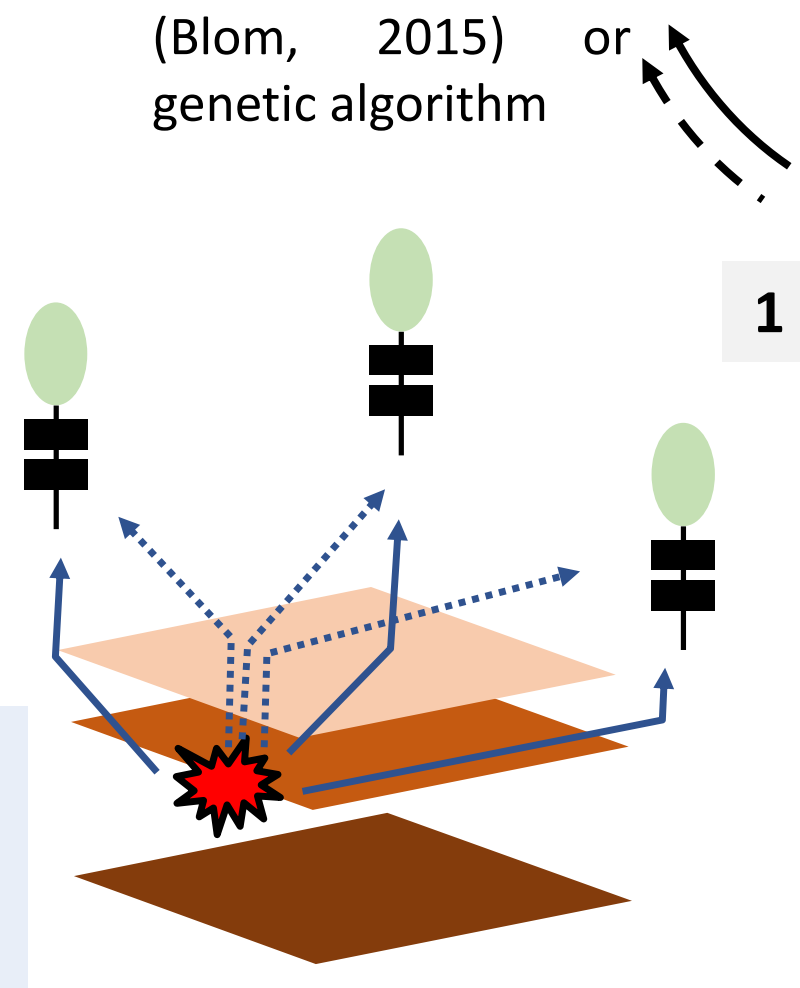

Seismo-acoustic arrival-

1 time predictions

Ray tracing (Blom, 2015) +

Green's functions-based

solver (Brissaud, 2021)

solver (Brissaud, 2021)

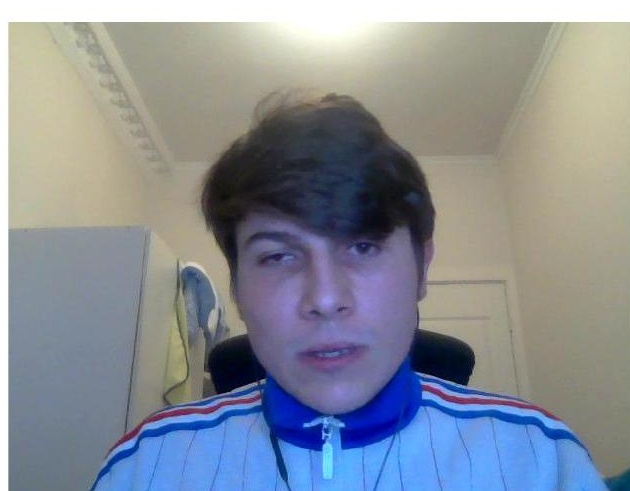




\section{Designing an inversion framework}

Epicentral + RW arrival

times (+ satellite

airglow detections

(Komjathy, 2018))
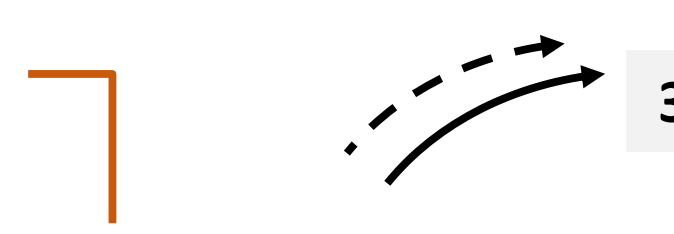

curve extraction

FTAN (Brissaud, 2021)

\section{Arrival-time}

2 epicenter localization

Grid-based solver

(Blom, 2015)

genetic algorithm
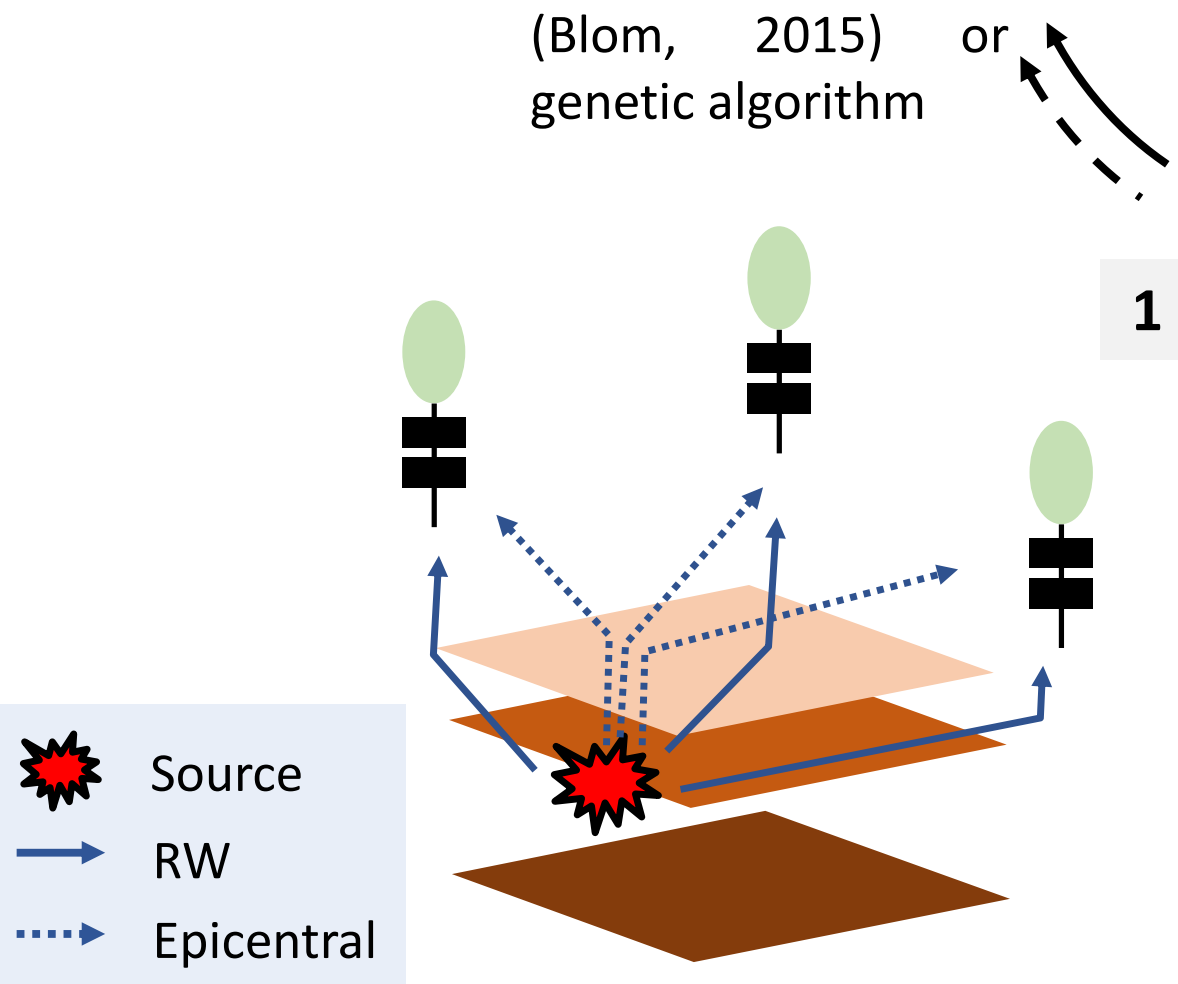

Seismo-acoustic arrival-

1 time predictions

Ray tracing (Blom, 2015) +

Green's functions-based

solver (Brissaud, 2021)

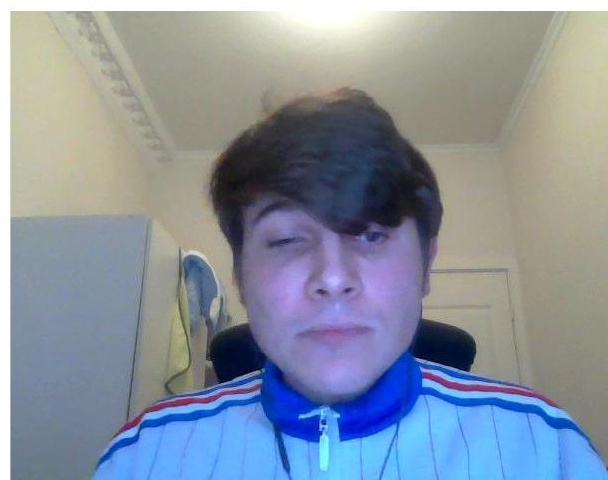




\section{Designing an inversion framework}

Epicentral + RW arrival

times (+ satellite

airglow detections

(Komjathy, 2018))
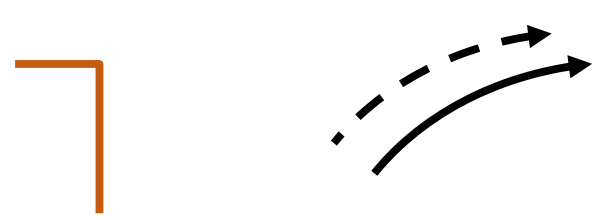

3

Group-velocity curve extraction

FTAN (Brissaud, 2021)

\section{Arrival-time}

2 epicenter localization

Grid-based solver (Blom, 2015) genetic algorithm

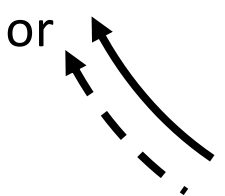

Source

RW

Epicentral

Seismo-acoustic arrivaltime predictions
- Best model

- - Uncertainty

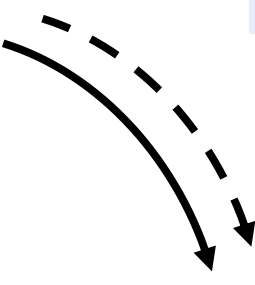

Initial crustal/upper

mantle velocity model

\section{D Velocity-structure} inversion

1D Eikonal inversion
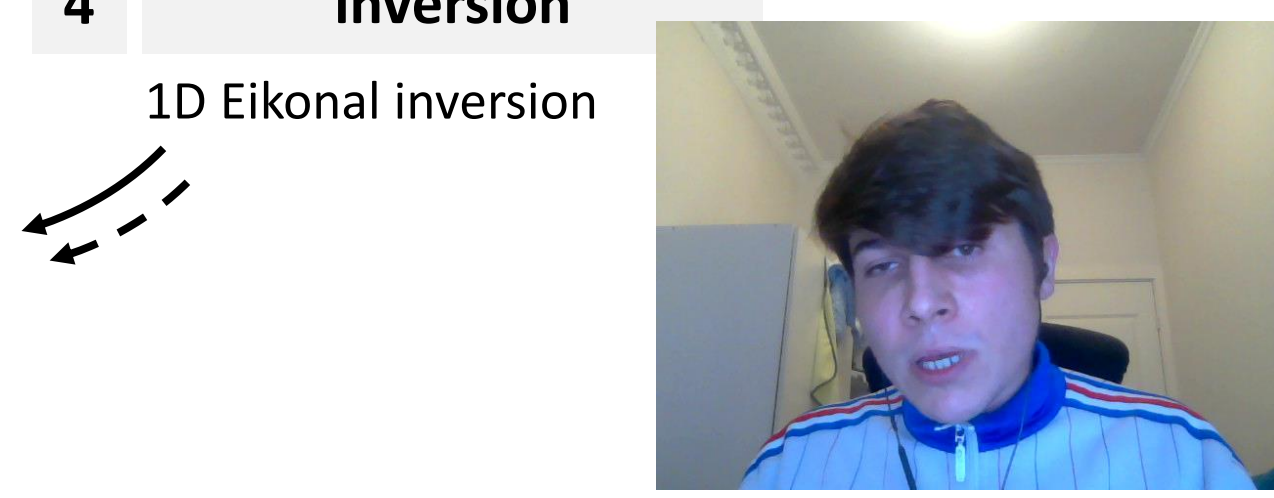

Ray tracing (Blom, 2015) +

Green's functions-based

solver (Brissaud, 2021)

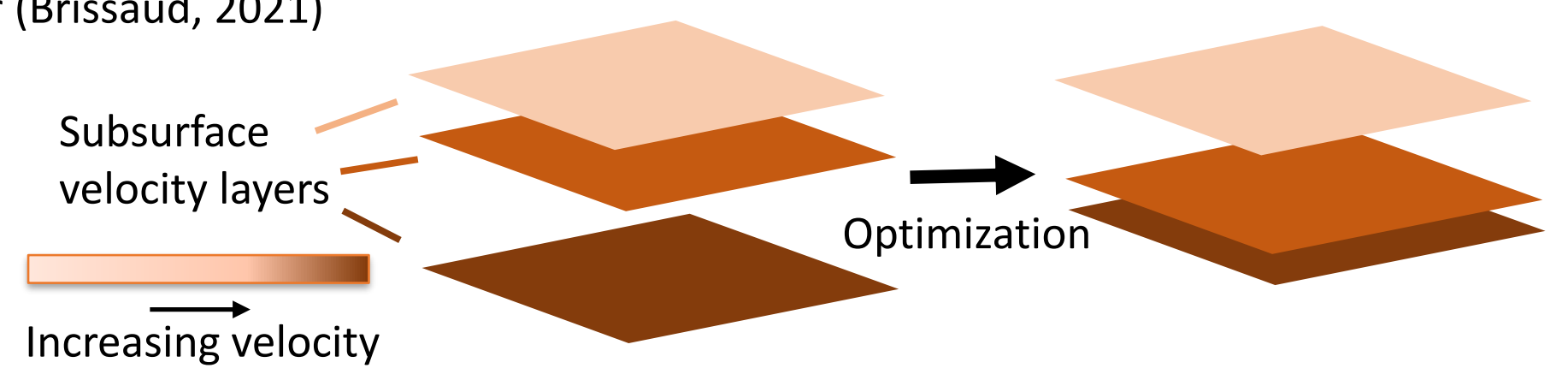




\section{Challenges and recommendations}

Accounting for all path effects (e.g., topography, lateral seismic and atmospheric velocity variations) in arrival time predictions will require $3 d$ range-dependent full-waveform modeling which is computationally expensive $\rightarrow$ corrections of analytical predictors (e.g., Green's functions across media with lateral disctoninuities) or modeling through machine learning (see for example S51A-04)

Determining uncertainties during data processing, modelling, and inversions is critical. However, this process significantly increases the computational cost when using basic grid-search approaches $\rightarrow$ Iterative Bayesian algorithms?

Accurate inversions require reliable Rayleigh and Epicentral wave arrival time and dispersion extractions (potentially at very low SNR) which is time consuming and prone to inconsistencies $\rightarrow$ Building balloon detection datasets and training machine learning for binary signal-noise detection (see for example SA11B-01) + Cross-correlating signals across each line array on each balloon can help reducing the noise level + Using the direction-of-arrival information from each line array on each balloon can help better constraining the range of seismic group velocities

Inversion algorithms will require initial conditions which are potentially poorly constrained (or even inexistent on Venus) $\rightarrow$ Regular randomization of initial condition over a range of possible velocity structures and source location is necessary + Considering prior distribution of possible seismic source locations such as volcanoes could help facilitating the convergence

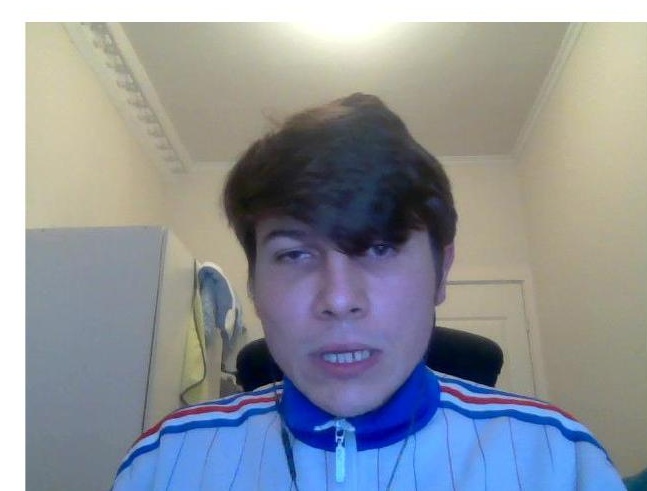




\section{Future directions}

This detection shows (1) low-magnitude earthquakes can be detected below the stratosphere, and (2) high signal-tonoise ratio signals provide insights into the subsurface velocity structure

Simulations indicate that competing path effects might lead to some potential misinterpretations of observed signals

And one low SNR detection is not enough to assess the full potential of balloon-based investigations...

Therefore, JPL, Caltech, and Sandia are currently funded to deploy balloons in Oklahoma, USA to monitor the low-magnitude earthquake activity

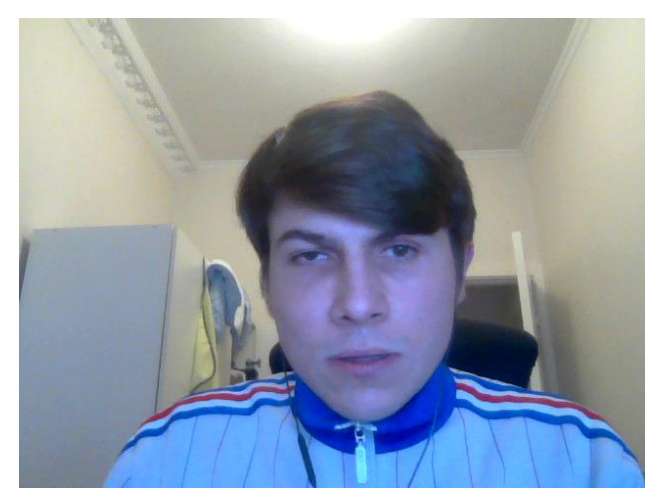

Figure: Deployment of heliotrope balloons in July 2021. Credit Brian R. Elbing

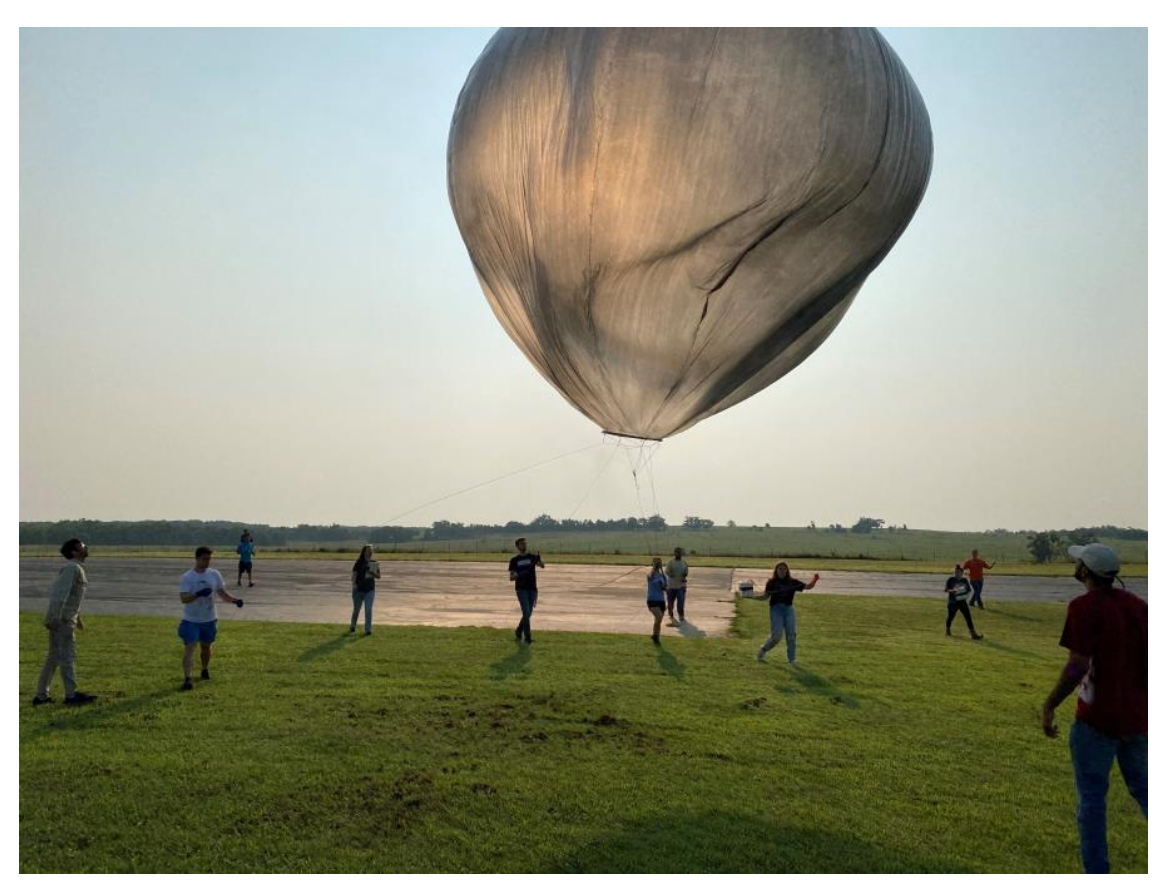




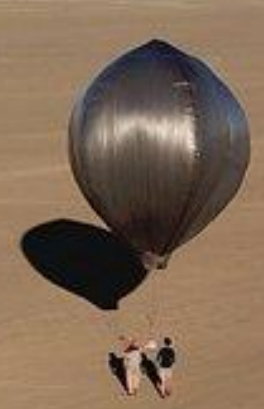

\section{Thank you! Questions?}




\section{References}

Kanao, M. (2018). Introduction: Progress of Seismology in Polar Region. In Polar Seismology-Advances and Impact. IntechOpen.

Inchin, P. A., Snively, J. B., Kaneko, Y., Zettergren, M. D., \& Komjathy, A. (2021). Inferring the evolution of a large earthquake from its acoustic impacts on the ionosphere. AGU Advances, 2(2), e2020AV000260.

Poler, G., Garcia, R. F., Bowman, D. C., \& Martire, L. (2020). Infrasound and gravity waves over the Andes observed by a pressure sensor on board a stratospheric balloon. Journal of Geophysical Research: Atmospheres, 125(6), e2019JD031565.

Lamb, O. D., Lees, J. M., \& Bowman, D. C. (2018). Detecting lightning infrasound using a high-altitude balloon. Geophysical Research Letters, 45(14), 7176-7183.

Matoza, R. S., Jolly, A., Fee, D., Johnson, R., Chouet, B., Dawson, P., ... \& Key, N. (2017). Seismo-acoustic wavefield of strombolian explosions at Yasur volcano, Vanuatu, using a broadband seismo-acoustic network, infrasound arrays, and infrasonic sensors on tethered balloons. The Journal of the Acoustical Society of America, 141(5), 3566-3566.

Garcia, R. F., Martire, L., Chaigneau, Y., Cadu, A., Mimoun, D., Bassas Portus, M., ... \& Martin, R. (2021). An active source seismoacoustic experiment using tethered balloons to validate instrument concepts and modelling tools for atmospheric seismology. Geophysical Journal International, 225(1), 186-199.

Krishnamoorthy, S., Komjathy, A., Pauken, M. T., Cutts, J. A., Garcia, R. F., Mimoun, D., ... \& Bowman, D. C. (2018). Detection of artificially generated seismic signals using balloon-borne infrasound sensors. Geophysical Research Letters, 45(8), 3393-3403.

Mancini, S., Segou, M., Werner, M. J., \& Parsons, T. (2020). The predictive skills of elastic Coulomb rate-and-state aftershock forecasts during the 2019 Ridgecrest, California, earthquake sequence. Bulletin of the Seismological Society of America, 110(4), $1736-1751$.

Brissaud, Q., Krishnamoorthy, S., Jackson, J. M., Bowman, D. C., Komjathy, A., Cutts, J. A., ... \& Walsh, G. J. (2021). The first detection of an earthquake from a balloon using its acoustic signature. Geophysical Research Letters, e2021GL093013.

Bowman, D. C., Norman, P. E., Pauken, M. T., Albert, S. A., Dexheimer, D., Yang, X., ... \& Cutts, J. A. (2020). Multihour stratospheric flights with the Heliotrope solar hot-air balloon. Journal of Atmospheric and Oceanic Technology, 37(6), 1051-1066.

J., Cutts, Stevenson, D., J. A., Mimoun, D., Arrowsmith, S., Banerdt, W. B., Blom, P., ... \& Tsai, V. C. (2015). Probing the interior structure of Venus. 
Shani-Kadmiel, S., Averbuch, G., Smets, P., Assink, J., \& Evers, L. (2021). The 2010 Haiti earthquake revisited: An acoustic intensity map from remote atmospheric infrasound observations. Earth and Planetary Science Letters, 560, 116795.

Liu, H., Zhang, K., Imtiaz, N., Song, Q., \& Zhang, Y. (2021). Relating Far-Field Coseismic lonospheric Disturbances to Geological Structures. Journal of Geophysical Research: Space Physics, 126(7), e2021JA029209.

Zedek, F., Rolland, L. M., Mikesell, T. D., Sladen, A., Delouis, B., Twardzik, C., \& Coïsson, P. (2021). Locating surface deformation induced by earthquakes using GPS, GLONASS and Galileo ionospheric sounding from a single station. Advances in Space Research, 68(8), 3403-3416.

Blom, P. S., Marcillo, O., \& Arrowsmith, S. J. (2015). Improved Bayesian infrasonic source localization for regional infrasound. Geophysical Supplements to the Monthly Notices of the Royal Astronomical Society, 203(3), 1682-1693.

Averbuch, G., Waxler, R. M., Smets, P. S., \& Evers, L. G. (2020). Probabilistic inversion for submerged source depth and strength from infrasound observations. The Journal of the Acoustical Society of America, 147(2), 1066-1077

Astafyeva, E., Shalimov, S., Olshanskaya, E., \& Lognonné, P. (2013). Ionospheric response to earthquakes of different magnitudes: Larger quakes perturb the ionosphere stronger and longer. Geophysical Research Letters, 40(9), 1675-1681. 


\section{Ground observations}

Epicentral infrasound provide an insight on the ground deformations near the epicenter

Backprojection of acoustic energy along observed backazimuth and celerities enables the reconstructions of ground motion maps \& retrieve focal mechanisms with a station $>1700 \mathrm{~km}$ away from the epicenter
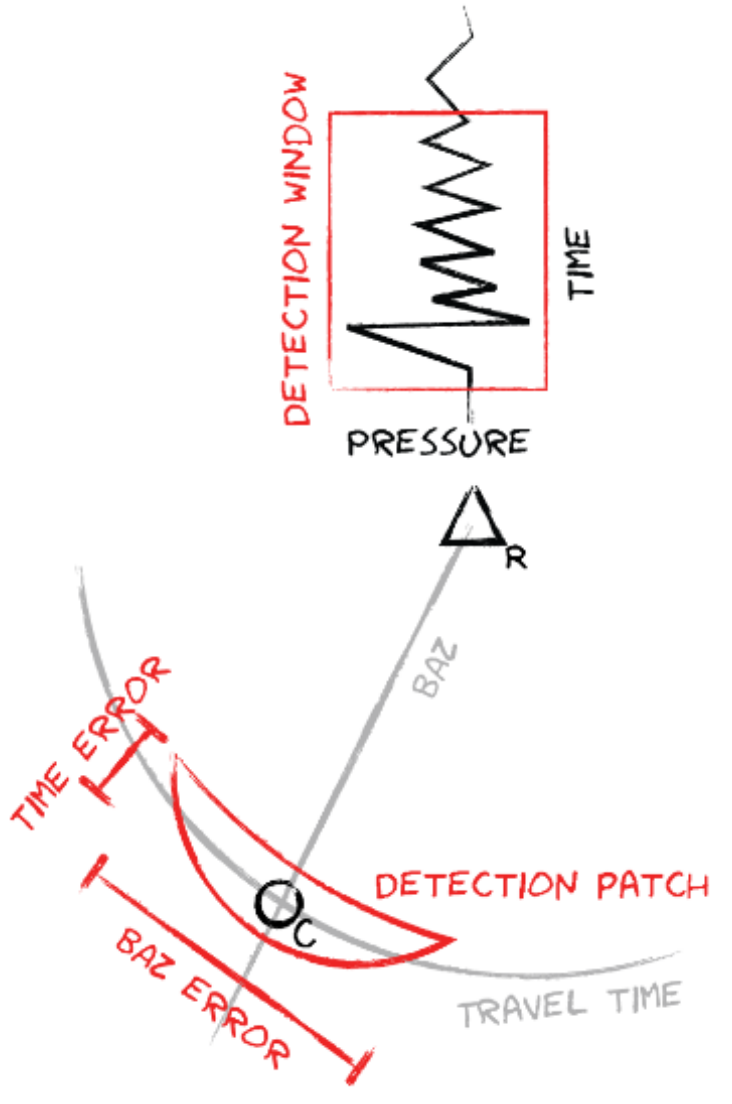

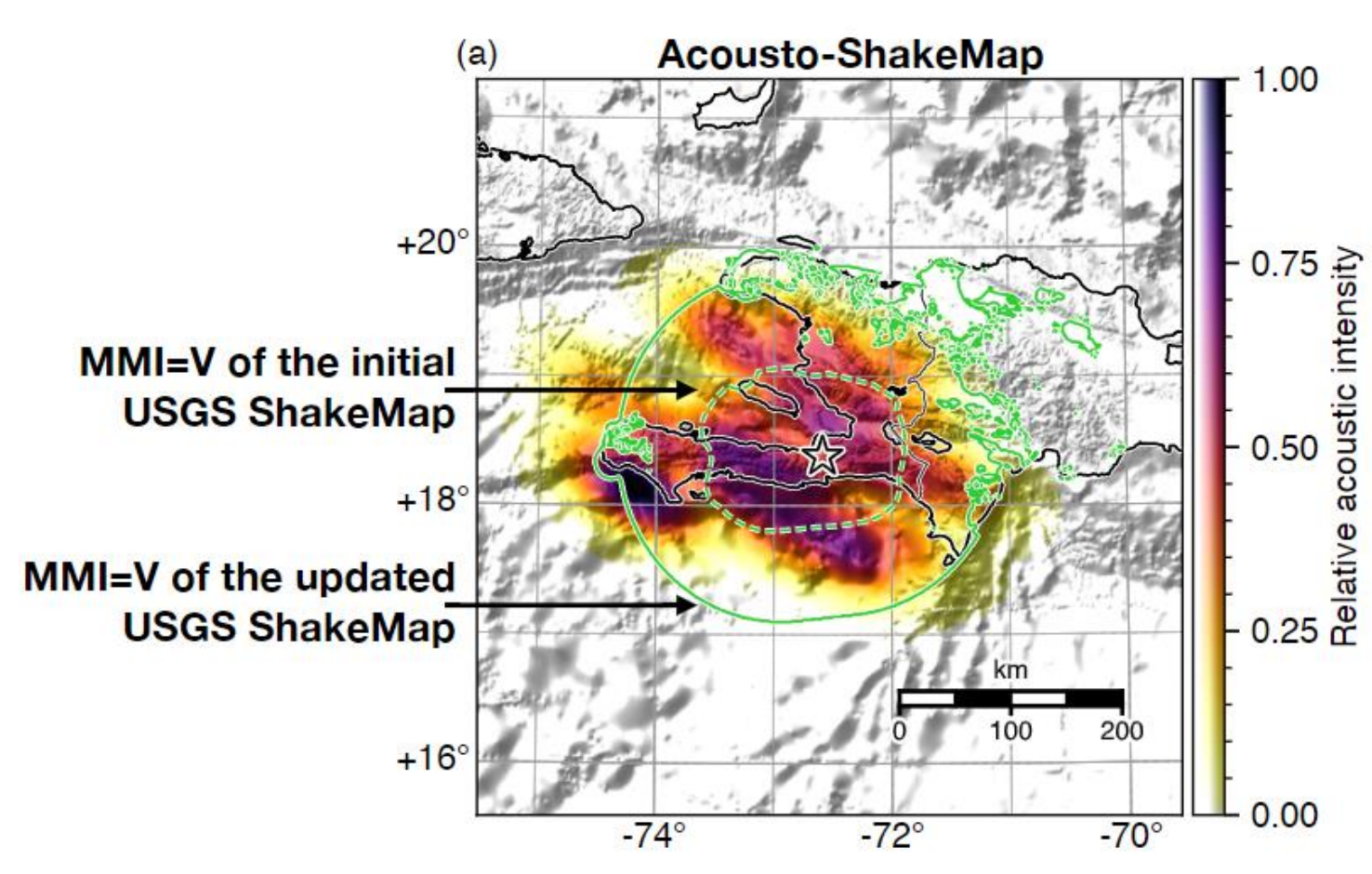

(b) Source radiation map

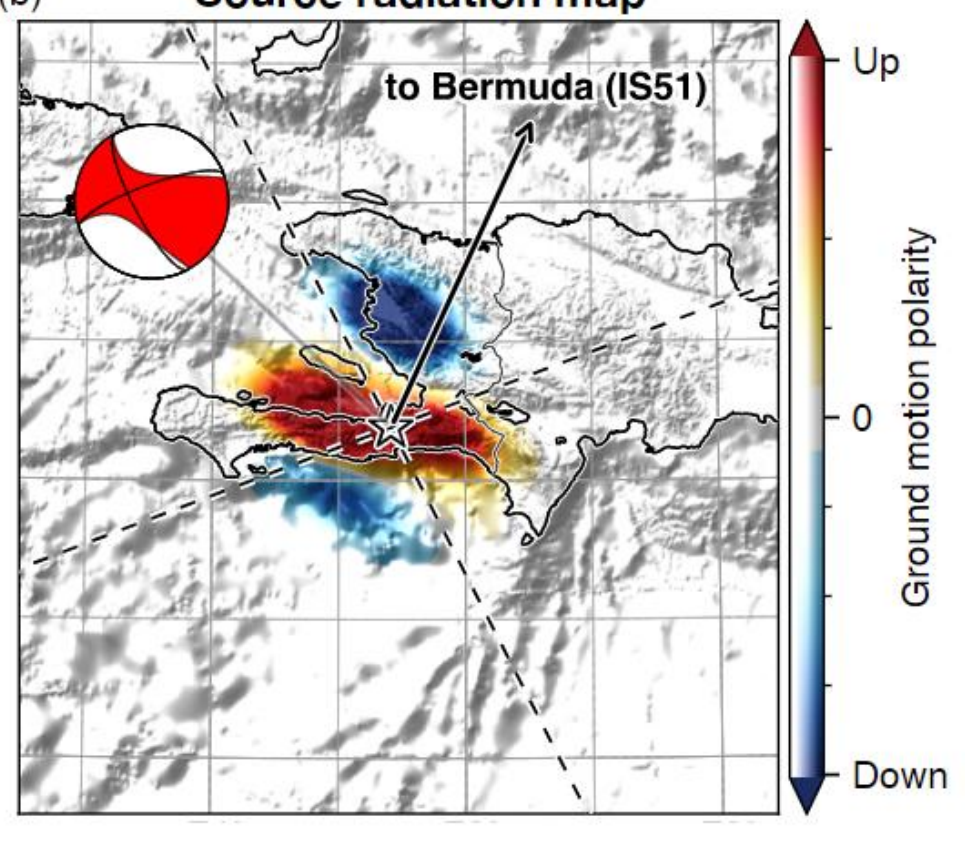

Figure: Reconstruction of seismic hazard maps and projected focal mechanisms after Haiti earthquake (Shani-Kadmiel, 2021) 


\section{Ionospheric observations}

On Earth, large earthquakes have often been observed through GPS ionospheric sounding or airglow response

Ionospheric observations can help locate large undersea surface deformations and constrain rupturing models

However, GPS sounding relies on ground stations and both techniques have limited Signal-to-Noise Ratio (SNR)

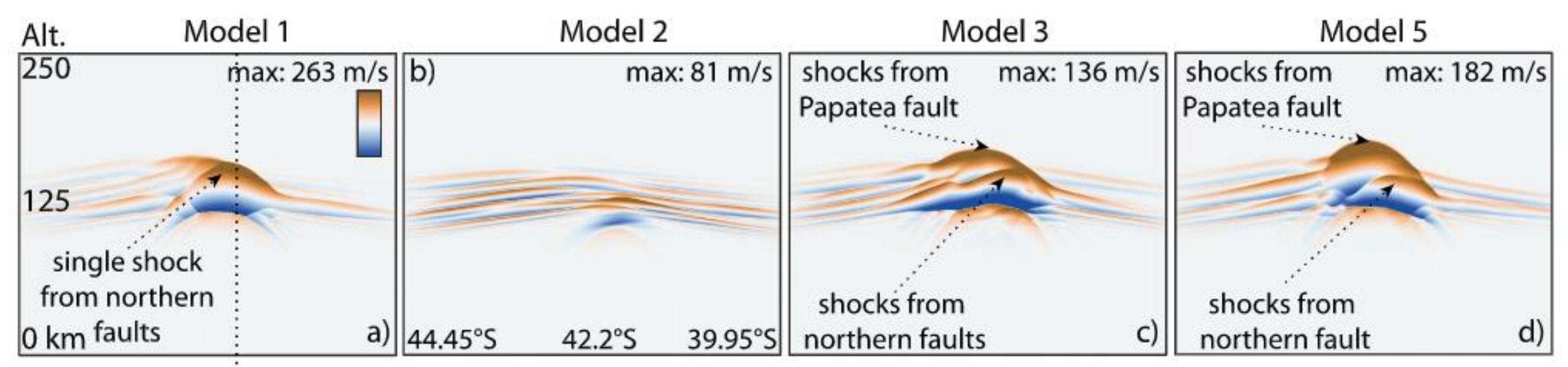

Figure: Latitude-altitude diagrams of vertical fluid velocity for the meridional slice along $173.98^{\circ} \mathrm{E}$ from simulations with different rupture models at $\mathrm{T}=500 \mathrm{~s}$ 


\section{Monitoring geophysical processes with balloons}
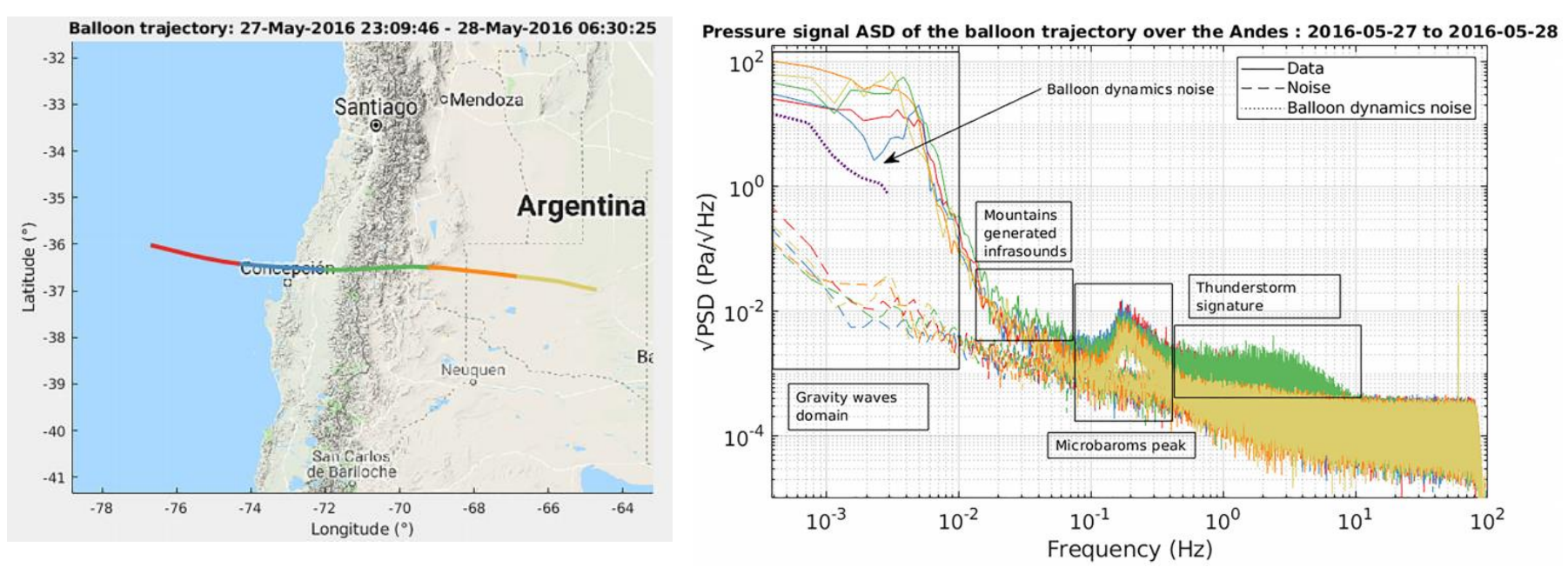

Figure: Balloon path and spectrum the acoustic wavefield generated by ocean and atmospheric processes (Poler, 2019)

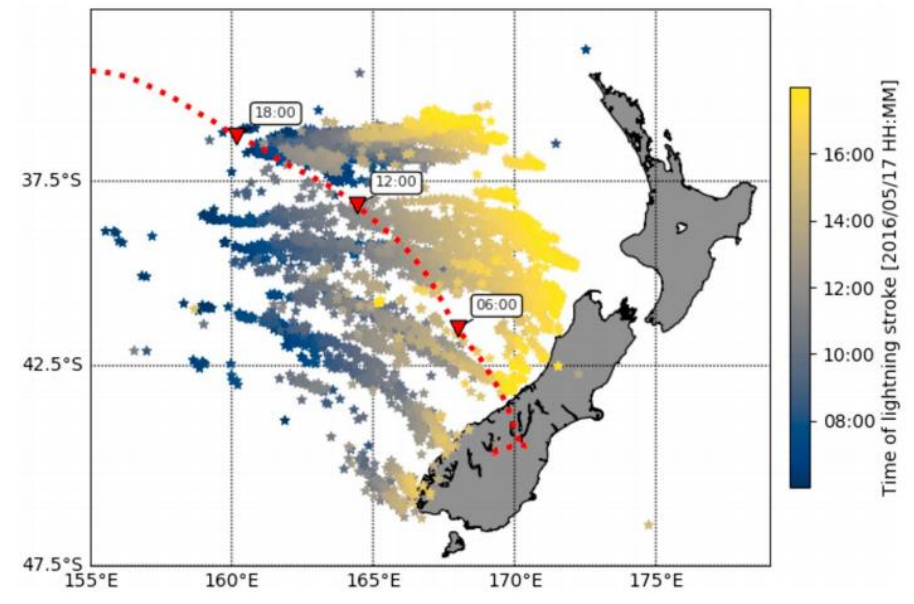

Figure: Balloon path (red) and lightning recordings at the balloon (Lamb, 2018) d

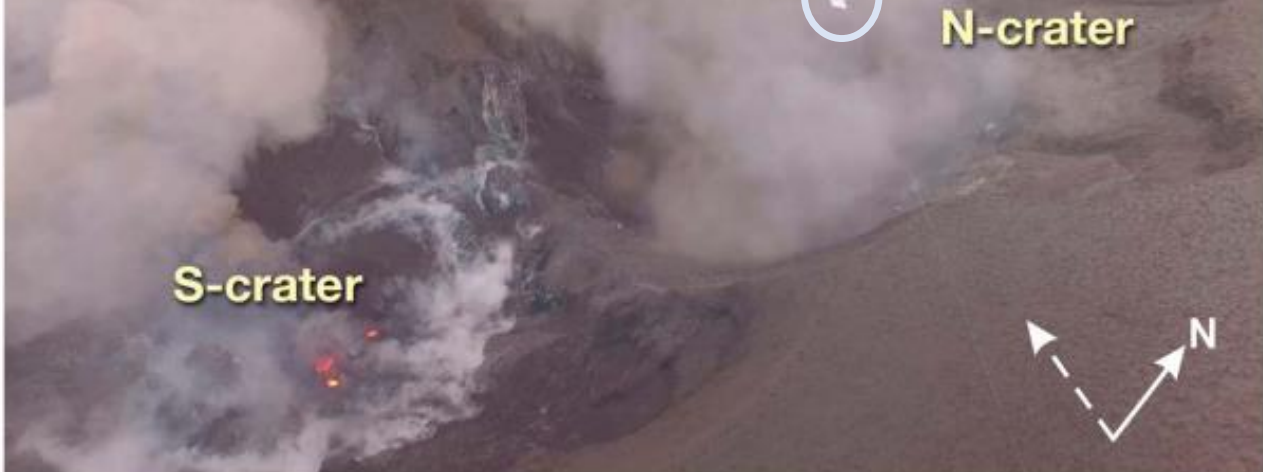

Figure: An aerial image of the north and south craters of the Yasur Volcano with the aerostat (Matoza, 2017)

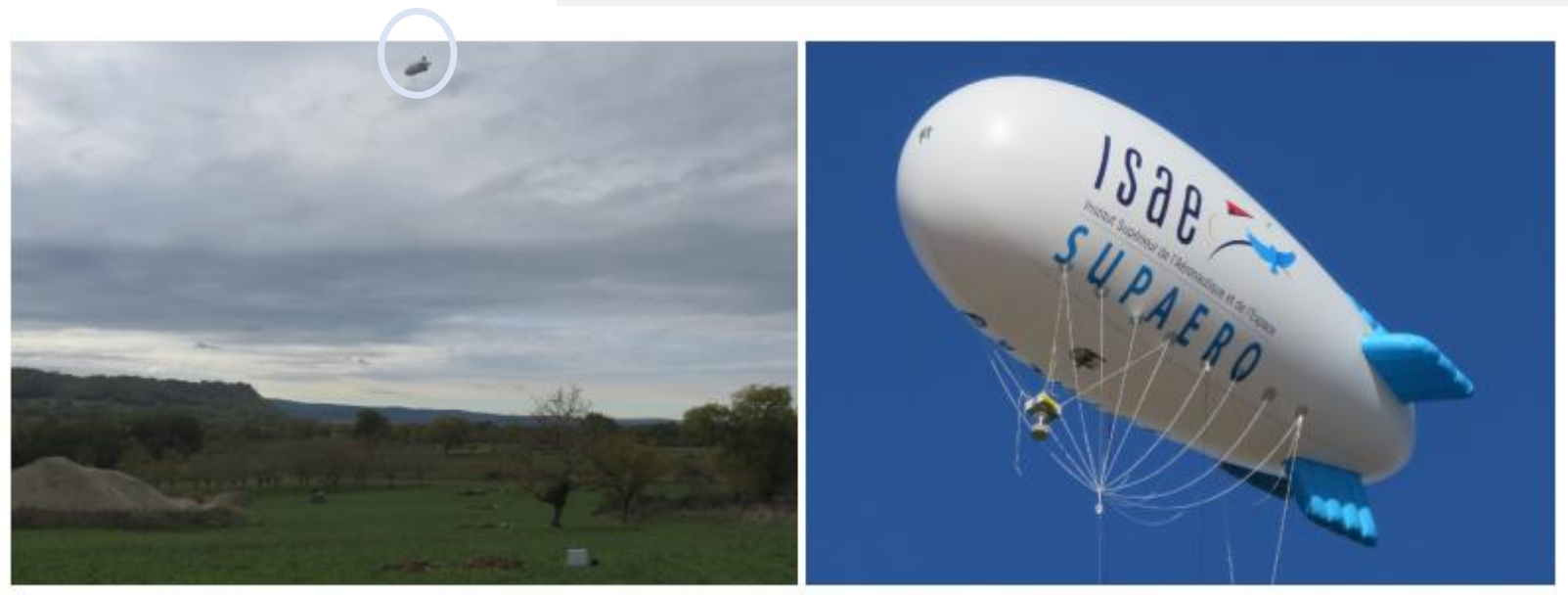

Figure: The recording of a mine blast using a tethered balloon in Southern France (Garcia, 2020) 


\section{What about seismic waves?}

While multiple surface and atmospheric sources have been studied using free flying or tethered balloons, until recently, the acoustic signature of seismic waves had never been detected

Tremendous efforts from JPL \& Caltech (Pasadena, USA) and ISAE (Toulouse, France) have demonstrated that seismic waves can be captured by pressure sensors on both tethered and free-floating balloons

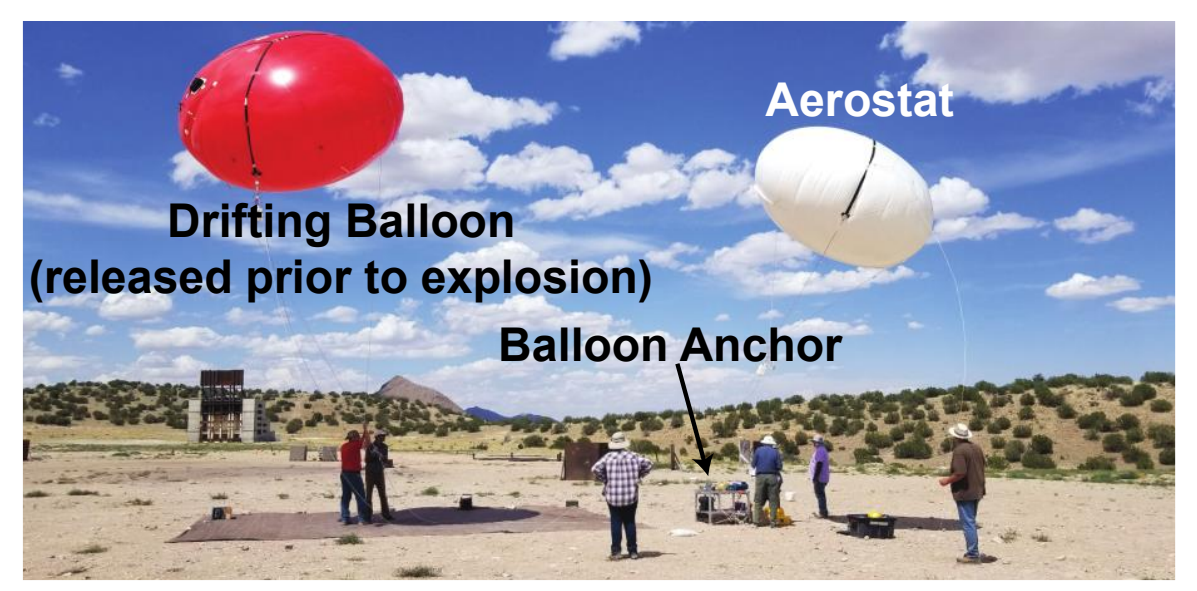

Figure: Experimental setup with both free-floating (red) and tethered (white) balloons

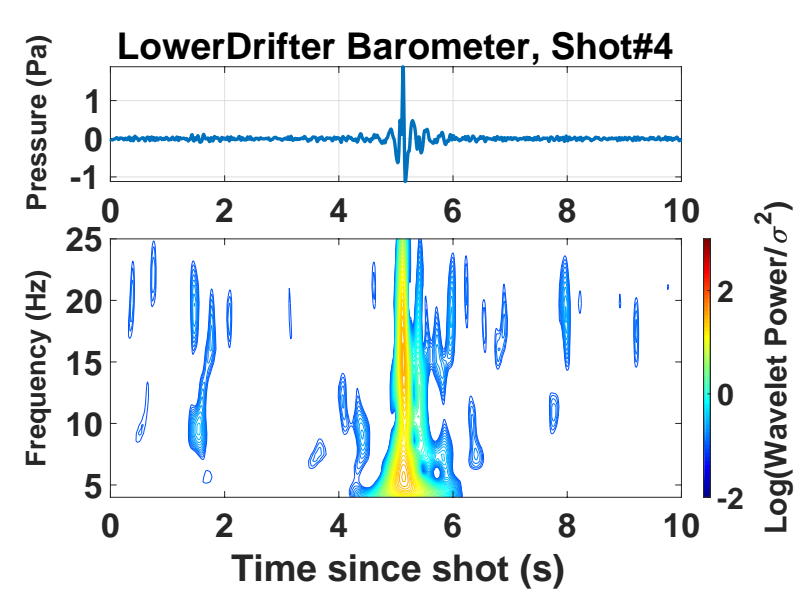

Figure: Active explosion generating both blast waves and seismic waves 


\section{What about earthquakes?}

Exact timing of active sources is known, and they are located at or just below the surface which creates a strong ground-air coupling $\rightarrow$ however, the acoustic signature of natural earthquakes had never been detected with a balloon

It remained unclear if epicentral and Rayleigh-wave infrasound could be detected from the stratosphere, especially for low-magnitude earthquakes (<Mw 5)

Without such demonstration, the feasibility of balloon seismology on Earth or Venus is limited

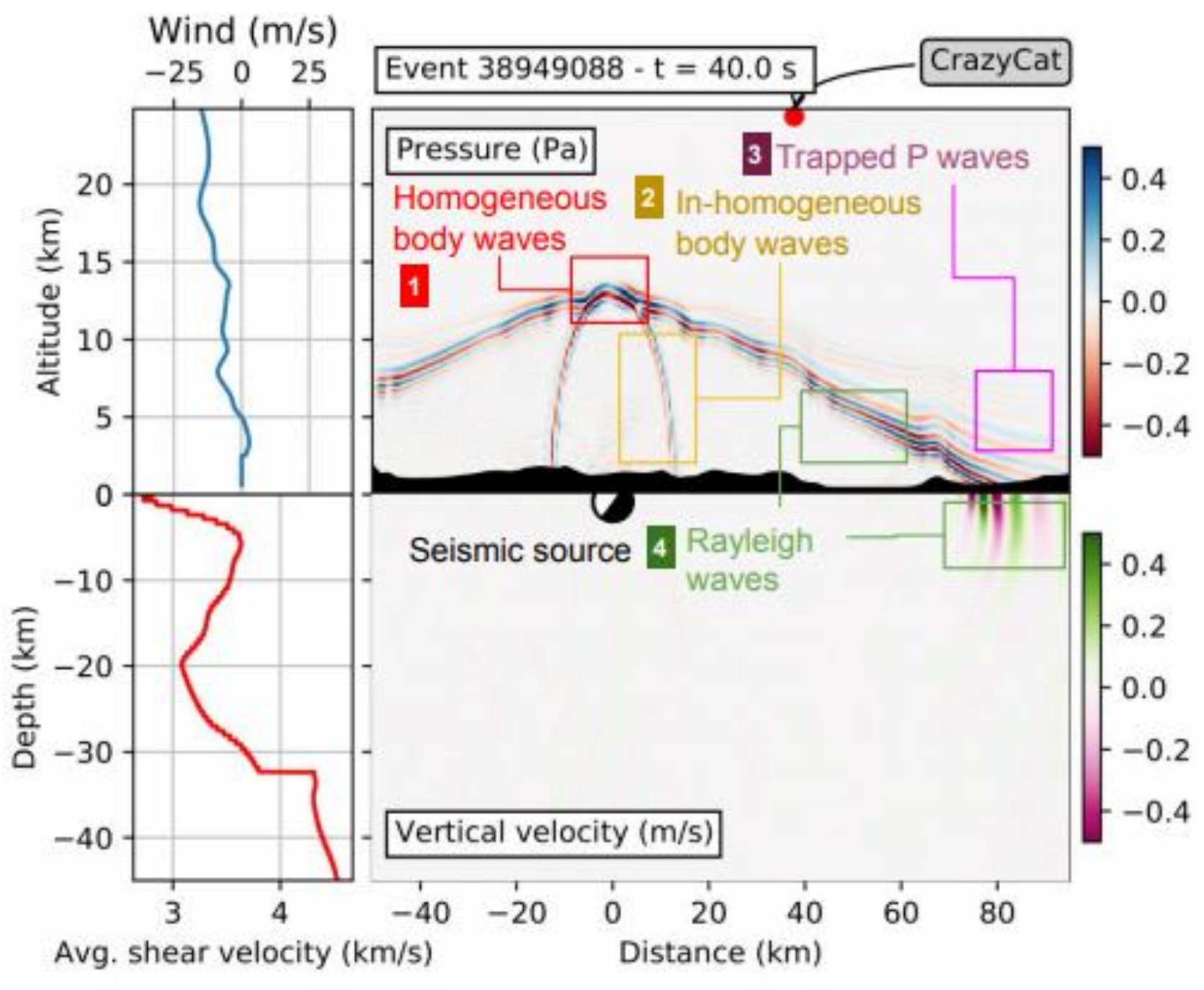

Figure: Visualization of the various seismo-acoustic contributions to the atmospheric wavefield excited by a shallow normal-faulting event 


\section{What about Venus?}

Temperature and pressure at 50-60 km are Earth-like

Likely volcanic activity

Large surface pressures lead to a much more efficient energy coupling between seismic and atmospheric media

Very fast $(60-150 \mathrm{~m} / \mathrm{s})$ atmospheric zonal "super-rotation"

Atmosphere is $98 \%$ CO2, thick sulfuric acid clouds and haze from $\sim 40-70 \mathrm{~km}$

Seismicity unknown

$\rightarrow$ High-risk high-reward planetary mission

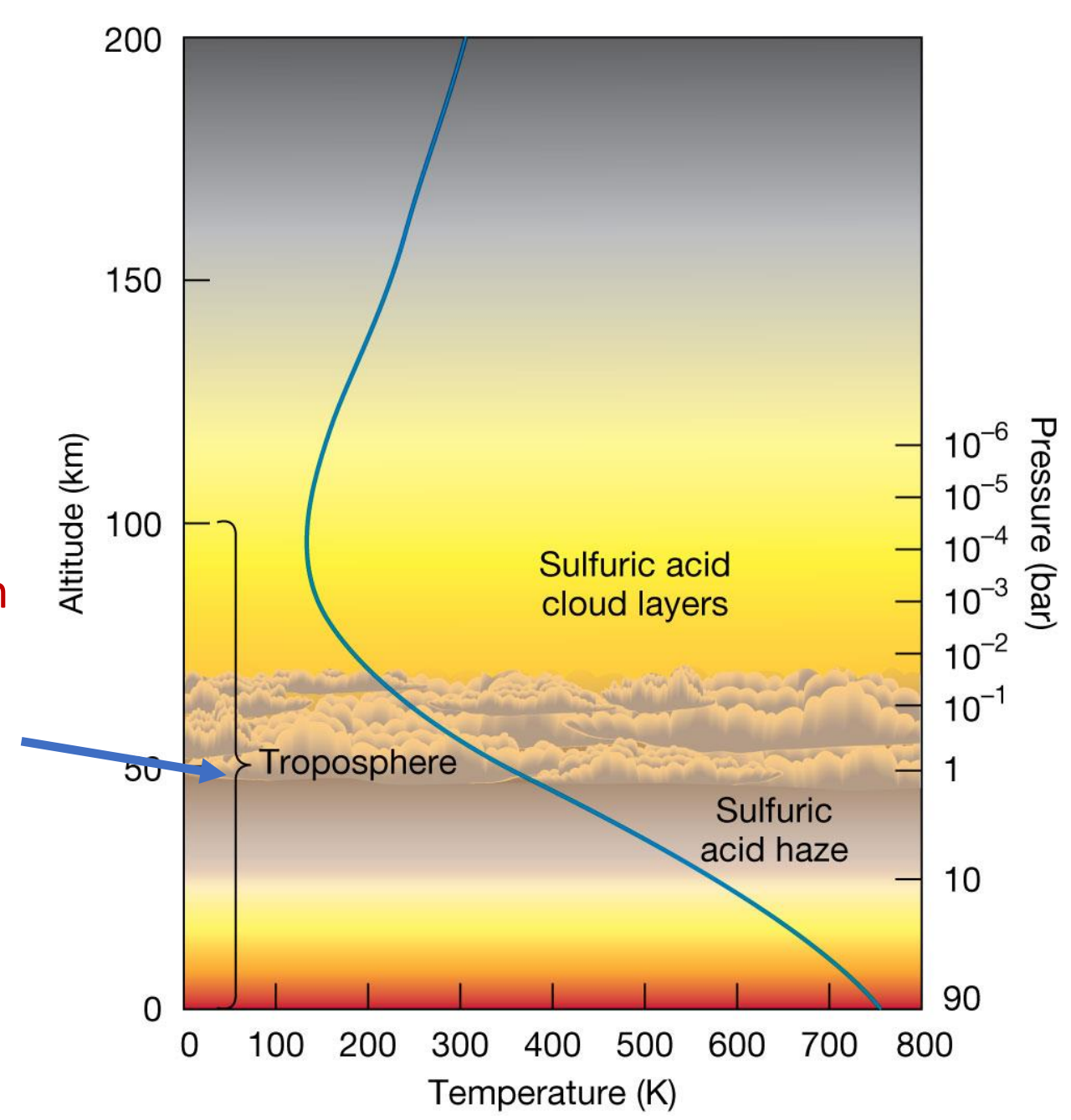

Figure: Expected temperature profile on Venus. credit: NASA 


\section{What about earthquakes?}

... But observations of epicentral and secondary infrasound from small earthquakes $(\mathrm{Mw}<5)$ exist at the ground
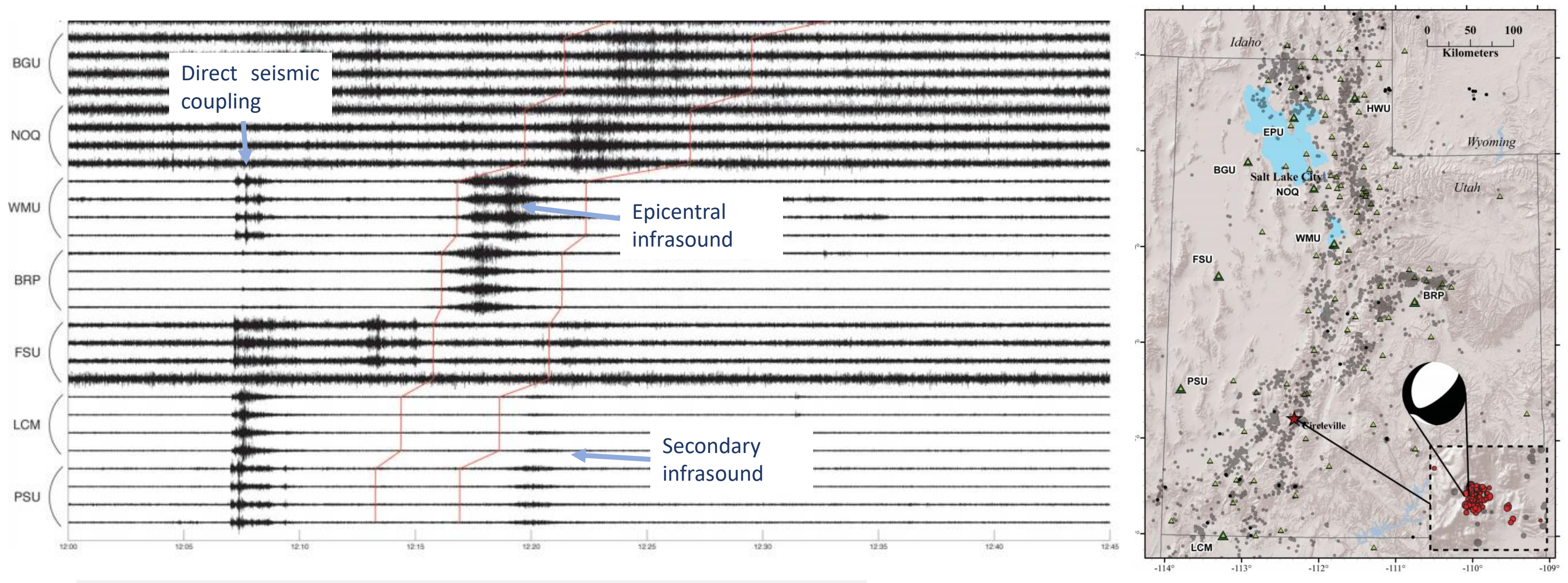

Figures: Infrasound records after the 2011 January 3 Circleville earthquake in Utah (Arrowsmith, 2012) 


\section{Seizing the Ridgecrest opportunity (Brissaud et al, 2021)}

The two main 2019 Ridgecrest earthquakes on July 4 and July 7, 2019 (Mw 6.4 and 7.1) led to a long aftershock sequence

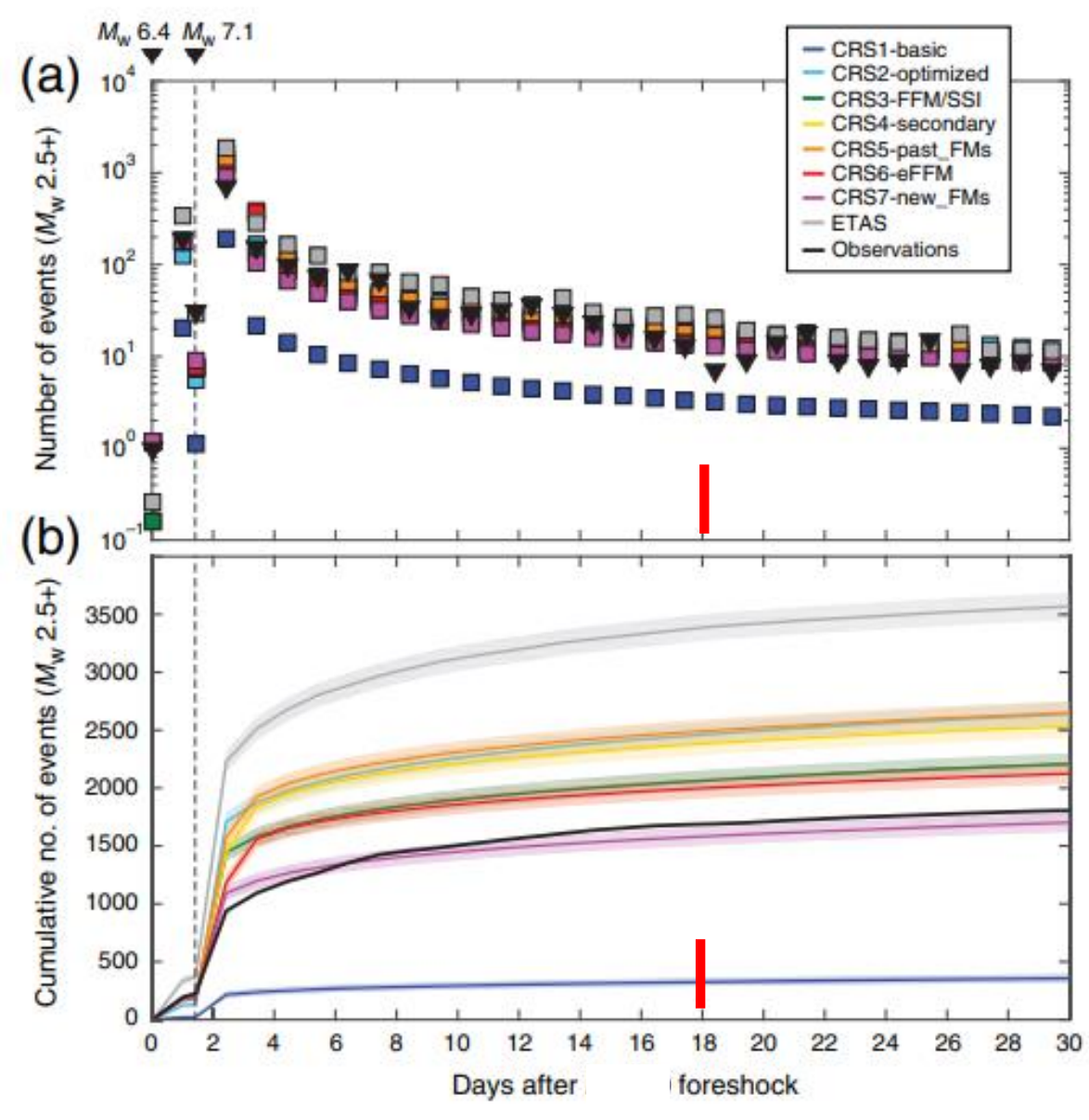

Figure: (a) number and (b) cumulative number of afteshocks given by forecast models (colors) and observations (black). (Mancini, 2021) 


\section{Seizing the Ridgecrest opportunity (Brissaud et al, 2021)}

Taking advantage of the relative proximity with Ridgecrest, JPL and Caltech rushed to build, test, and deploy 4 heliotrope balloons on July $22^{\text {nd }}$ and August $9^{\text {th }}$

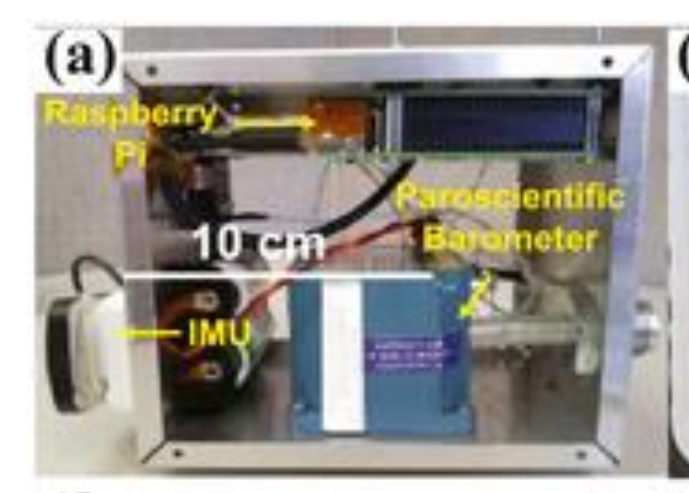

(f)

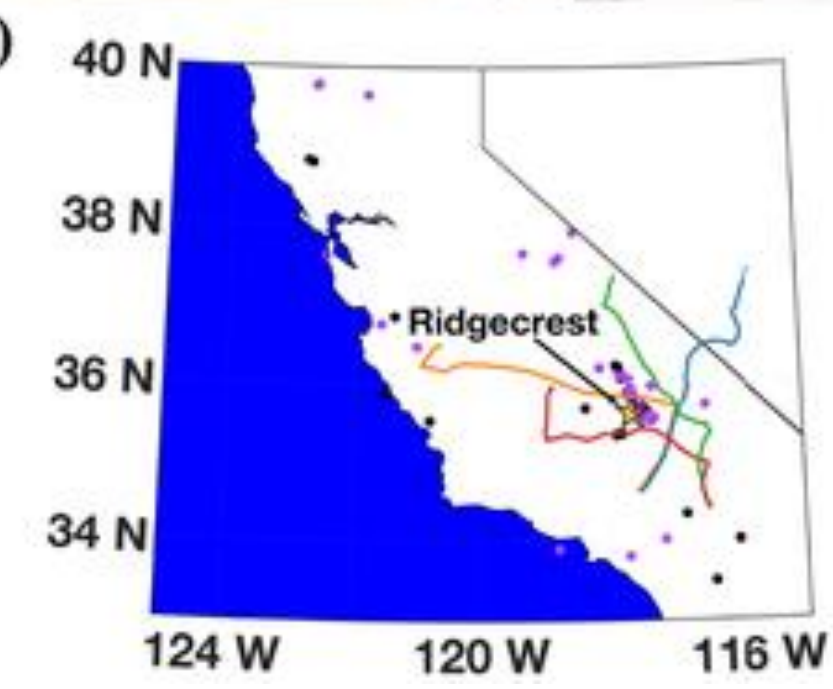

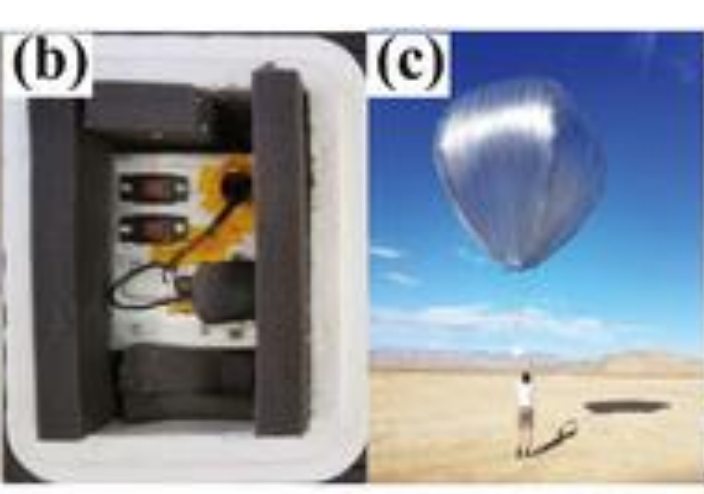

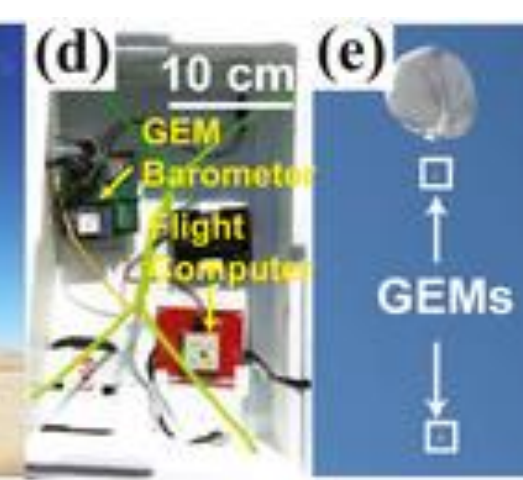

(g)

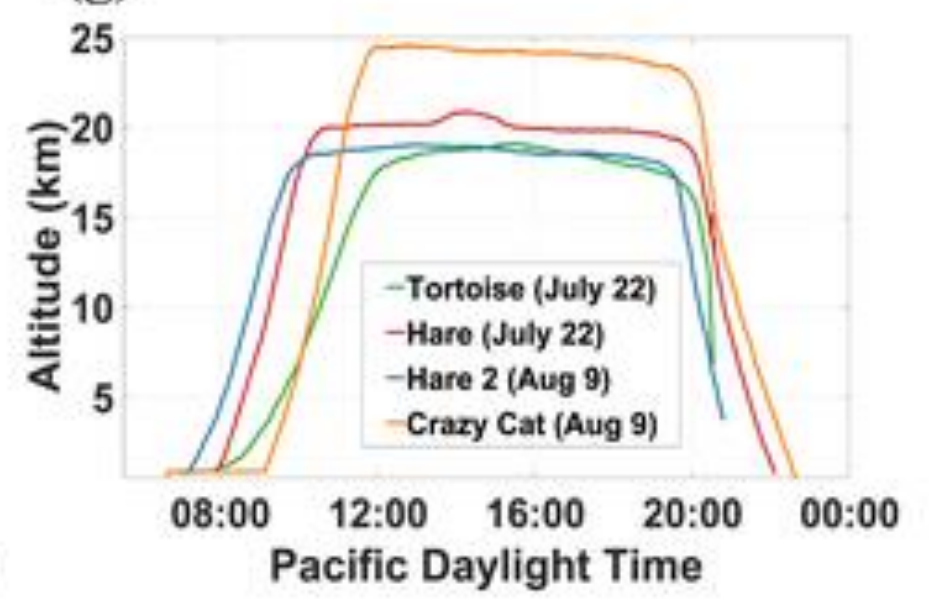

Figure: (a) Sensor package for Tortoise, Hare, and Hare 2 balloons, IMU = Inertial Measurement Unit (b) packaged sensor, (c) Launch of Hare, (d) Sensor package for the CrazyCat balloon, (e) CrazyCat with two sensor packages on a 36-m tether, (f) and (g), The trajectory and altitude profile of the balloons 


\section{Making sense of the noise}

To investigate our noisy balloon dataset, we adopt a multi-step procedure:

1

2

Seismic catalog SCEDC

Modeling epicentral infrasound ray paths

Estimation of Signal-toNoise Ratio (SNR) at balloon for each event

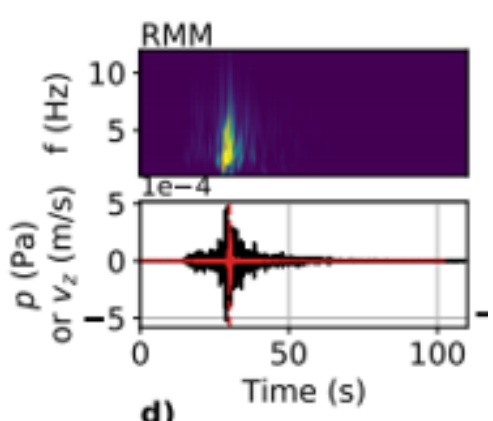

Cross-correlations with seismic data at the ground

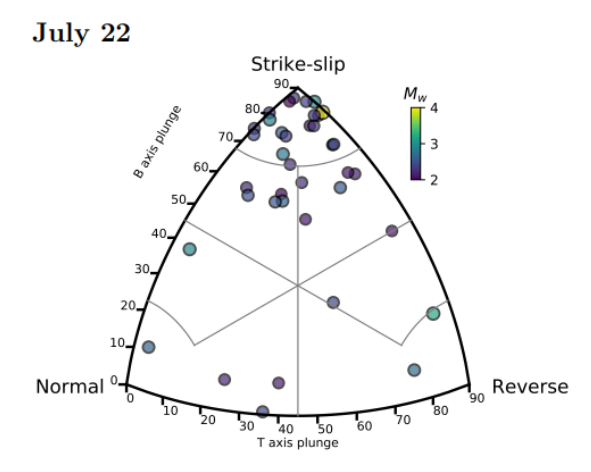

Range (NS) [km] ${ }^{250} \underbrace{}_{500} 250$ Range (EW) [km]

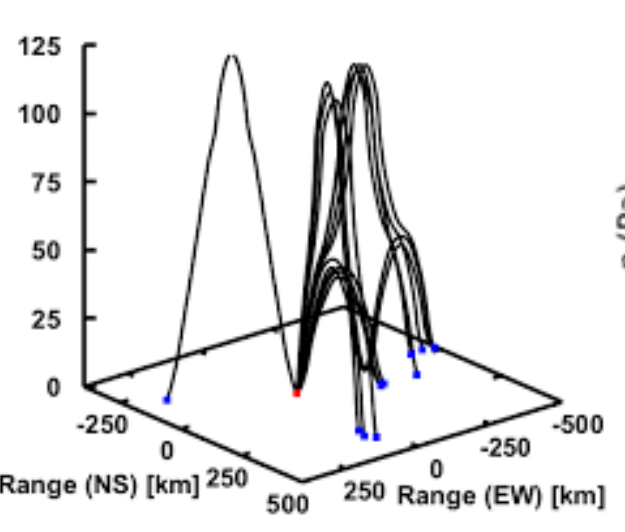

d)

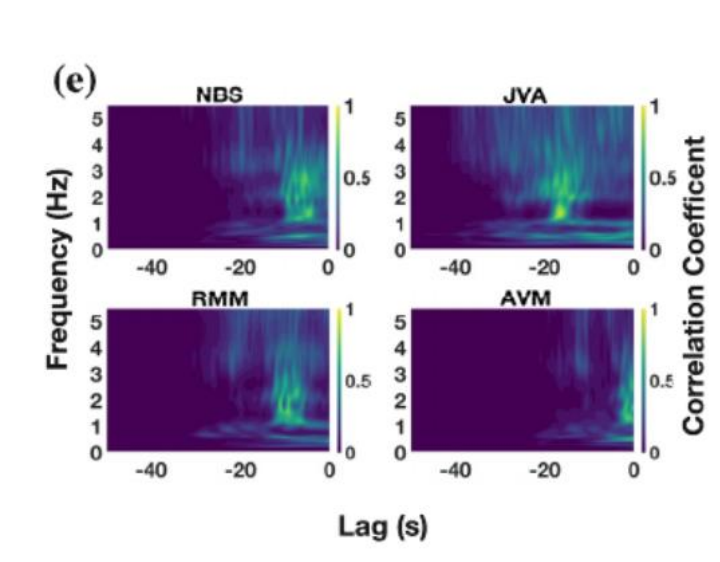

5

Shortlisting events with SNR > 1 and fullwaveform simulations

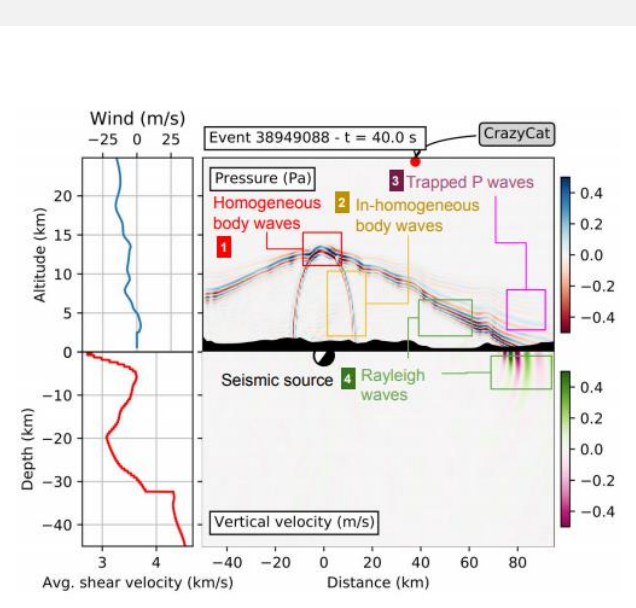




\section{July $22^{\text {nd }} 16: 26: 56$}

One of the shortlisted event on July $22^{\text {nd }}$ showed high correlation with seismic arrivals and good match with numerical simulations

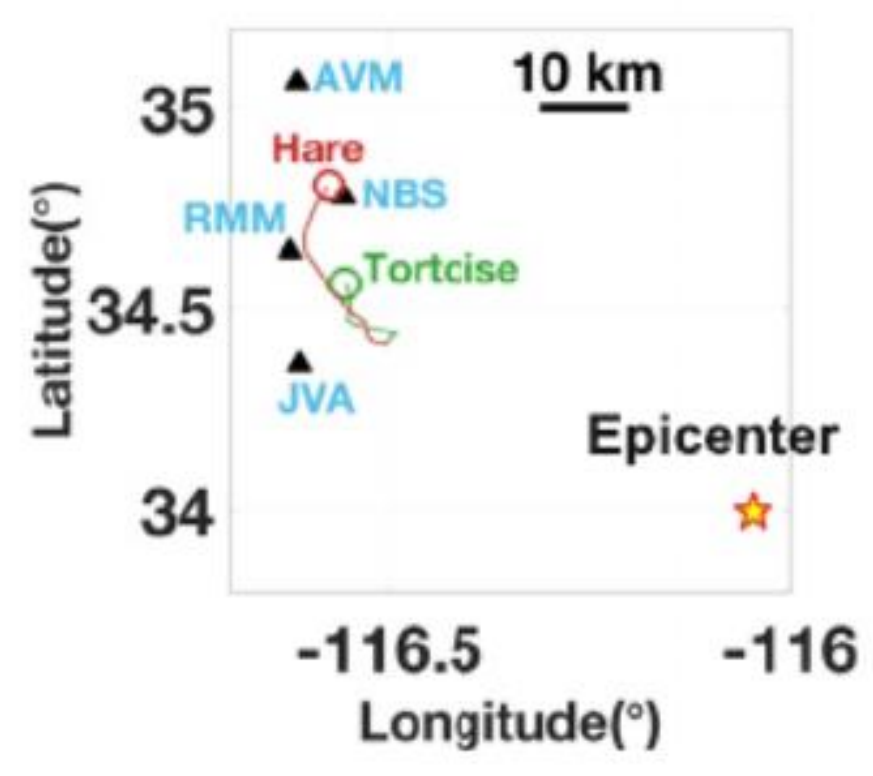

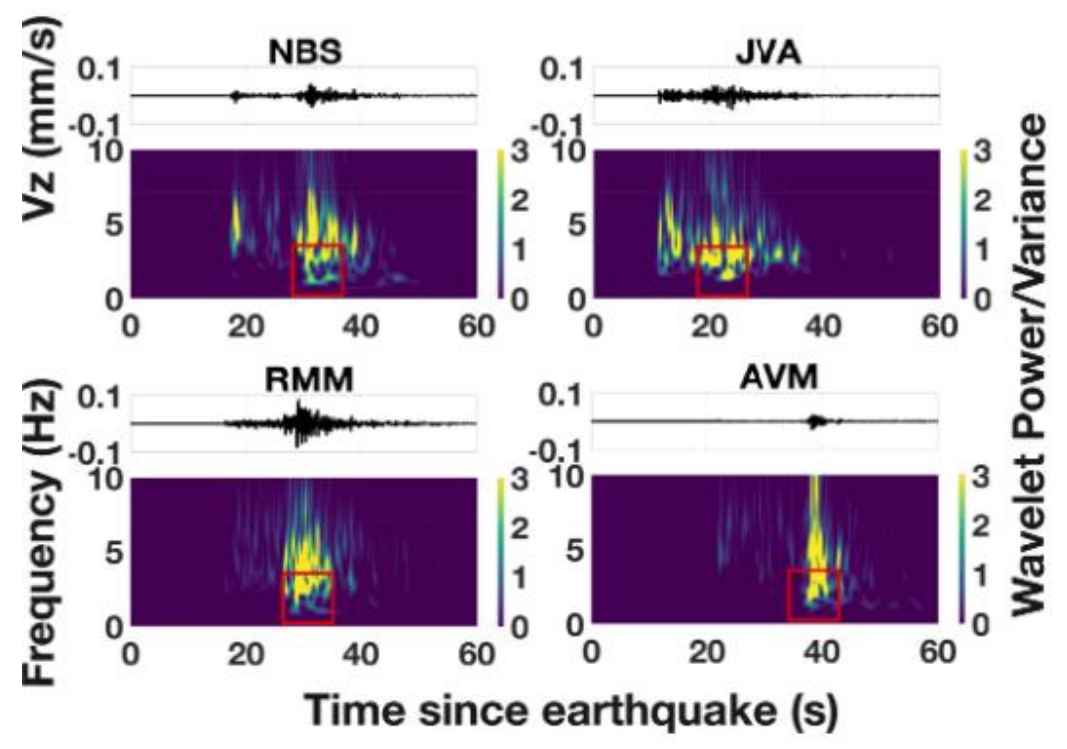

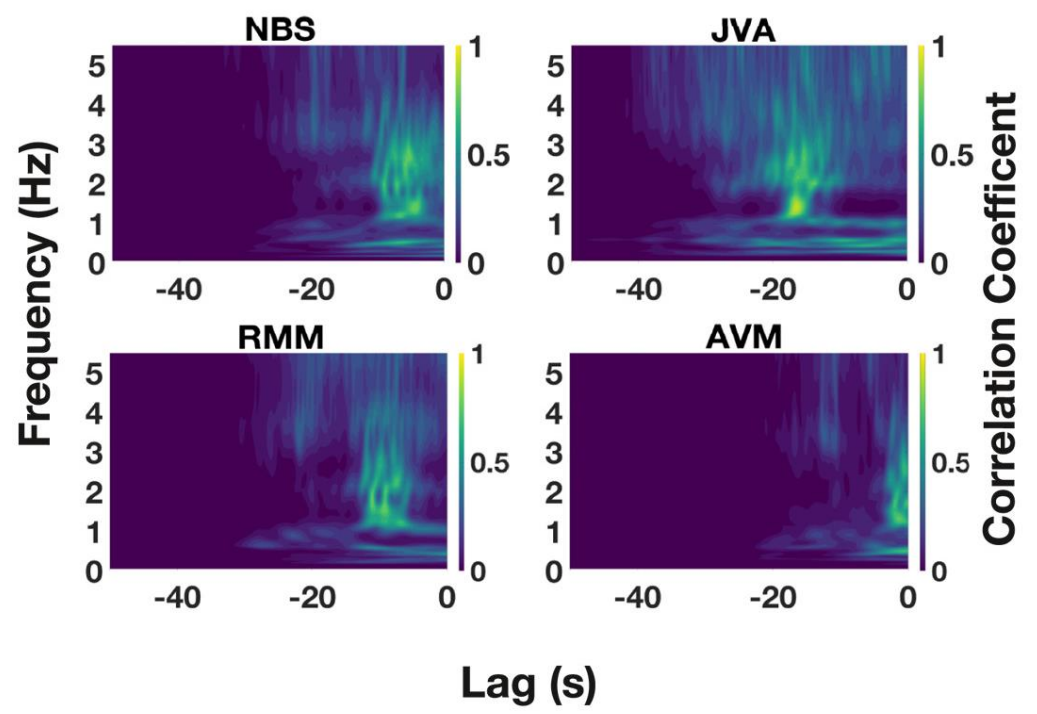




\section{Seismo-acoustic path effects}

Uncertainties in both topography or subsurface velocity models lead to significant variations in both amplitude and frequency content and their effects
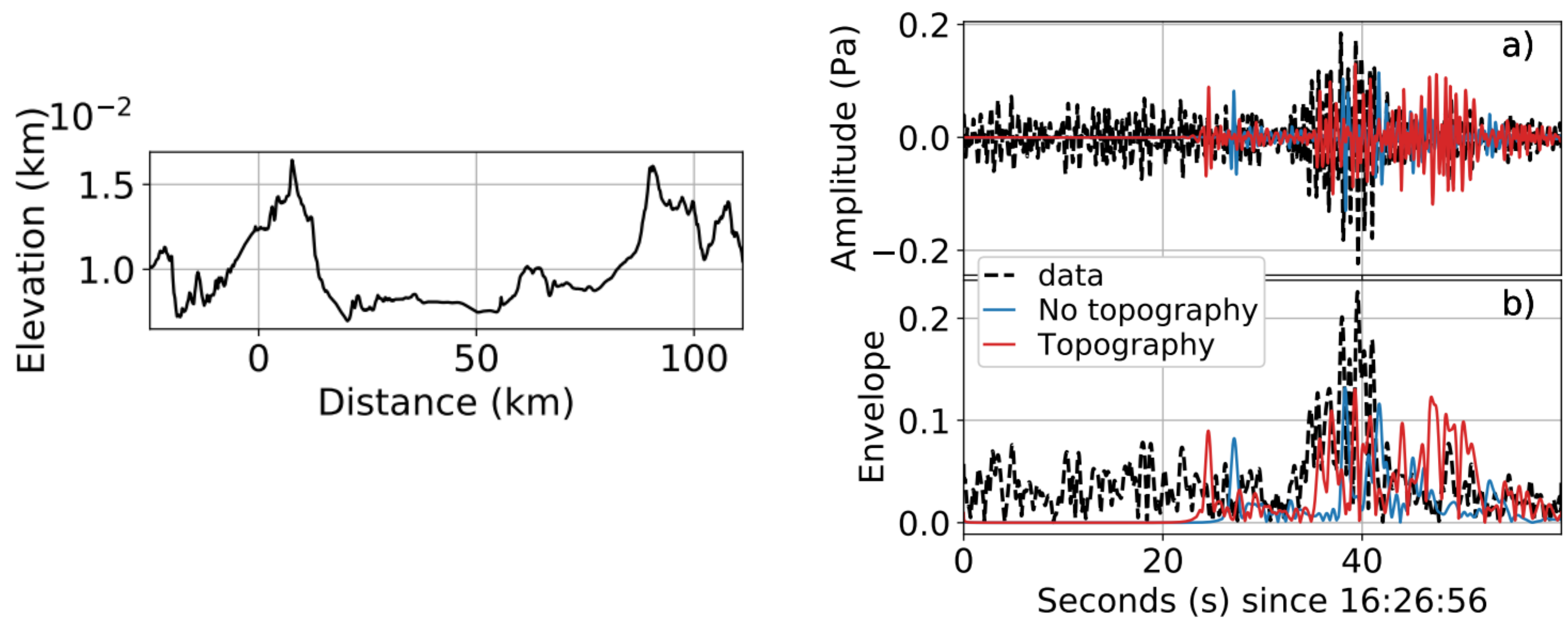


\section{What about Venus?}

Three missions have been selected in June 2021: VERITAS, DAVINCI+, and EnVision

However, none of them include geophysical probes besides a Radio Science experiment...

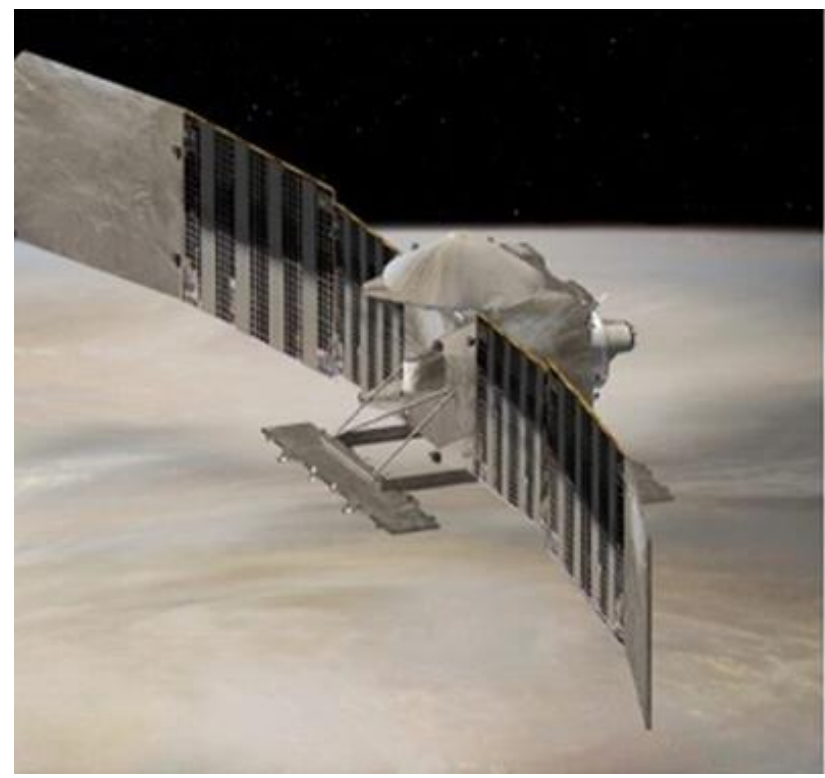

\section{VERITAS}

Surface topography \& rock composition

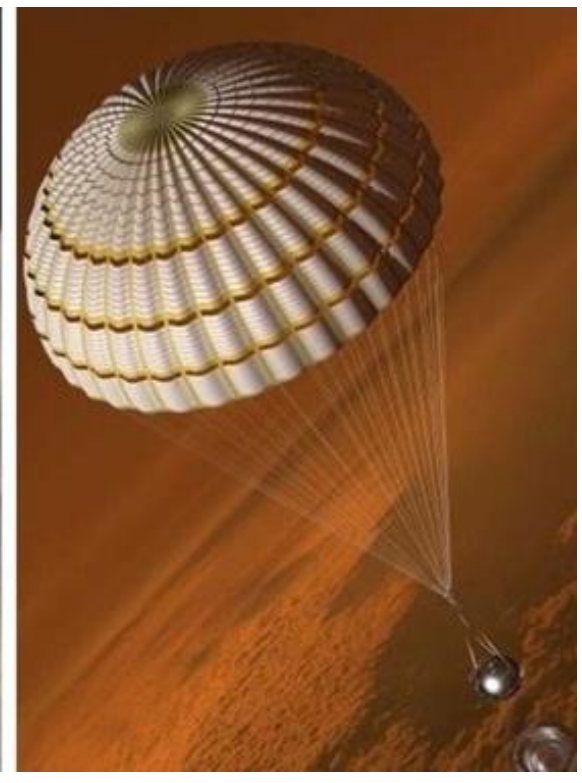

DAVINCl+

Atmospheric composition \& surface picture

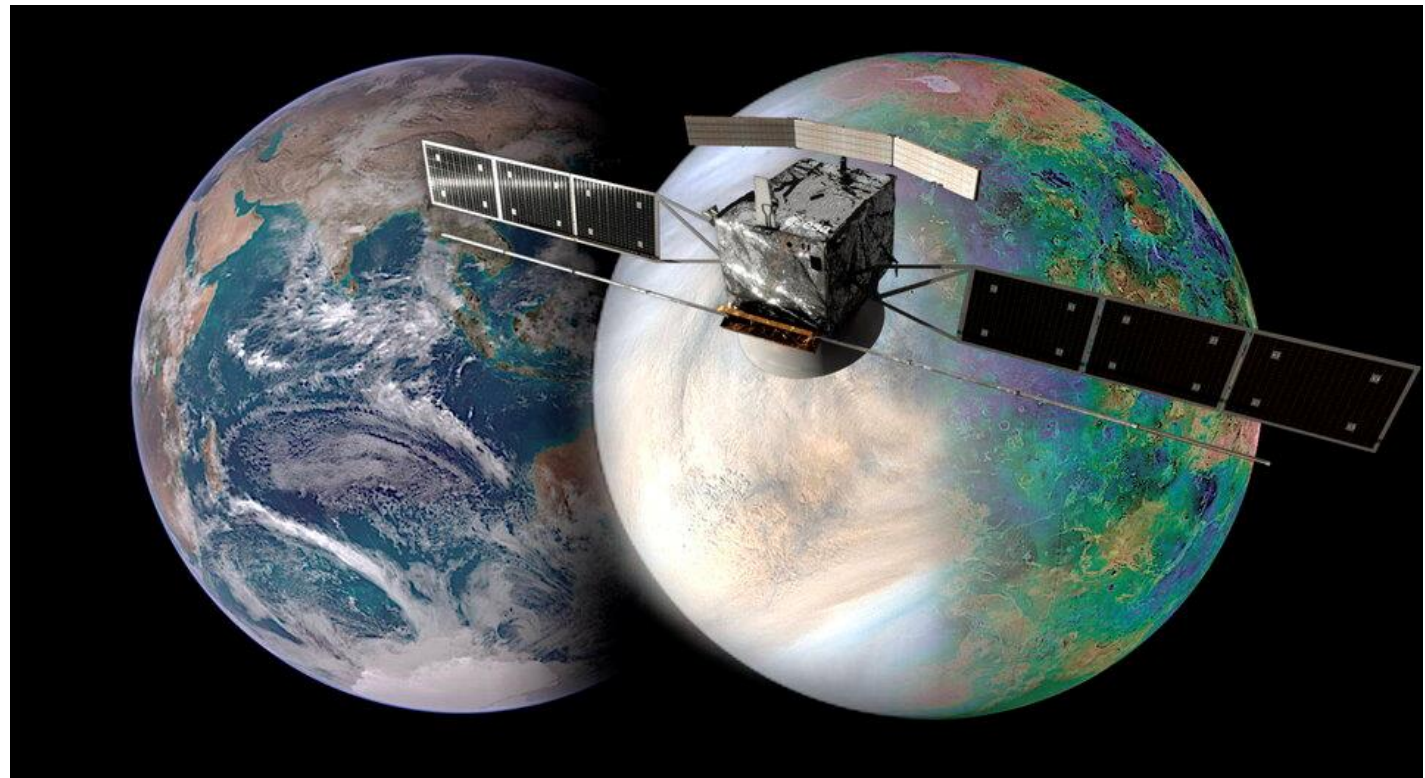

EnVision

Atmospheric composition, surface thermal signature, core size 


\section{NORSAR}

Research activities directly or indirectly participate towards a better understanding of seismo-acoustic couplings processes and building efficient inversion methods

Studying infrasound propagation through DAS

Ismael Vera Rodriguez, Andreas Wuestefeld

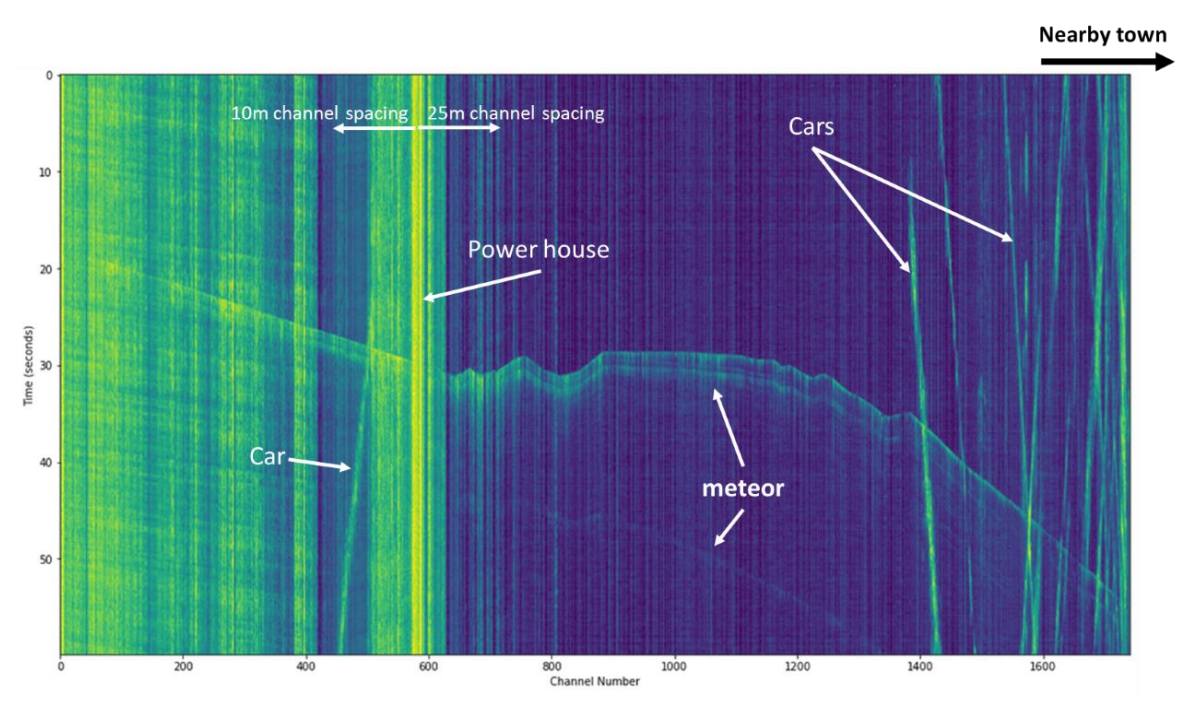

Machine learning aided acoustic modeling

Peter Naesholm, Antoine Turquet

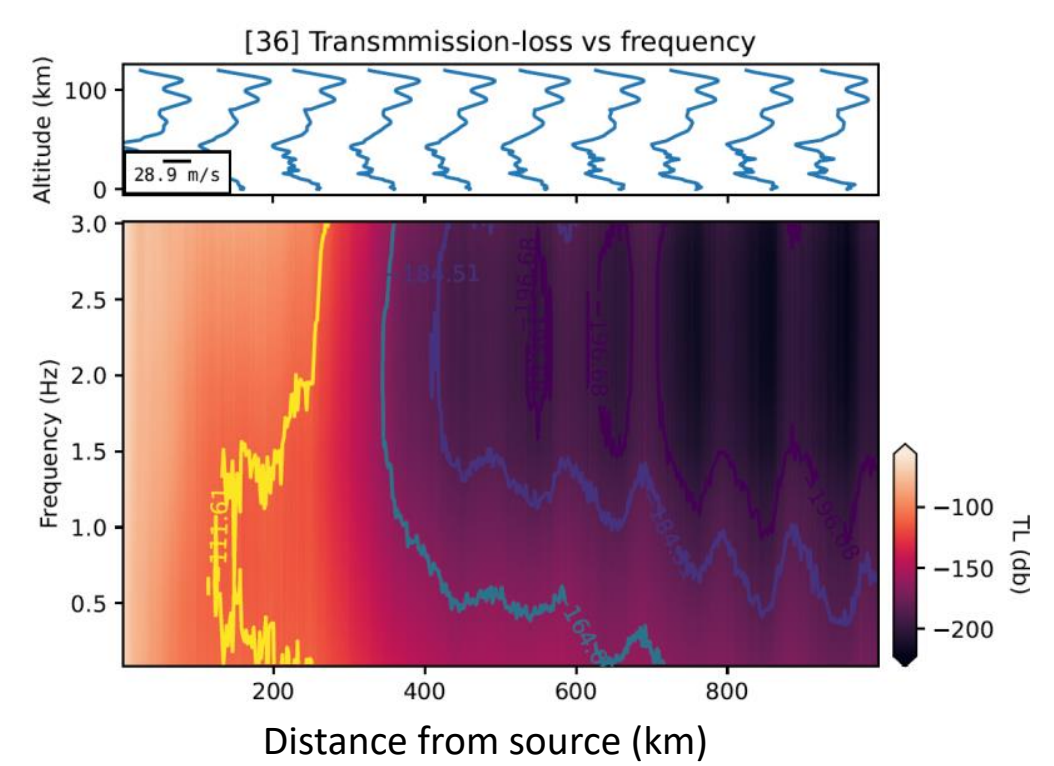

Collaborations with Swedish (miniBOOSTER) and US (PSTAR) balloon projects

Peter Naesholm, Tormod Kvaerna

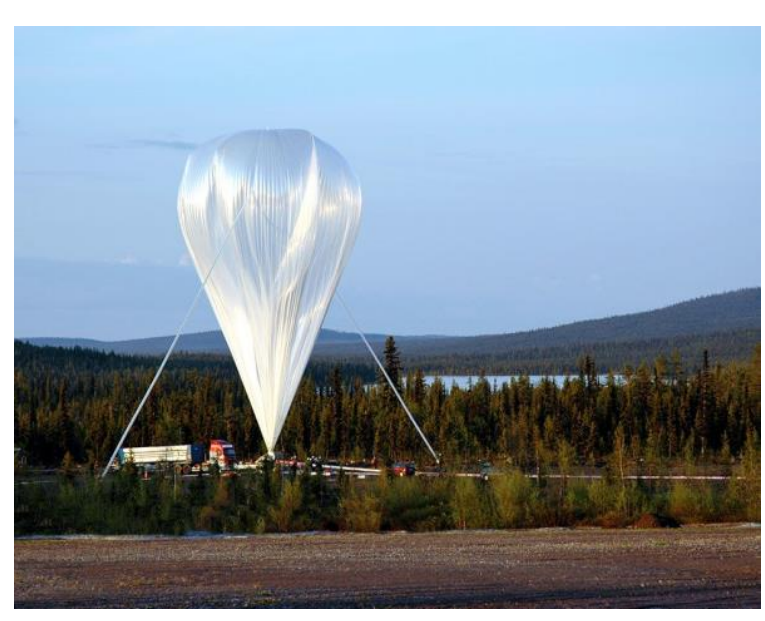




\section{Recent seismo-acoustic records}

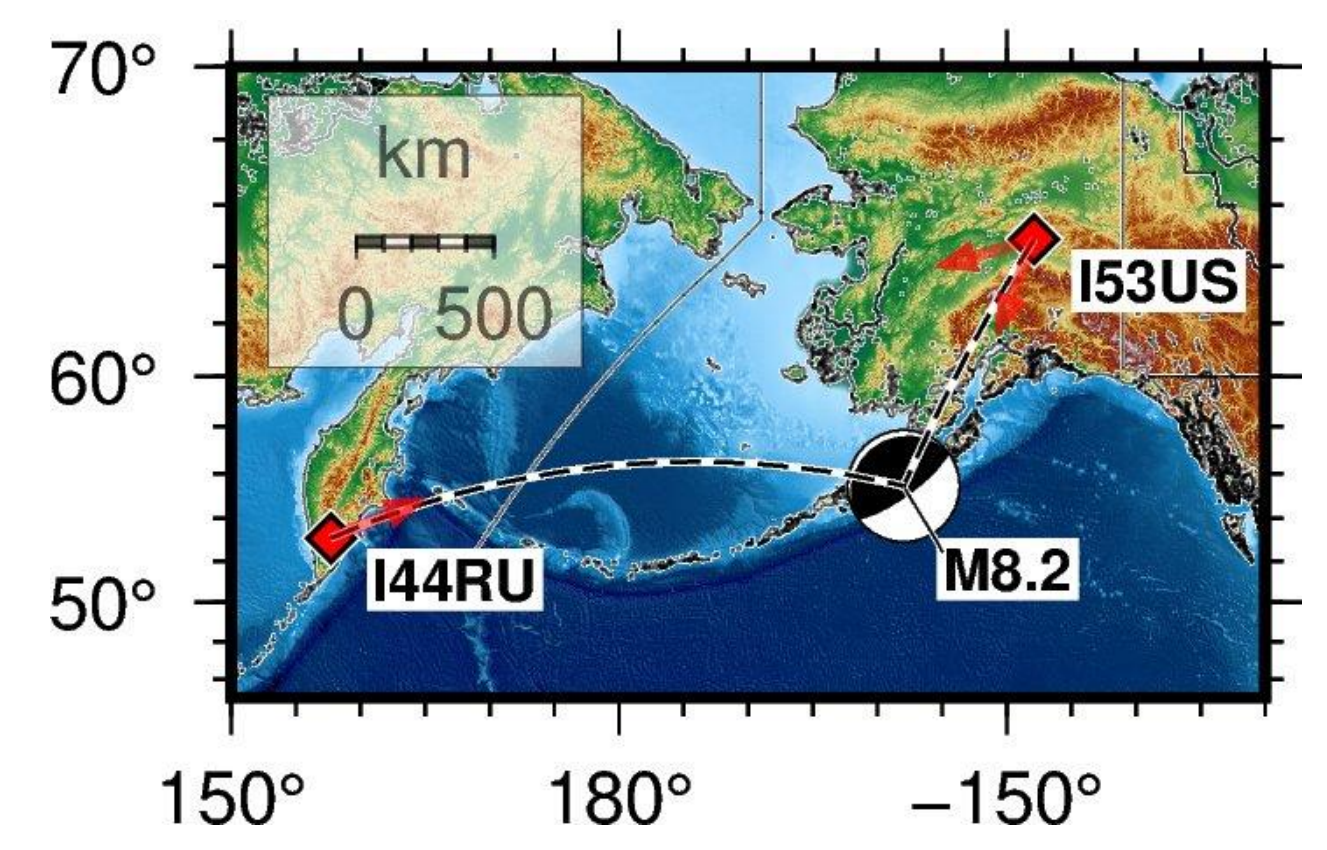

Figures: Infrasound records after the Mw 8.2 Alaska earthquake on July 29 th
Time Fisher | wlen: $25.00 \mathrm{~s}$ | overlap: $90 \%$ Array: I44RU | 4 elements | freq: $0.40 \rightarrow 4.00 \mathrm{~Hz}$ Array: 144RU 4 elements | freq: 0.40 --> $4.00 \mathrm{~Hz}$ Event mag: 8.2 range: $2849 \mathrm{~km}$ | back-azimuth: 67 Event origin time: 2021-07-29T06:15:48.034000Z UTC
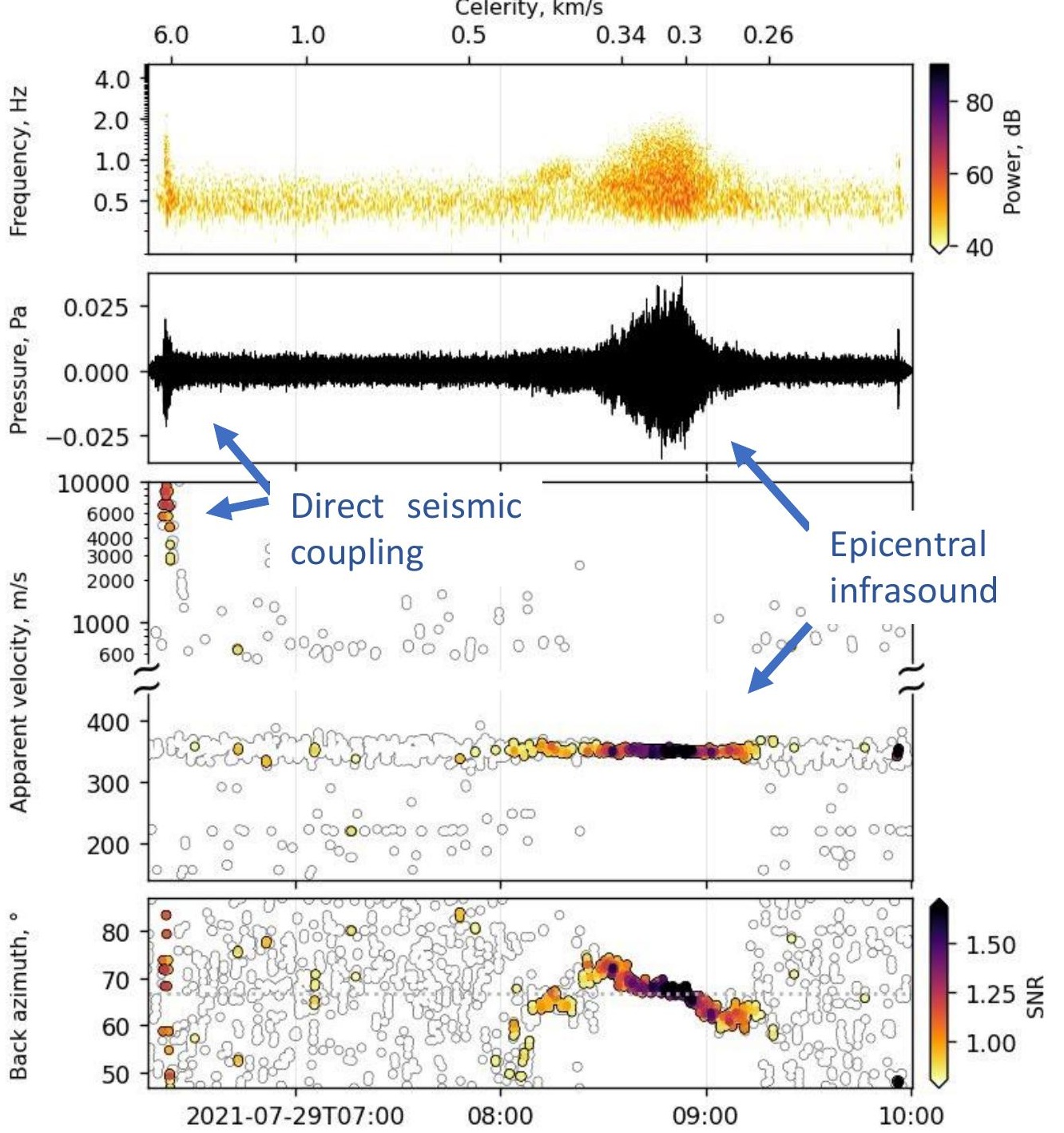


\section{Balloon deployment}

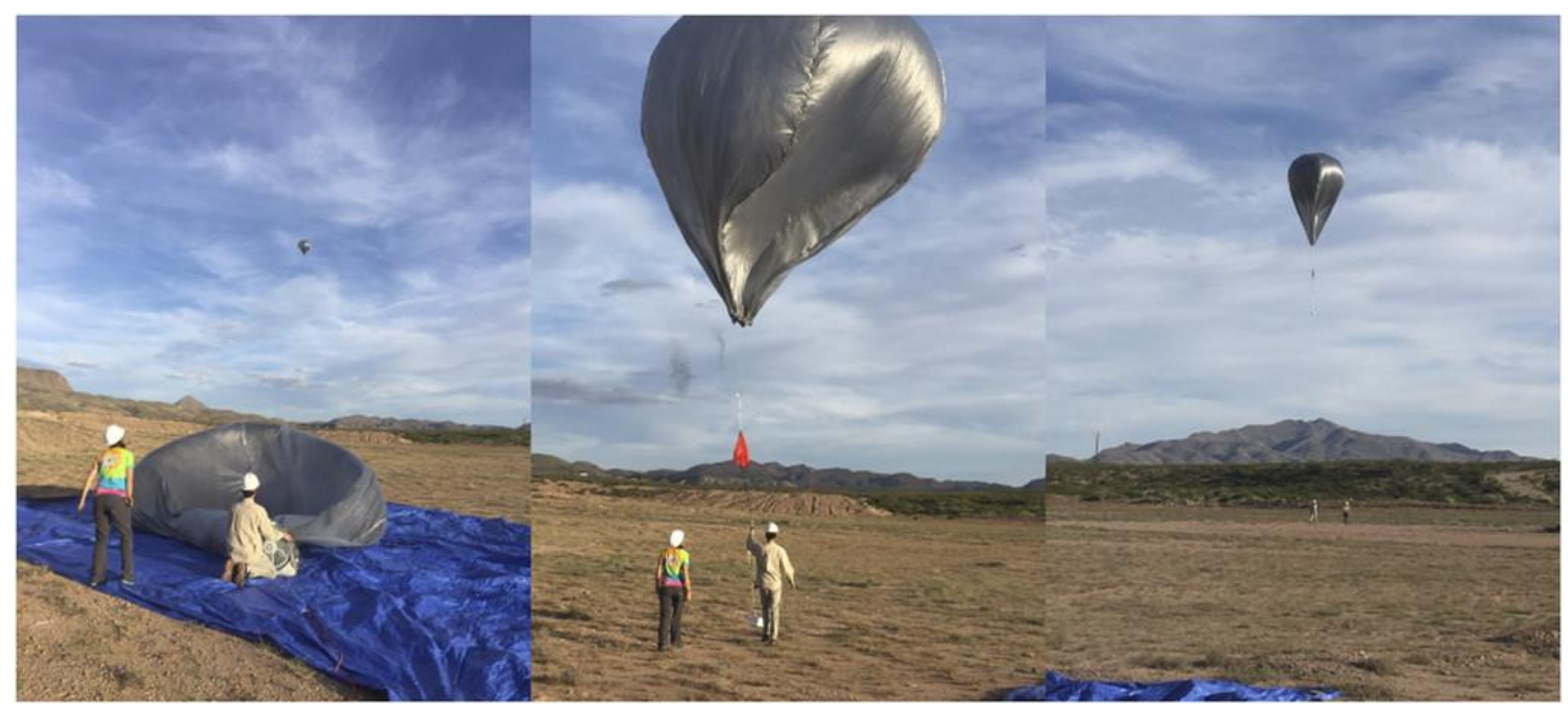

Figures: (left) Inflating a $6 \mathrm{~m}$ heliotrope with a box fan, (center) walking the inflated envelope across an open area until it gains sufficient lift to pick up the payload, and (right) a successful launch. (Bowman, 2020) 


\section{Balloon landing}

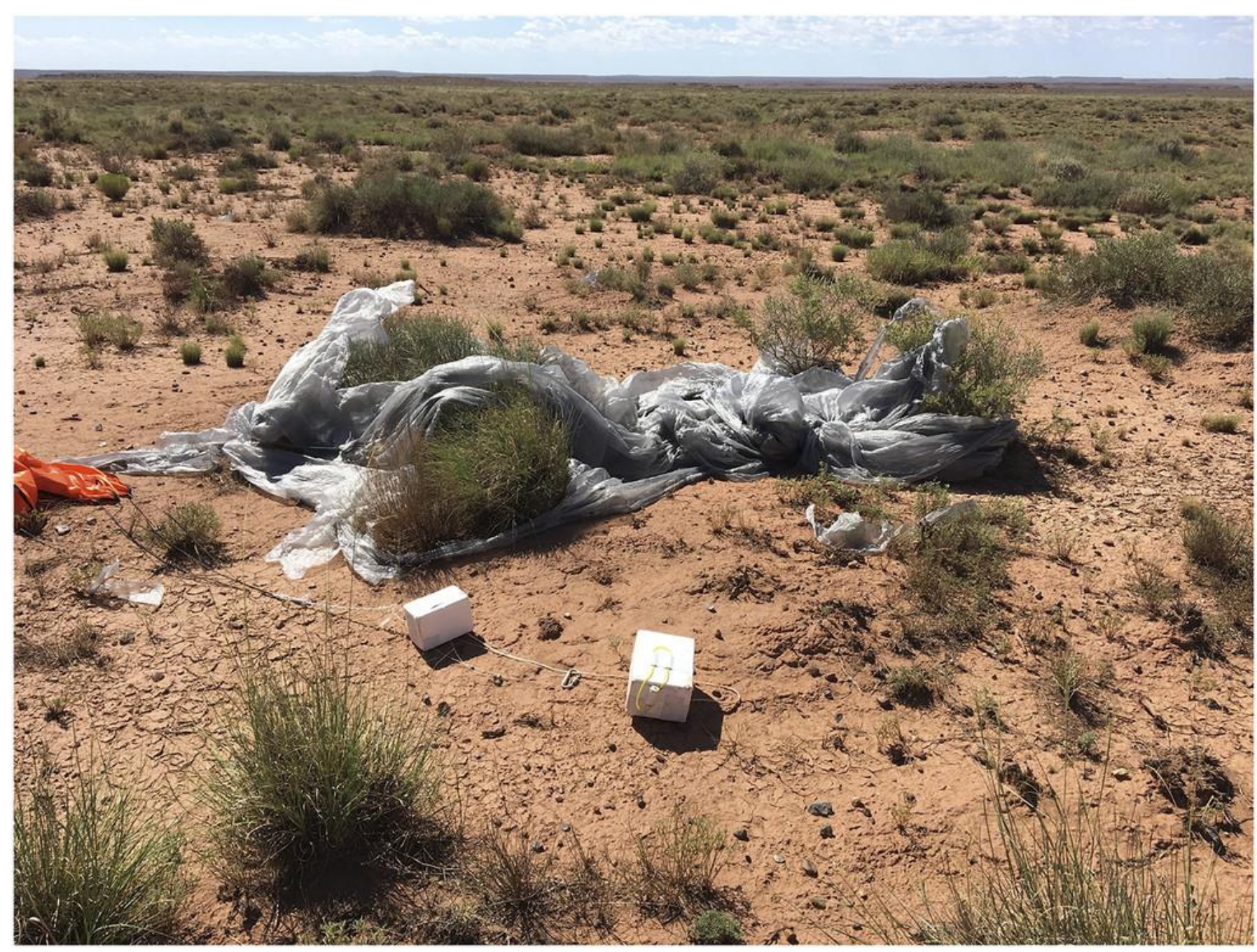

Figures: A $6 \mathrm{~m}$ heliotrope balloon after landing in the Arizona desert.. (Bowman, 2020) 


\section{Predicted vs true trajectories}

Figures: Predicted trajectories (dots) and actual trajectories (lines) for a heliotrope campaign on 22 Jul 2019. (Bowman, 2020)

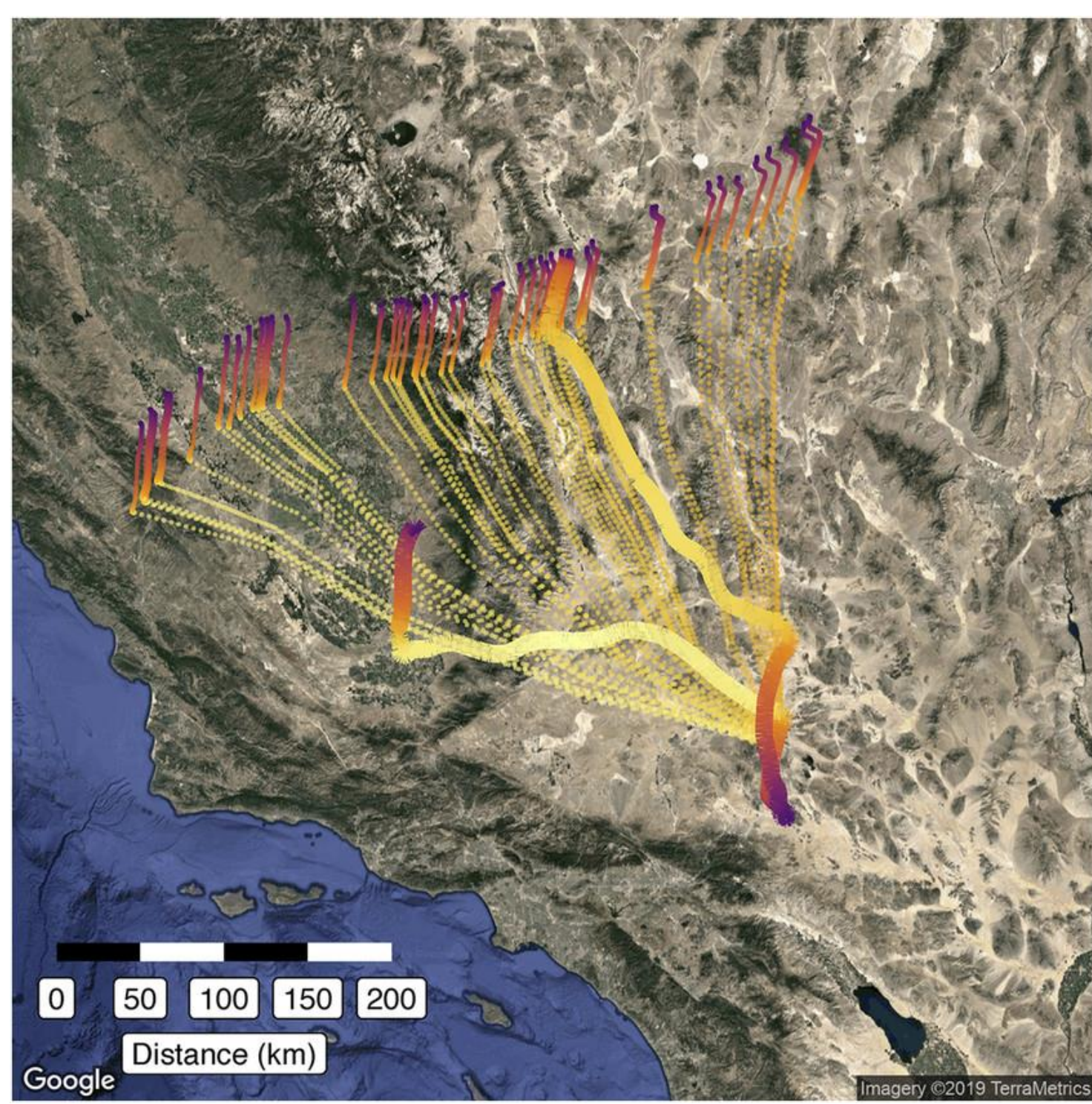

Elevation (km)

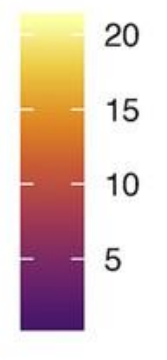




\section{Observation of small magnitude earthquakes}
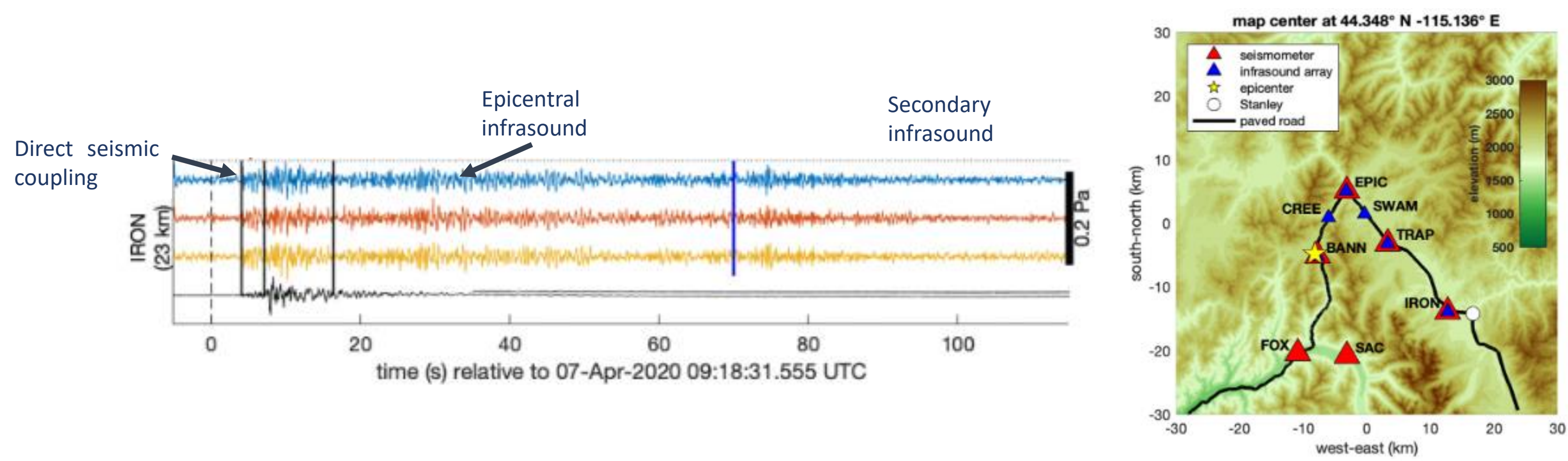


\section{Ray tracing predictions for event E2c}

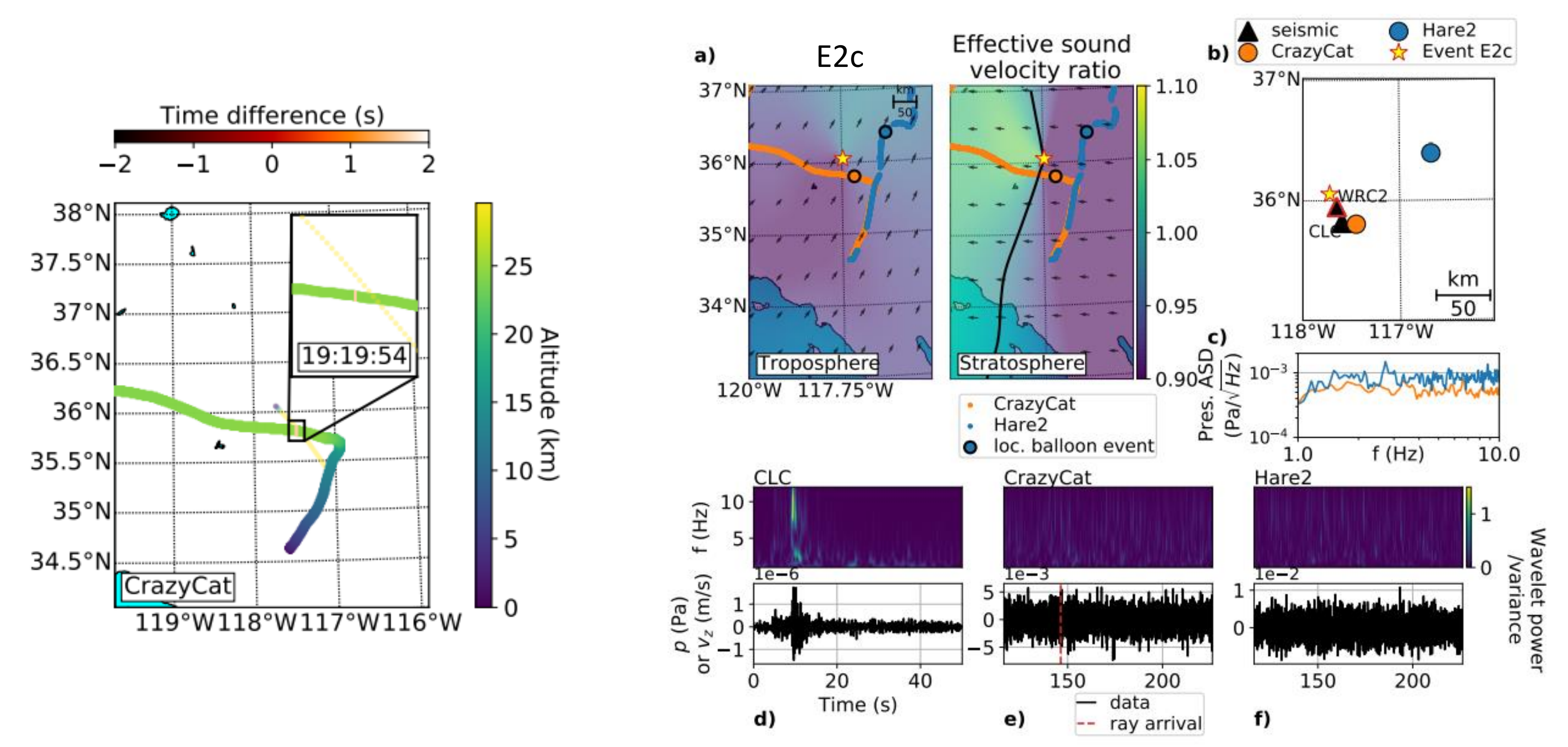




\section{RW-atmos predictions for event $\mathrm{R} 1 \mathrm{~b}$}
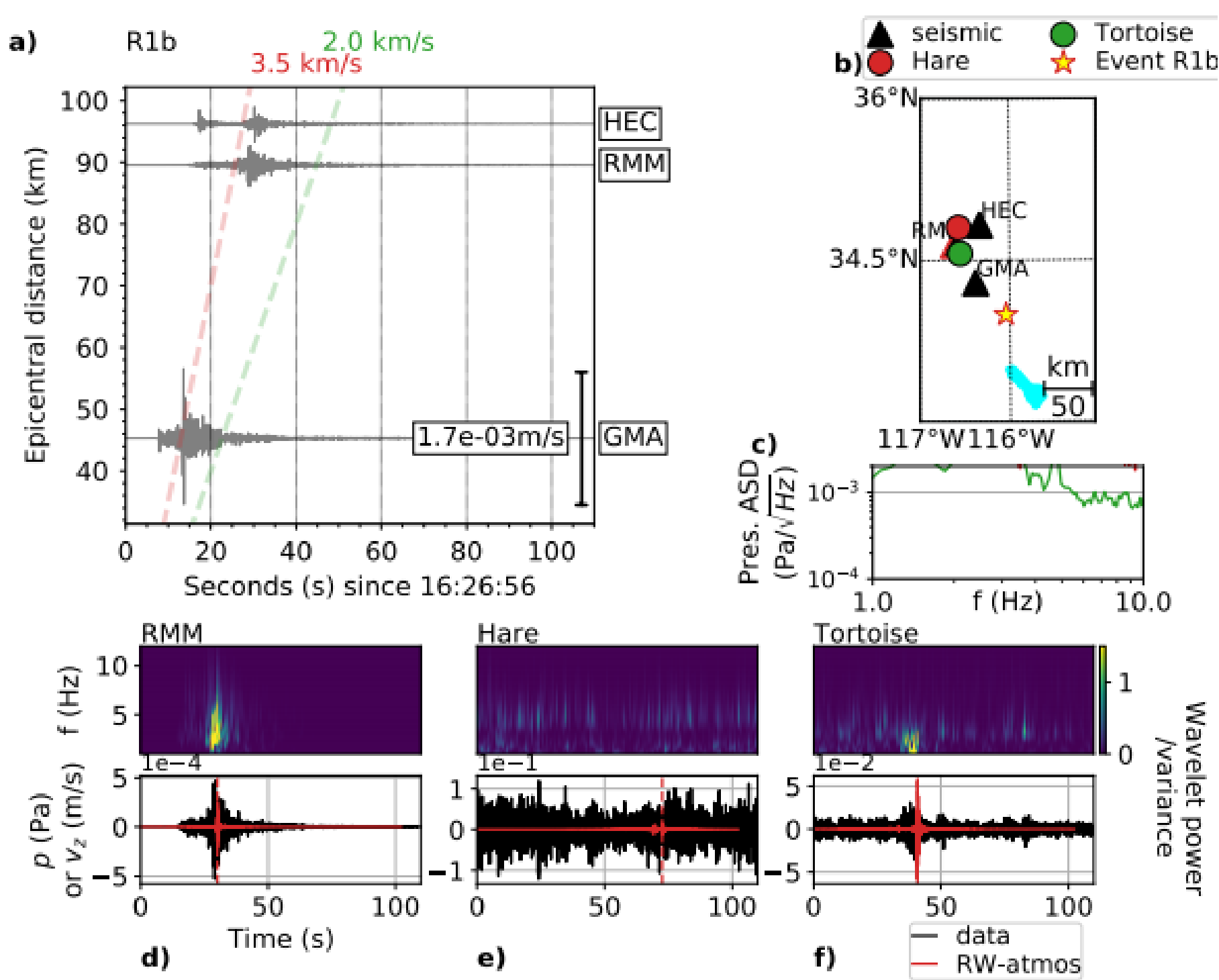


\section{Estimating SNRs}

(a)

Hare $\quad$ Tortoise CrazyCat $\square$ Hare2
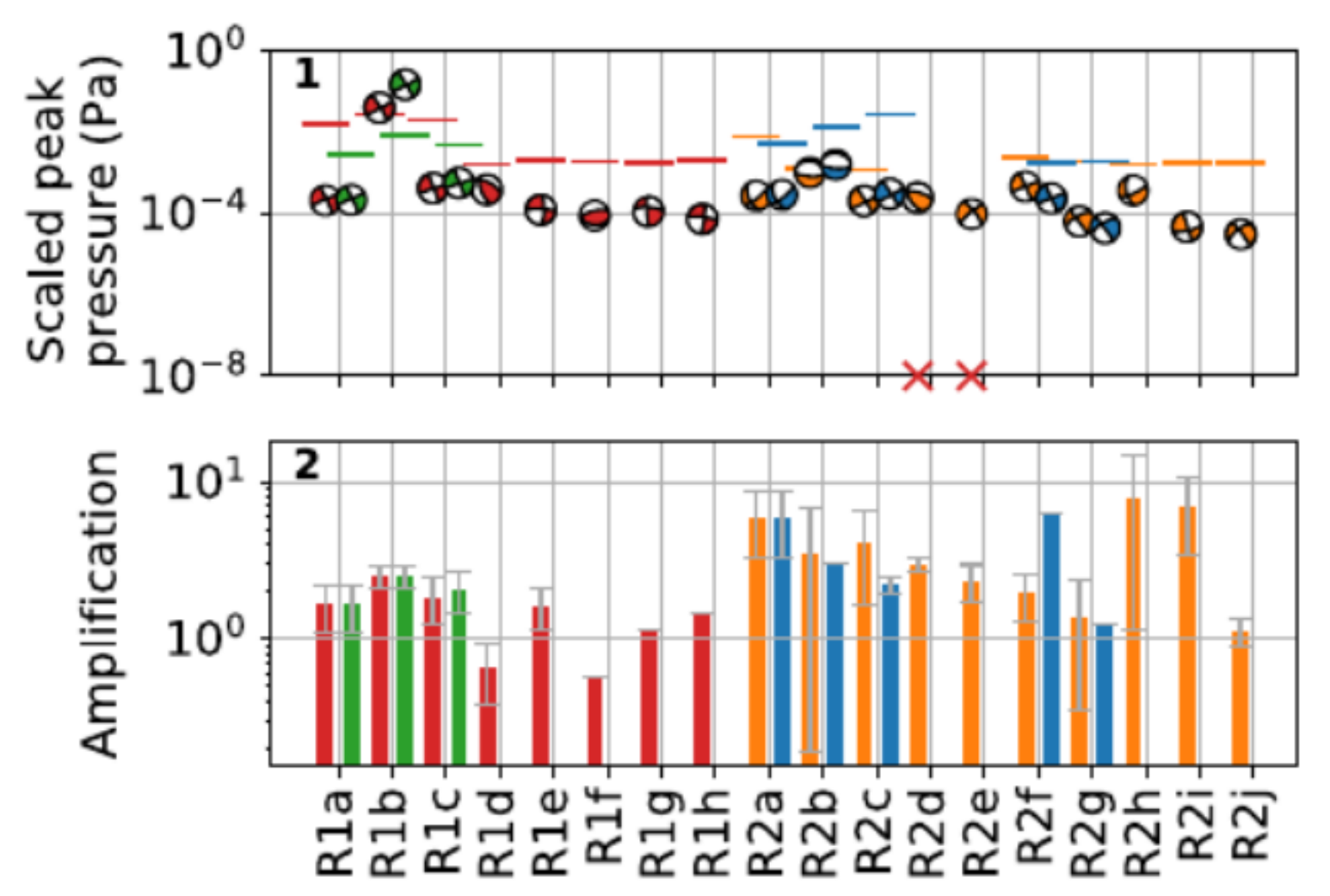

(b)

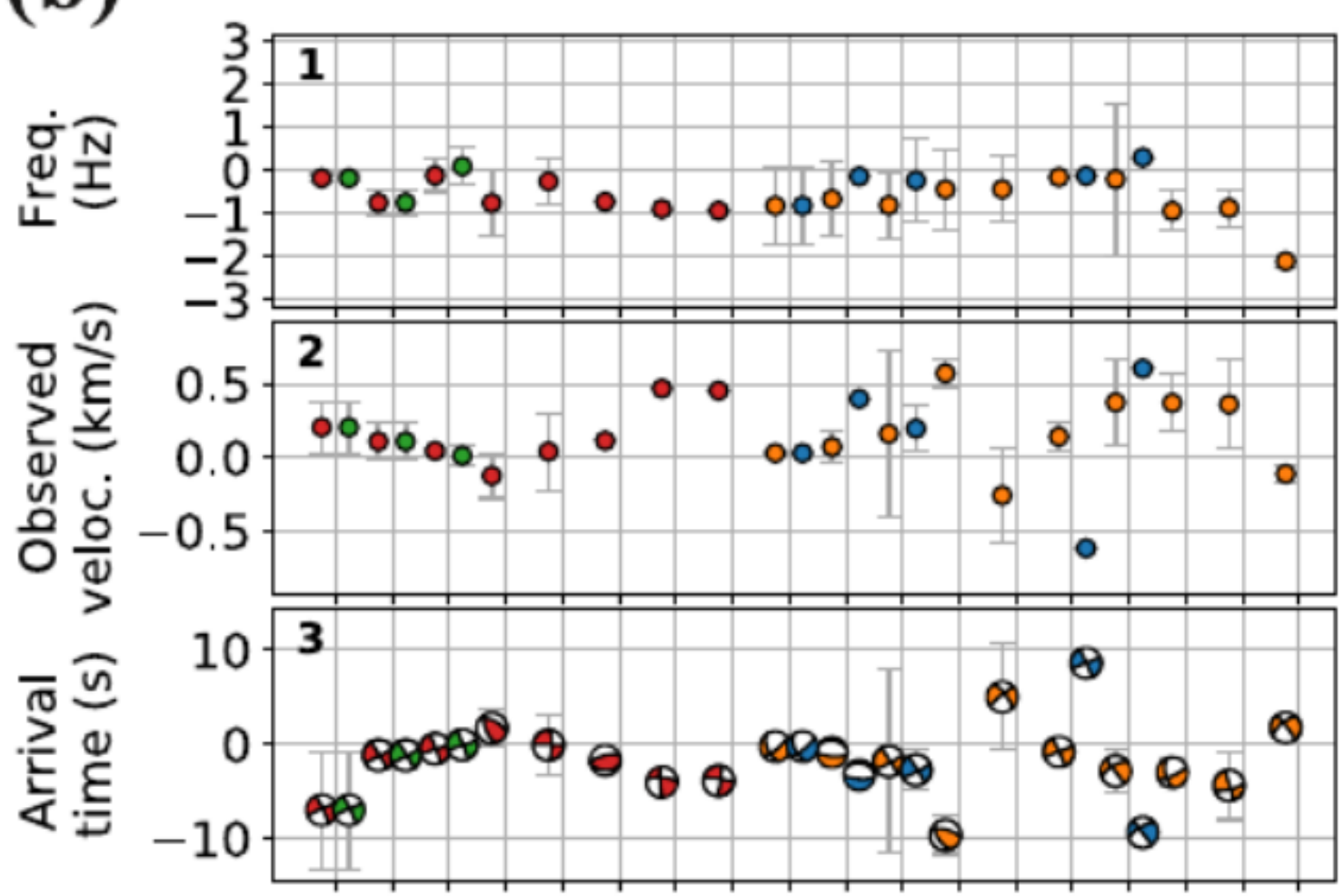

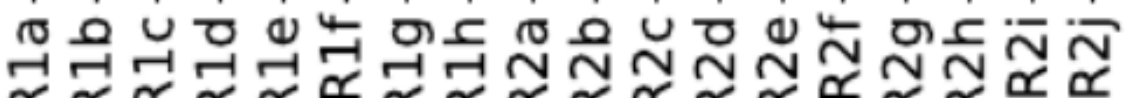

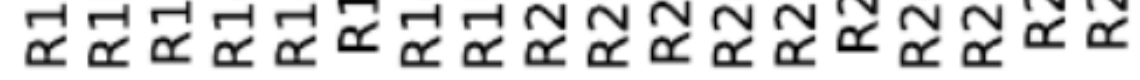




\section{Frequency Time Analysis (FTAN)}

FTAN analysis corresponds to the filtering of a signal with narrowband Gaussian filters to extract the group velocity at given frequencies

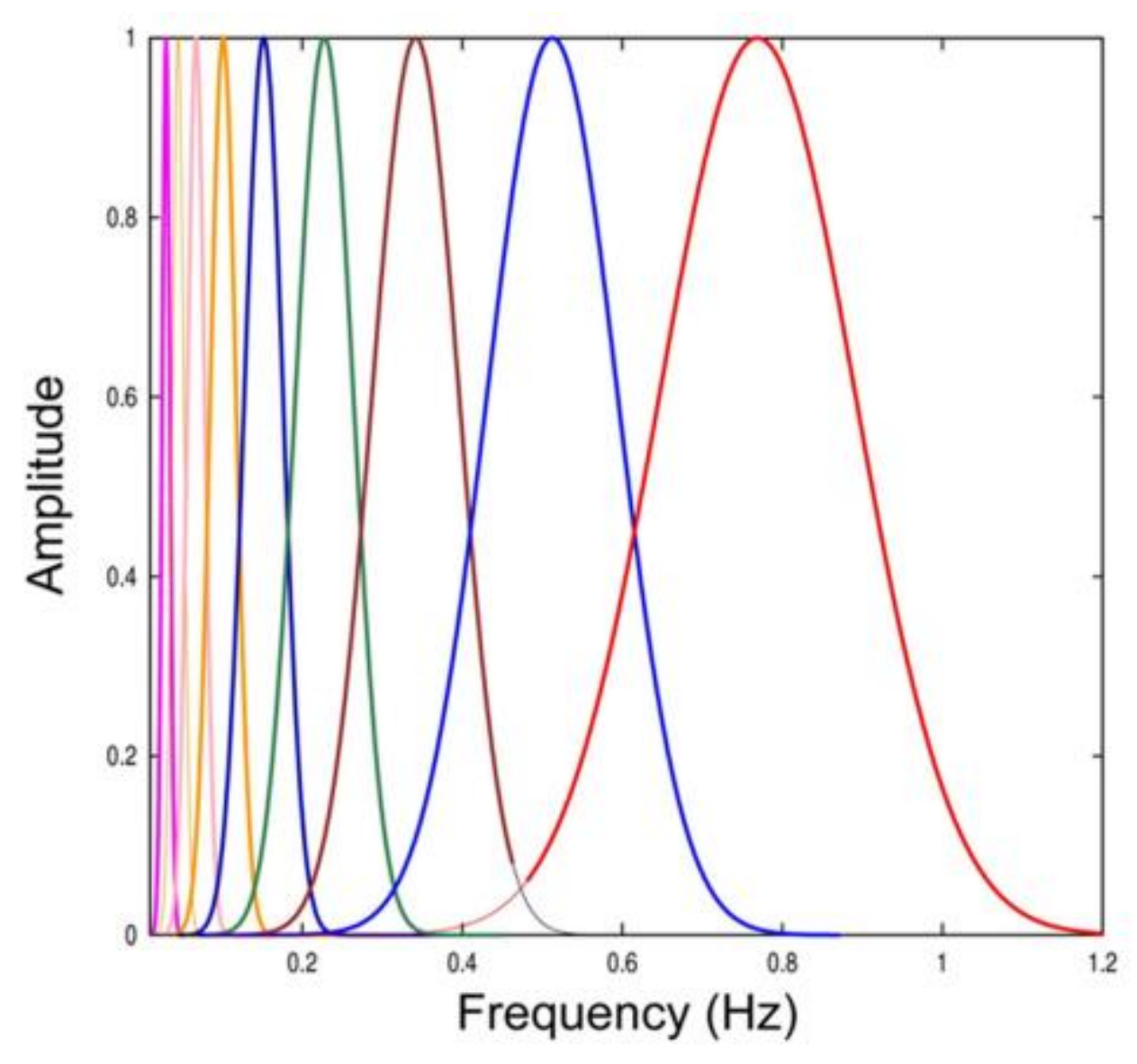

Figure: Typical FTAN Gaussian filters
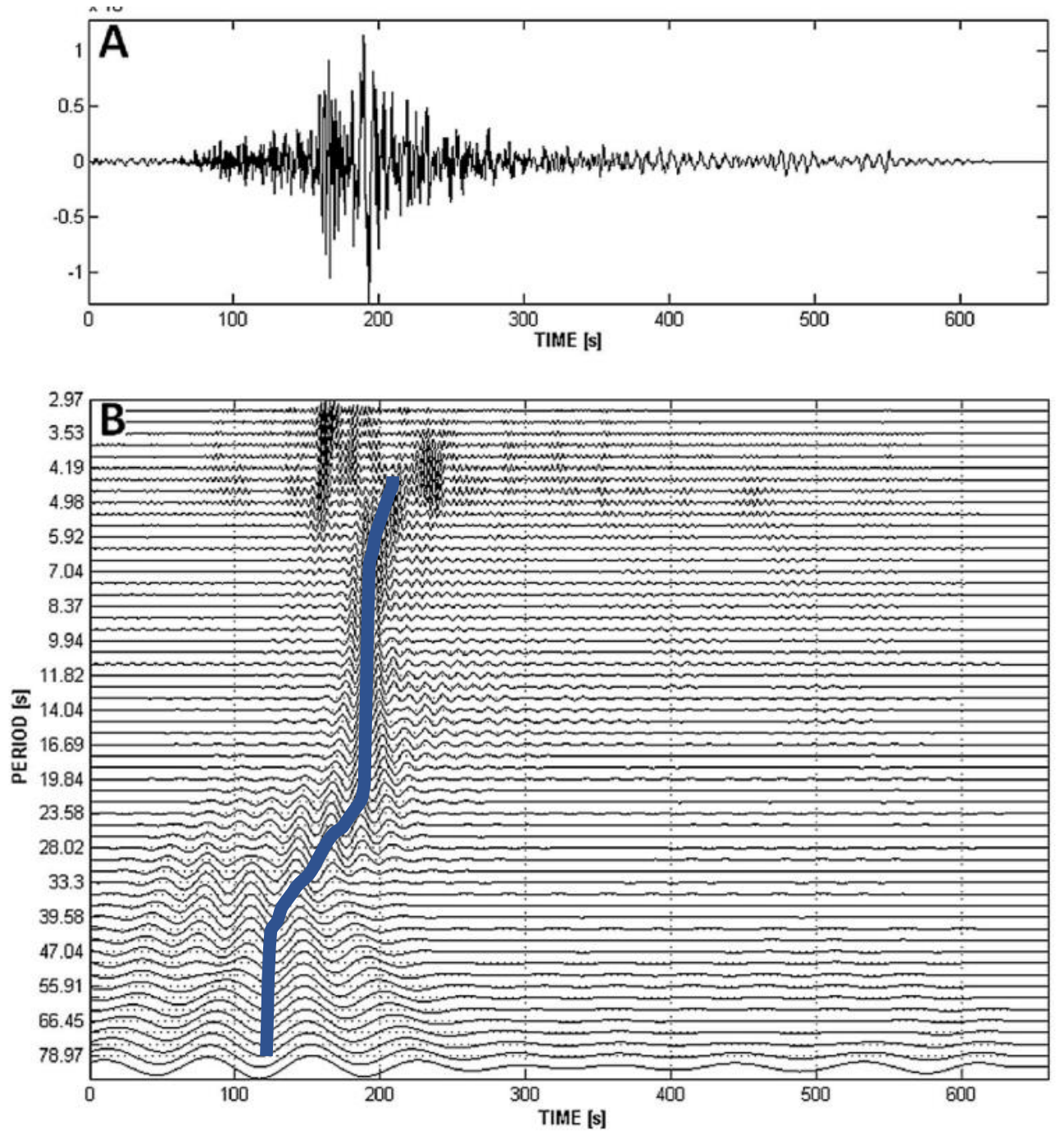

Figure: Example of FTAN results of a seismic signal (Granados, 2019) 


\section{FTAN of simulated signals}
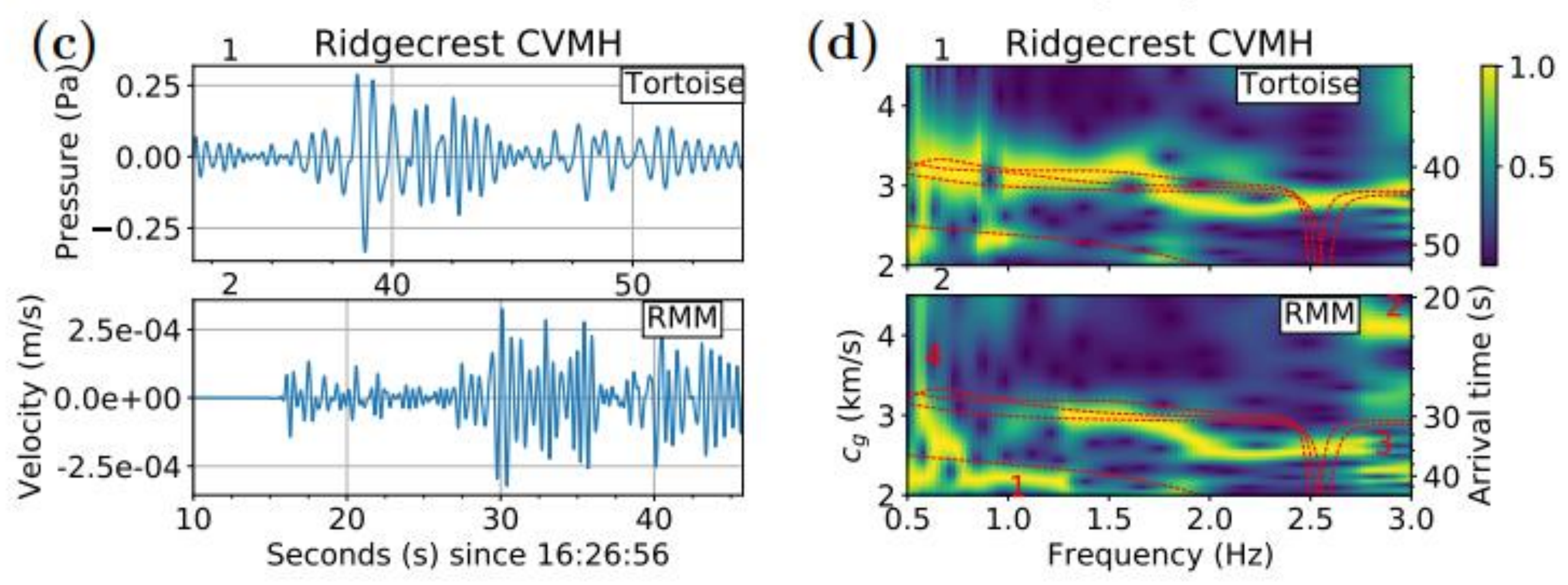


\section{Background velocity models}

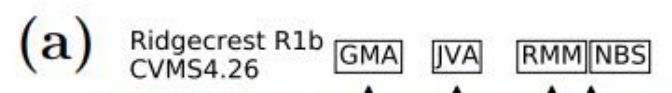

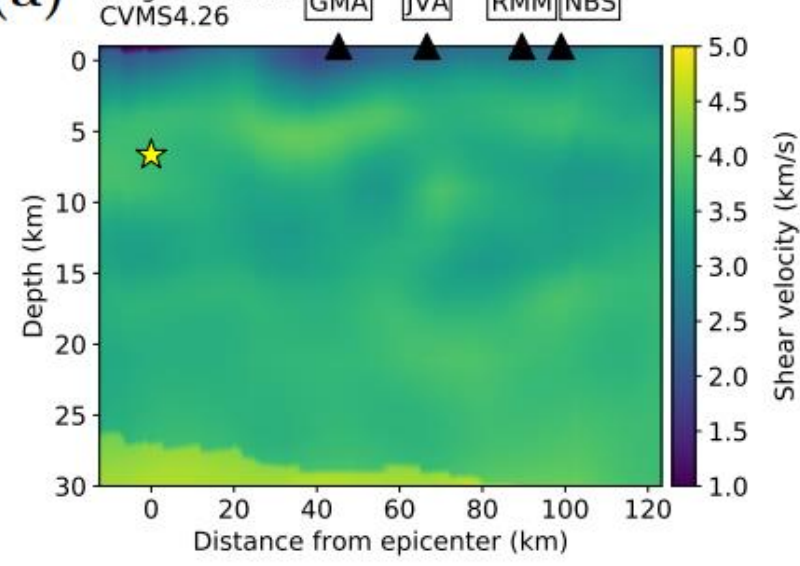

(c) Los Angeles basin [GMA [VA RMM] [NBS

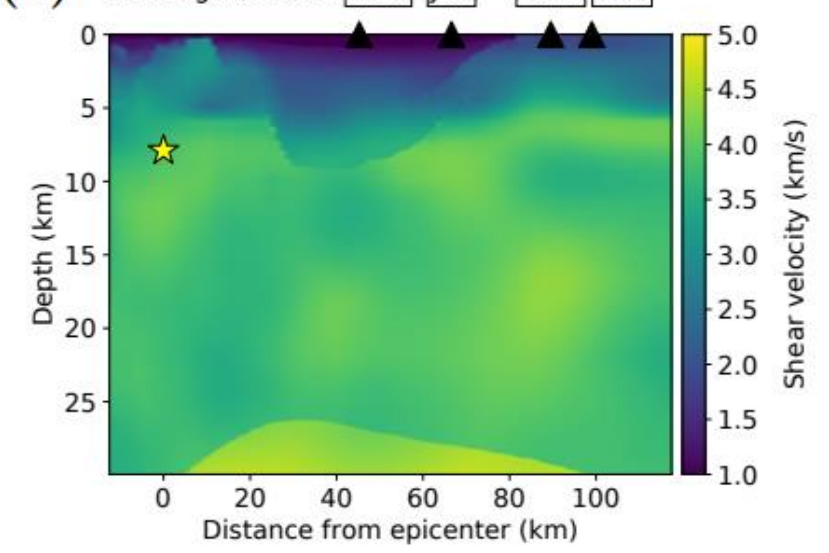

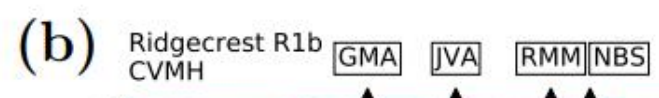

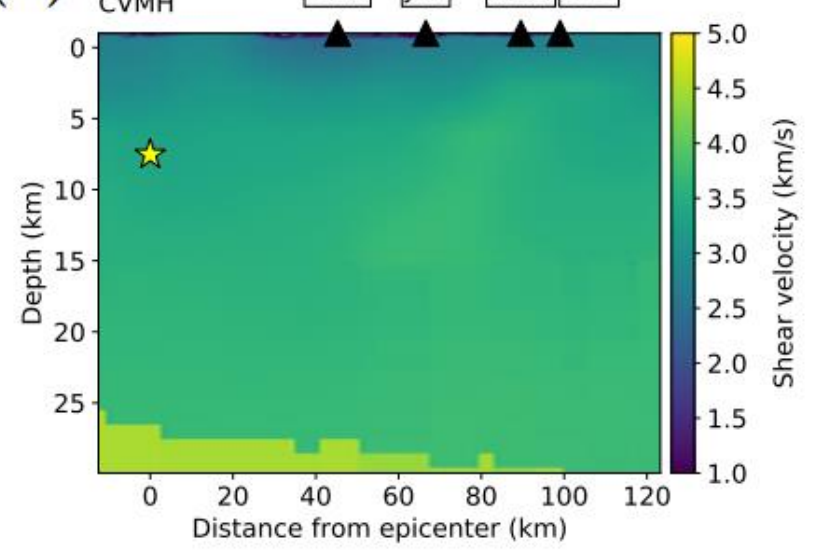

(d)

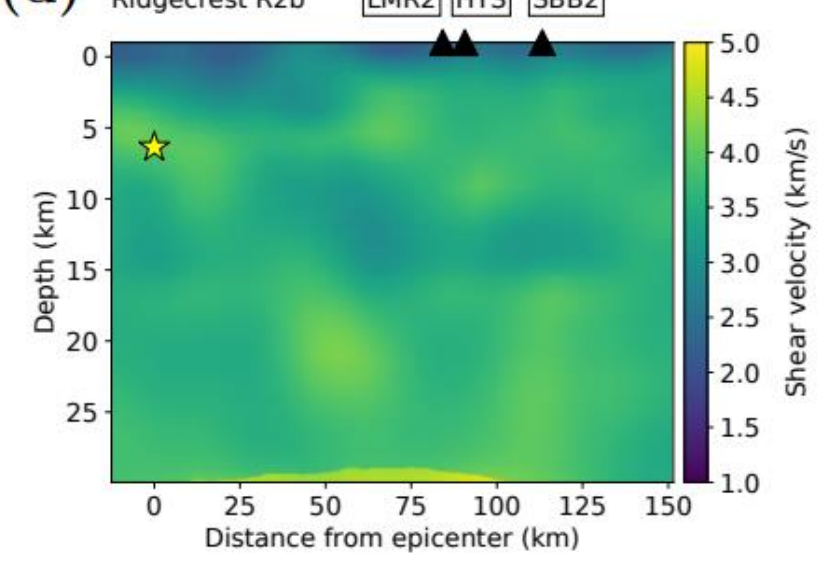

Figure S52: Shear velocity model versus depth used in SPECFEM simulations for event R1b in the Ridgecrest region extracted from the CVMS4.26 dataset (panel a), in the Ridgecrest region extracted from the CVMH dataset (panel b), event R1b in the Los-Angeles basin extracted from the CVMS4.26 dataset (panel c) and event R2b in the Ridgecrest region extracted from the CVMS4.26 dataset (panel d). The star indicates the epicentral location. Black triangle indicate the regional seismic station epicentral distance. 


\section{Venus Interior and Seismicity (courtesy of JPL)}

- The surface of the planet has its own distinctive tectonic and volcanic character

- Estimates of Venus seismicity vary over a large range - no direct or indirect measurements available

- There is a lot of circumstantial evidence pointing to ongoing volcanic activity

- Detection of seismic activity can establish if tectonism is still active and can be used to probe the crust and interior of the planet

- Surface conditions are harsh, spacecraft lifetime is limited
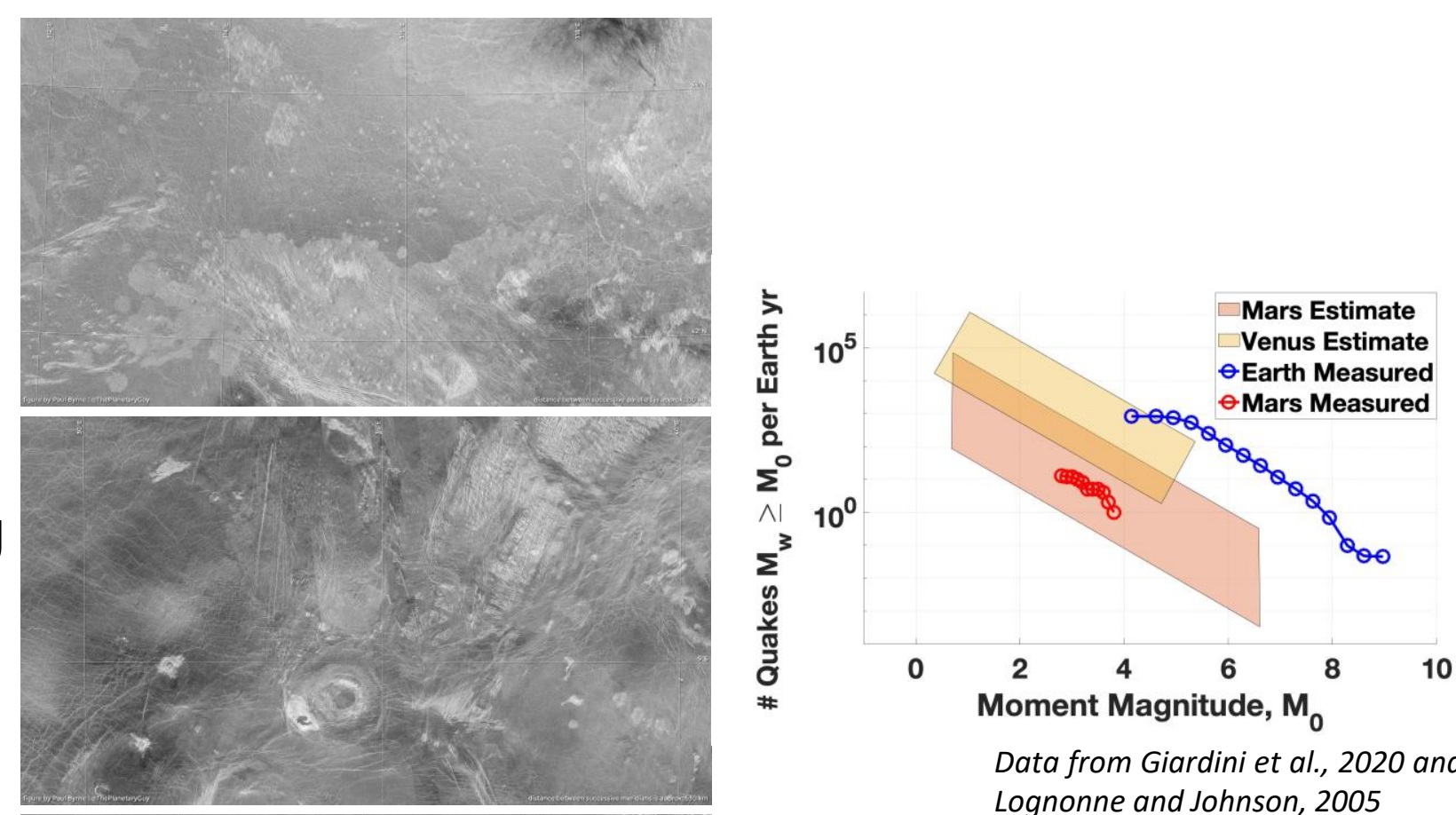

Moment Magnitude, $\mathbf{M}_{0}$

Data from Giardini et al., 2020 and Lognonne and Johnson, 2005 


\section{Balloon data can be traitorous}

In addition to possible turbulence in the atmosphere, balloon oscillations can generate acoustic noise in the right frequency range

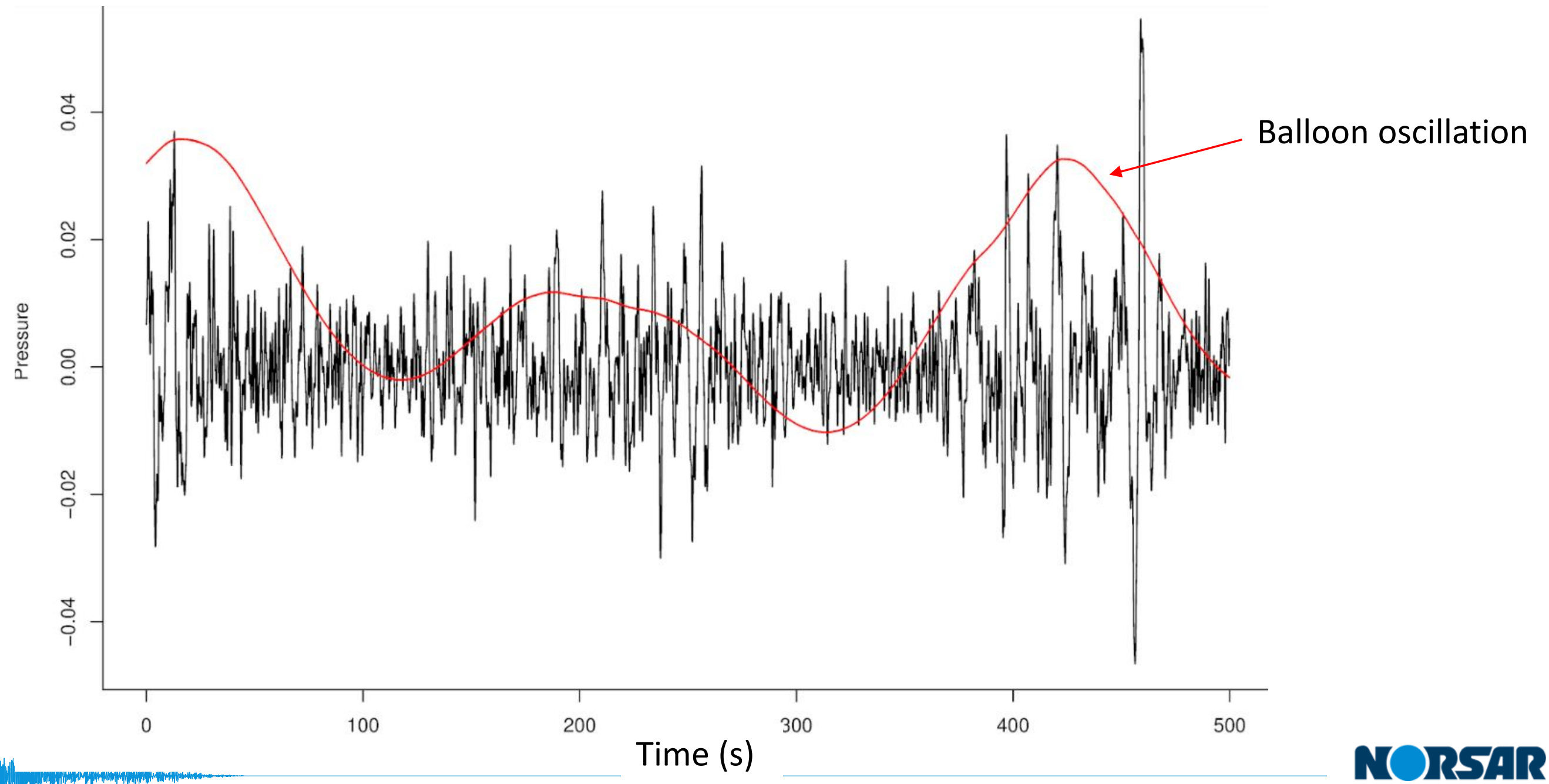

Figure: Example of pressure records (black) at balloon Hare on July $22^{\text {nd }}$ along with balloon oscillations (red) 


\section{Piggybacking on long duration flights}

E.g., CNES' Stratospheric balloon flying for 2-3 months about 18-20 km altitude and carrying more than $15 \mathrm{~kg}$ payload
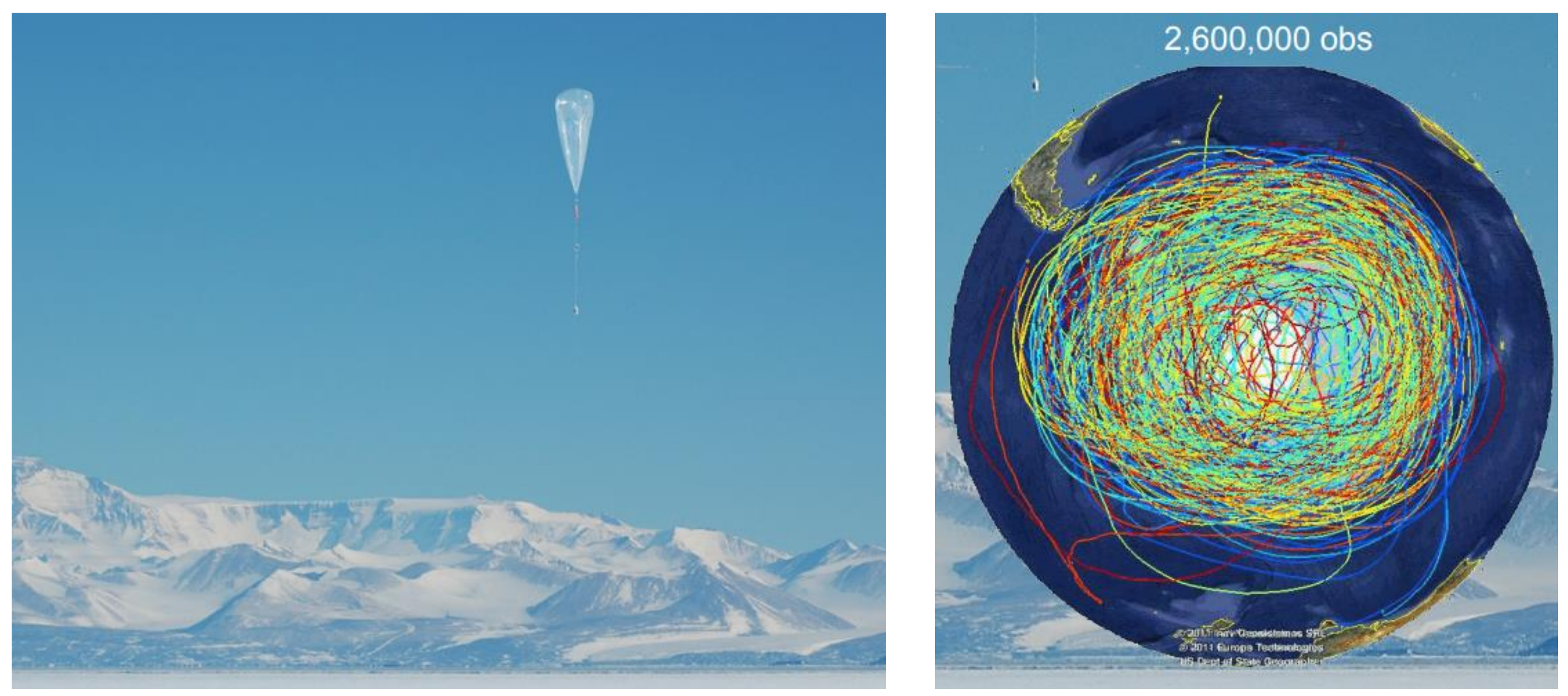


\section{Seismo-acoustic path effects}

Focal mechanisms also change the structure of the infrasound wavefield

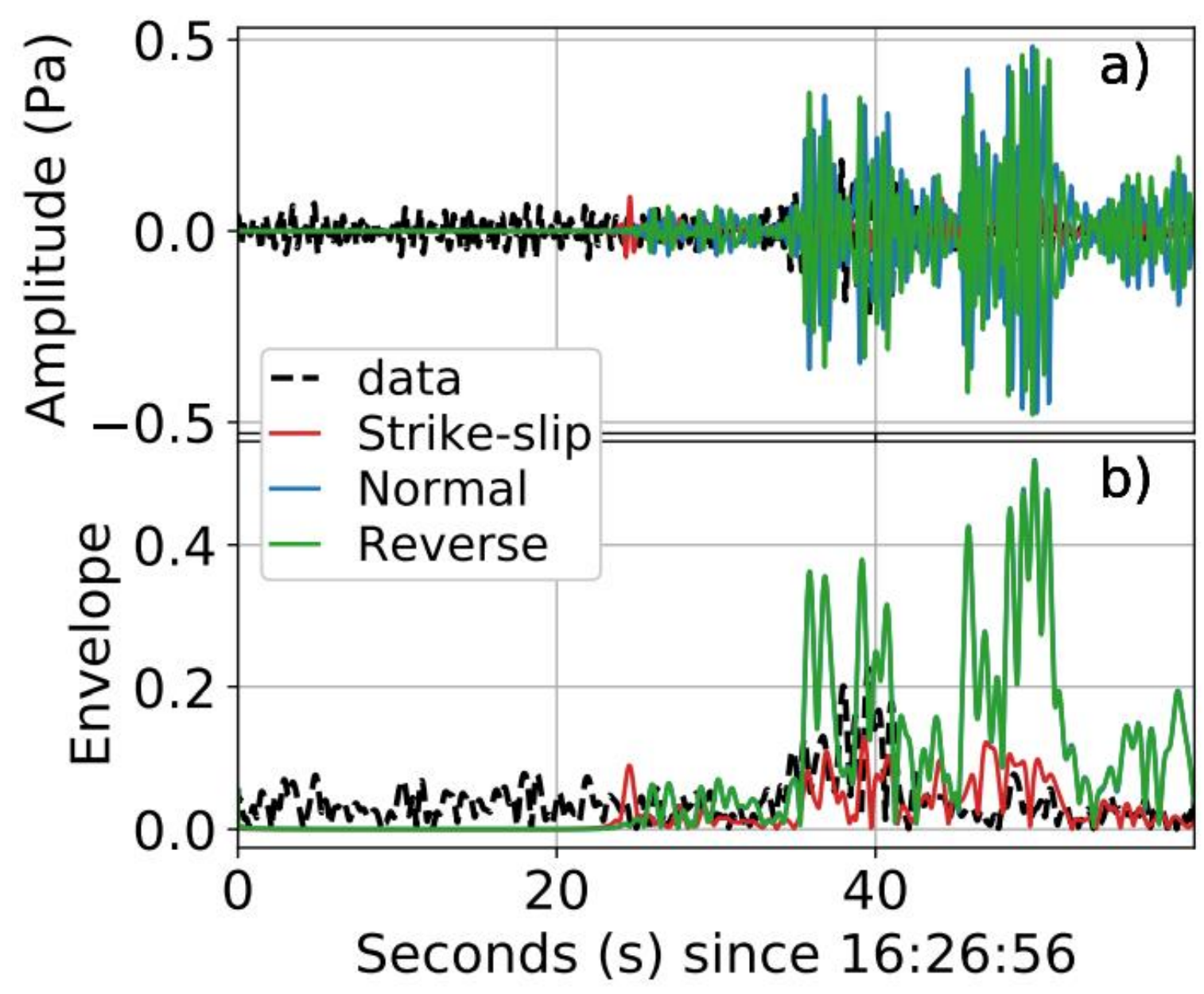

